\title{
The Emergence of Life
}

\author{
E. Camprubí $^{1}$ (D) J.W. de Leeuw ${ }^{2,3}$ - C.H. House ${ }^{4}$. \\ F. Raulin ${ }^{5}$ M.J. Russell ${ }^{6}$ - A. Spang ${ }^{2,7}$. \\ M.R. Tirumalai ${ }^{8} \cdot$ F. Westall ${ }^{9}$
}

Received: 7 May 2019 / Accepted: 27 November 2019 / Published online: 12 December 2019

(C) The Author(s) 2019

\begin{abstract}
The aim of this article is to provide the reader with an overview of the different possible scenarios for the emergence of life, to critically assess them and, according to the conclusions we reach, to analyze whether similar processes could have been conducive to independent origins of life on the several icy moons of the Solar System. Instead of directly proposing a concrete and unequivocal cradle of life on Earth, we focus on describing the different requirements that are arguably needed for the transition between non-life to life. We
\end{abstract}

Ocean Worlds

Edited by Athena Coustenis, Tilman Spohn, Rafael Rodrigo, Kevin P. Hand, Alexander Hayes, Karen Olsson-Francis, Frank Postberg, Christophe Sotin, Gabriel Tobie, Francois Raulin and Nicolas Walter

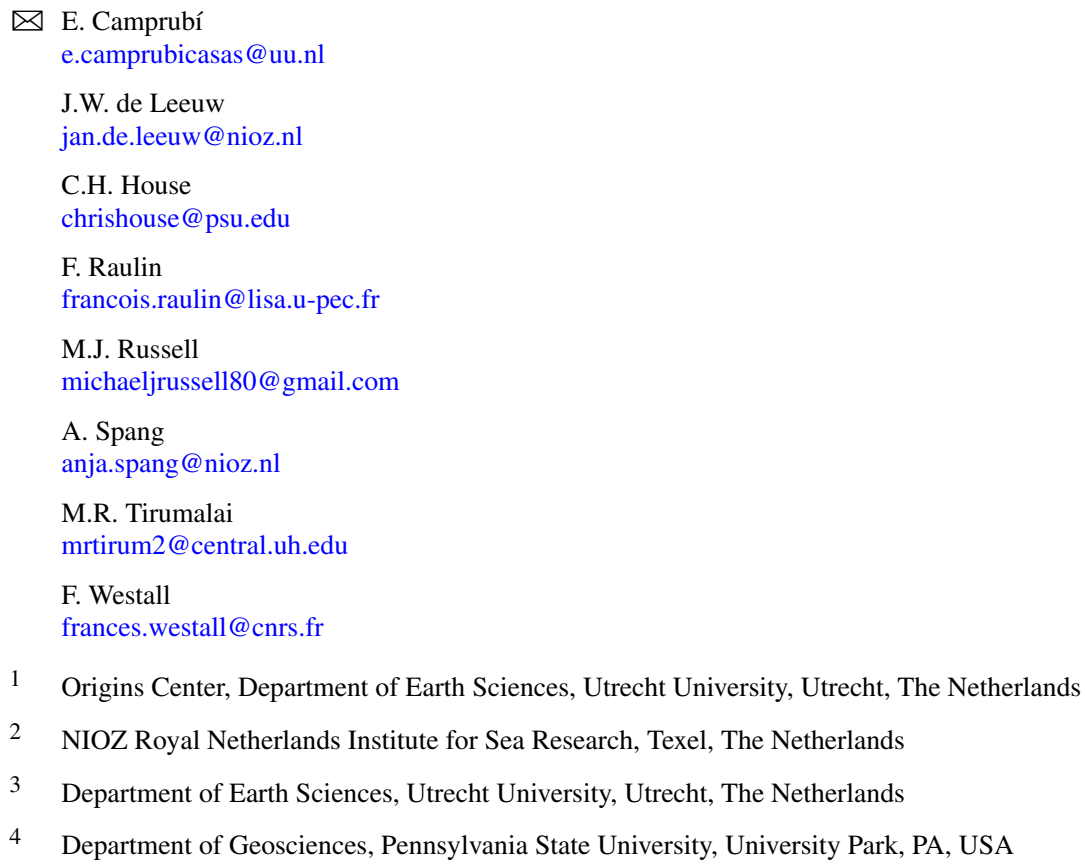


approach this topic from geological, biological, and chemical perspectives with the aim of providing answers in an integrative manner. We reflect upon the most prominent origins hypotheses and assess whether they match the aforementioned abiogenic requirements. Based on the conclusions extracted, we address whether the conditions for abiogenesis are/were met in any of the oceanic icy moons.

Keywords Emergence of life · Icy moons · Hadean Earth · Hydrothermal environments · RNA world · Tree of life

\section{Introduction-a Universal Enquiry}

The origin of life has been one of humanity's most compelling enquiries since the cradle of civilization. Innumerable creation myths have tried to shed light on this essential issue without the limitations that a scientific approach to the issue would entail. Until the 19th century, the theory of spontaneous generation was widely accepted, since it was the most comprehensive way to conceive how maggots in rotting meat, or mice in grain, could appear from apparently thin air. Using the scientific method, Louis Pasteur disproved this theory by showing that small organisms (later known as microorganisms) are ubiquitous and cannot emerge in strictly isolated sterile organic media. We should note that inorganic mediaincluding minerals-were not mentioned (Pasteur 1862; Leduc 1911; Ligon 2002). Yet, Pasteur's findings did not go unchallenged (Strick 1988). Darwin, for example, had been convinced that "the intimate relation of Life with laws of chemical combination, and the universality of latter render spontaneous generation not improbable" (Peretó et al. 2009). In turn, Darwin continued to distance himself from the view and Pasteur himself was said to have second thoughts towards the end of his life (Strick 1988). It is significant to record, in the context of this article, that the views of Pasteur and his acolytes had a negative effect on mineral-based hypotheses (see Butcher's Translator's Preface p. vi to Leduc 1911). Moreover, notwithstanding Goldschmidt's posthumous publication (Goldschmidt 1952), no other significant mineral-based hypothesis was proposed until Graham Cairns-Smith-partly influenced by Bernal's focus upon the likely significance of clays and mineral surfaces to the emergence of life (Bernal 1949)—published his 'Genetic takeover: and the mineral origins of life' (Cairns-Smith 1982). Indeed, Leduc's lonely plea that: "Without the idea of spontaneous generation and a physical theory of life, the doctrine of evolution is a mutilated hypothesis without unity or cohesion" went largely unheard until the present century when it has been rejuvenated under the rubric of "chemobrionics" (Barge et al. 2015). Last century's thought was dominated by the organic soup hypothesis of Haldane, Oparin, Miller, and Orgel, which gave birth to the RNA world hypothesis - a common view to this day, as we discuss later in this article (Nissenbaum 1976; Kurland 2010; Lane et al. 2010).

Thus, 'How and where did life originate?' continues to be one of the most fundamental questions for humanity to date. Unfortunately, these enquiries are confronted by the harsh

5 LISA, UPEC-UP/CNRS/IPSL, Paris-Créteil, France

6 Planetary Chemistry and Astrobiology, Jet Propulsion Laboratory, California Institute of Technology, Pasadena, CA, USA

7 Department of Cell and Molecular Biology, Science for Life Laboratory, Uppsala University, Uppsala, Sweden

8 Department of Biology and Biochemistry, University of Houston, Houston, TX, USA

9 CNRS - Centre de Biophysique Moléculaire, Orléans, France 
reality that the phenomenon of life has not yet been fully comprehended. One of the best examples to visualize this is the lack of a common definition of life (Cleland and Chyba 2002). The definition most commonly used was proposed by NASA: life is "a self-sustaining chemical system capable of Darwinian evolution". Another, reminiscent of a von Neumann automata, states that "life is the harnessing of chemical energy in such a way that the energyharnessing device makes a copy of itself" (Sousa et al. 2013). Such definitions have other problems, the most important one being the term 'self-sustaining'. Life is most definitely not self-sustained, just the opposite: it is an open system that exchanges matter and energy with its environment in order to maintain its far-from-equilibrium state. In Peter Mitchell's (1959) own words: life and its environment "may be regarded as equivalent phases between which dynamic contact is maintained by the membranes that separate and link them". After all these years, one of the best definitions of life may have been formulated already in 1937 by Noble Prize winner Albert Szent-Gyorgyi: "Life is nothing but an electron looking for a place to rest", thereby referring to metabolism and the electron transport chain.

In turn, most modern definitions avoid the term 'life' (a noun) and instead use 'living' (an adjective), pointing to the fact that life is more of a transient state affecting some matter: "a living being is any autonomous system with open-ended evolutionary capacities" (RuizMirazo et al. 2004). Indeed, Helmreich (2007) develops this view, categorizing "life as a verb"-suggesting that the present tense transitivity in life-as-we-know-it and the modal compound conditional mood of life-as-it-could-be, should be joined by a whole series of possible other conjugations of 'life as a verb'-from the future imperfect tense of life-asit-will-be-unfolding to the preterite present of life-as-it-may-be to the present imperfect of life-as-it-is-becoming. With this in mind we can take a philosophical approach and rephrase the issue around the questions 'why, where and how, does life emerge?' (Wicken 1987; Russell and Kanik 2010). Or, to borrow a phrase from Wittgenstein (1953) from another context, namely, "don't ask for meaning, ask for use", we could say that as "life overall hydrogenates carbon dioxide" (Nitschke and Russell 2009)— the base of the food web being chemo- or photo-autotrophs. As the same may be said about the root of the evolutionary tree, these ideas might afford clues as to its gestation and birth (Berg et al. 2010; Lane et al. 2010; Say and Fuchs 2010).

However, the controversies surrounding the definition of life are probably just symptoms of a deeper problem, and unfortunately these have led to the larger issue of the classical divide on the approaches to the origin of life. Each definition of life has put its emphasis on a trait(s) expressed by living entities, such as their replicative capabilities, their far-fromequilibrium state, their compartmentalization, or their evolutionary potential. Each trait has classically been associated with different scientific disciplines (e.g. replication with RNAfocused molecular biology or compartmentalization with molecular biophysics of lipids), so each resulted in independent lines of research. Mostly due to limitations associated with each highly specialized discipline, but also due to often-antagonistic philosophical positions, these disciplines have historically remained isolated from each other. Needless to say, research on the origin of life is a remarkably broad area of enquiry, requiring transdisciplinary expertise encompassing non-equilibrium thermodynamics, electro-conformational coupling nanomechanics, geochemistry, organic chemistry, bioenergetics, and biology (Tsong and Astumian 1988; Branscomb et al. 2017). What cannot be avoided in these discussions is that individual cells require between a million and a billion electrons a second to function, or as Albert Szent-Györgyi (1968) put it, life is "bioelectronics" (Makarieva et al. 2005; ElNaggar et al. 2010; Beratan et al. 2014). Indeed, a distinction between 'overall uphill life' and 'downhill chemistry' involves not only electron transfer and feed, but also life's obligatory use of (i) the proton motive force, (ii) electron bifurcation, and (iii) thereby the use 
of disequilibrium-converters, i.e. nanoengines (Peters et al. 2016; Branscomb et al. 2017; Astumian 2018; Branscomb and Russell 2018).

Despite still being far from the goal, it is undeniable that during the last few decades, considerable experimental and theoretical progress has been made. It is also noticeable that some of the old controversies have somewhat shifted away from the spotlight in favor of a more case-by-case examination. Hopefully, a better understanding of 'how, where, and when' life started on Earth will help comprehending 'why' life, as a phenomenon, emerges in the Universe; a goal humankind has always striven to achieve.

Needless to say, finding evidence of independent origins would be invaluable for our overall understanding of life and its limits, and nowhere is this more likely to materialize than beyond Earth. Thus, active space exploration remains one of our best bets for simultaneously broadening our understanding of life, whilst narrowing down the conditions under which it can emerge. Despite remarkable advances in remote sensing, finding clear evidence of extraterrestrial life on exoplanets still probably lies in the future. Due to their smaller sizes, the same prospect for exomoons is even more remote. Fortunately, our own Solar System contains numerous planetary bodies which likely contained (or still do) living beings. Mars has long been a prime astrobiological target, but the limited amount of liquid-probably in the form of briny-water found there has tamed our expectations. On the other hand, the icy moons of the Solar System (e.g. Enceladus, Europa, Titan) contain vast amounts of liquid water which, at least in the case of Enceladus, arguably promotes hydrothermal processes (Waite et al. 2017). The detection of reduced inorganic molecules (Waite et al. 2009, 2017), as well as nitrogen- and oxygen-bearing organics (Khawaja et al. 2019) in the plumes of Enceladus coupled to studies indicating Earth-based methanogens can grow under simulated Enceladus' conditions (Taubner et al. 2015, 2018), suggests that organic molecules are currently being synthesized in its global ocean. It is even possible these molecules derive, at least partially, from life. Therefore, it seems clear that space missions in the near future should aim to intimately explore the icy moons of the Solar System, particularly Enceladus (Choblet et al. 2019) where we have strong evidence of active organosynthesis.

This article aims to provide the reader with a broad overview of the field of the emergence of life, with the goal of extrapolating our conclusions to life elsewhere. The literature on abiogenesis is certainly vast, which implies it is virtually impossible to discuss every aspect. Hence, even though they are all connected, each section in this article focuses on a specific topic. We start this article discussing the geological and planetological aspects which were conducive to life's emergence during the Hadean eon of the Earth. We continue by assessing the (bio)chemical and bottom-up approaches, where we particularly consider the RNA World hypothesis. This is followed up by a dissection of the more biological top-down approach, where we assess how much information on the remote past can be extracted from genomic data of extant life and phylogenetic analyses. Finally, we focus on the prospects of extraterrestrial life based on the conclusions extracted from the other sections of this article.

\section{How Did Hadean Earth's Geological Conditions Promote and Constrain the Emergence of Life?}

Understanding of the environmental conditions critical for the emergence of life on the early, Hadean Earth (4.5-4.0 Ga) is difficult due to the lack of hard and fast data. Not only are there no rocks from this Eon, but informed interpretation of such phenomena, such as when the Earth became habitable (i.e. when water had condensed at a suitably low temperature onto 
the surface of the Earth, after the magma ocean situation following the Moon-forming impact at $\sim 4.51 \mathrm{Ga}$ ), the composition of the atmosphere, the temperature of the oceans, the distribution of landmasses, if any, versus ocean, sources of essential ingredients for life and sources of free energy, is widely variable and dependent upon analogue studies of the oldest crustal remnants, modelling and comparative planetology. Indeed, the very reasons for the lack of Hadean crust says much about early terrestrial conditions: hot, relatively soft crust that was rapidly recycled back by plume tectonics combined with 'impact gardening' during which myriads of impactors effectively bombarded and destroyed the Earth's upper surface, paints an initially catastrophic picture of global environmental conditions. Nevertheless, within this apparently globally infernal context (on geological timescales), life appeared - on a microbial scale. Obviously environmental conditions for the emergence of life on timescales of $10^{5}-10^{6}$ years, were sufficiently benign, but also sufficiently dynamic, to allow prebiotic chemistry to take place and gradually transition into biology.

We will here attempt to create a resume of present understanding (or lack of it) of the early environmental conditions. Much of our information comes from inherited mineralogical and geochemical signatures preserved in crustal rocks dating from the Early Archaean (i.e. from $\sim 3.9 \mathrm{Ga}$ onwards), although interpretations of the same data vary. Likewise, data from modelling is very informative but does not necessarily represent the reality. An example of this is related to the period of heavy bombardment purportedly having occurred between 4.1 and $\sim 3.85 \mathrm{Ga}$ (see below).

\subsection{Early Oceans and Atmosphere}

Geochemical and isotopic evidence suggests that the atmosphere of the post-Moon forming impact Earth was more neutral rather than completely reducing (Holland 1984; Sleep 2010; Zahnle et al. 2010). Indeed, at the dawn of the Hadean the atmosphere would have been dominated by $\mathrm{H}_{2} \mathrm{O}, \mathrm{CO}_{2}, \mathrm{SO}_{2}, \mathrm{~N}_{2}$ and minor concentrations of $\mathrm{NO}_{x}$, many of which were potential electron acceptors rather than donors (Yung and McElroy 1979; Dasgupta and Hirschmann 2006; Martin et al. 2007; Hirschmann et al. 2009; Wong et al. 2017). Other main atmospheric electron acceptors include the five elements that Falkowski (2006) termed the planetary "electron market", H, C, N, O and S, occurred as electron acceptors in the Hadean atmosphere and ocean with electron donors emanating from the reduced Earth (Yung and McElroy 1979; Dasgupta and Hirschmann 2006; Martin et al. 2007; Hirschmann et al. 2009). Wong et al. (2017) demonstrated the potential for $\mathrm{NO}_{x}$ production from $\mathrm{CO}_{2}$ and $\mathrm{N}_{2}$ in cloud-to-cloud lightning. $\mathrm{NO}_{x}$ dissolved in the ocean would have yielded the electron acceptors such as nitrate and nitrite.

While volcanic outgassing contributed importantly to the creation of a volatile envelope around the Earth, a large portion of the volatiles was imported together with extraterrestrial material forming a so-called "late veneer" (Marty 2012), including a cometary component, as the analyses of the comet Churymov-Gerasimenko by the Rosetta mission have shown (Marty et al. 2017), much of it arrived in the form of volatile components in meteorites of chondritic origin (Zahnle et al. 2010).

The Hadean era began as the Earth rapidly cooled following the collision with the putative planet Theia. This early atmosphere was rapidly eroded by the solar wind (Lammer et al. 2014; Massol et al. 2016). Cooling thereafter would have been rapid and Zahnle et al. (2007) estimate that it took only around 10,000 years for the equivalent of two present ocean volumes to rain out, producing an all-enveloping ocean probably by about $4.4 \mathrm{Ga}$ (Valley et al. 2005; Cavosie et al. 2007). Half that volume has since been lost by subduction of serpentinized and otherwise hydrated crust to the now relatively wet mantle, and to photodissociation (Bounama et al. 2001; Elkins-Tanton 2008; Genda 2016). Without continents the 
more or less global Hadean ocean would have been shallower than today, although Bounama et al. (2001) and Korenaga et al. (2017) estimate an ocean depth of approximately 6 kilometers. However, if the preserved Early Archaean age-crust can be considered as a proxy for the Hadean Earth, the early protocontinents resembled submerged oceanic plateaus (Arndt and Nisbet 2012; Kamber 2015) with exposed volcanic edifices and ocean depths were of the order of a couple of kilometers.

The oldest evidence for water on the planet actually derives from highly resistant minerals such as Hadean zircons that have been reworked from altered crust into younger sedimentary materials. The abundance of these Hadean minerals, formed by fractionation of hydrated crust (and generally common in granites, the cores of continents), suggests that oceans must have existed on the Earth by at least $4.3 \mathrm{Ga}$, if not earlier (Wilde et al. 2001; Mojzsis et al. 2001). Earlier estimates of low temperatures $\left(<150{ }^{\circ} \mathrm{C}\right)$, based on isotopic analyses of oxygen isotopes the zircons (Wilde et al. 2001), may have been confounded by later contamination of the oxygen isotopic history of the zircons (Valley et al. 2014) but the salient message is that, quite early in the history of the Earth, the planet was covered by water. Even several hundreds of millions of years later, the preserved Early Archaean rocks formations still document an overwhelmingly aqueous planet with little exposed continental landmass.

\subsection{High Hadean Mantle Heat Flow and the "Heat-Pipe" Earth}

By $4.4 \mathrm{Ga}$ it is assumed that heat from the hot $(\sim 2000 \mathrm{~K})$ lower mantle was transferred to the planet's cool exterior through numerous mantle plumes, mechanisms prompting Moore and Webb (2013) to assign the title "the heat-pipe Earth" to those times (see also Morgan and Morgan 1999; Bédard 2006, 2018). These plumes fed large igneous provinces comprising mafic and ultramafic flows and intrusions generated, as evidenced by Early Hadean zircons, from a strictly chondritic, though somewhat oxidized, magma reservoir (Wade and Wood 2005; Frost et al. 2008; O'Neill et al. 2013). While there is no direct evidence for the kind of dioritic or granitic masses comprising continental crust generated through later plate tectonics, remnant portions of ancient crust dating 3.9-3.2 Ga exposed in northern Canada, Greenland (Isua), northwestern Australia (Pilbara) and eastern South Africa (Barberton) contain a petrological and geochemical signature indicating formation of the largely mafic provinces on top of pre-existing, at least partially silicic (felsic) proto-continental crust (Green et al. 2000; Tessalina et al. 2010; see also reviews in Kamber 2015 and Van Kranendonk et al. 2015). Arndt (1994) and Arndt and Nisbet (2012) argue that the presence of abundant Hadean zircons indicates significant production of fractionated felsic crust through plate tectonic recycling of hydrothermally-altered hydrated crust. Nevertheless, the prevailing understanding is that the Hadean zircons reflect natural fractionation processes in mafic mantle and not necessarily by-products of modern-style plate tectonics (Fisher and Vervoort 2008; Harrison et al. 2008; O'Neill et al. 2013). This is similarly demonstrated on the Moon where zircons formed from relatively dry magmas enriched in highly incompatible elements (Warren and Wasson 1979), and also on Mars where felsic rocks were documented in the Late Noachian/Early Hesperian Gale crater. The latter, originally interpreted as "granites" (Sautter et al. 2015), were later demonstrated to be the result of felsic fractionation unrelated to plate tectonic-derived, granitic continental crust (Bédard 2006; O’Neill et al. 2013; Udry et al. 2018).

Thus, the Hadean mantle plumes produced thickened, mostly mafic crust that also contained a fractionated, more felsic rich component which formed submerged continental plateaus; modern-style continents did not exist. Without modern plate tectonic recycling, 
how then was room made for continual magmatic additions to the Hadean ocean floor? Kamber (2015) makes the cogent argument that, with a specific gravity of around 5 and interlayered with basalt and komatiite with specific gravities of $\sim 2.9$, the Hadean crust was 'doomed' to founder — rather than slide (i.e. subduct as a slab) back—into the hot, dry mantle, thus explaining its absence.

\subsection{Ocean Temperature, Salinity and pH}

Sodium chloride was likely introduced to the early atmosphere as a vapor, and then, in cooler conditions, in aqueous solution, directly to the ocean (Van Groos and Wyllie 1969). Thus, the early ocean was likely saline and possibly twice as saline as at present unless the ocean were to have been twice its present volume (cf. de Ronde et al. 1997; Korenaga et al. 2017). Direct and indirect evidence of early $\mathrm{NaCl}$ differentiation from the mantles of Earth (Kamenetsky et al. 2004), Europa (Hand and Carlson 2015; Poston et al. 2017; Trumbo et al. 2019), Mars (Chojnacki 2015; Ojha et al. 2018), Enceladus (Glein et al. 2015), Io (Lellouch et al. 2003) and even the moon (Clanton et al. 1978) supports such a hypothesis. That carbonate and $\mathrm{CO}_{2}$ are immiscible in the Earth's mantle support the earlier views of Goldschmidt (1952) that the atmosphere, and hence the ocean, would have been carbonic and thereby acidic, oscillating perhaps from pH 5 to 6 (McLeod et al. 1994; Kusakabe et al. 2000). Recent modelling (Krissansen-Totton et al. 2018) also confirms an initially slightly acidic (pH 6.6) ocean. Lacking much surficial erosion and weathering-the present Earth's thermostat - because of the lack of exposed landmass, and dependent on the atmospheric pressure of $\mathrm{CO}_{2}$, the climate was likely to have been extremely unstable, oscillating between freezing and perhaps $100{ }^{\circ} \mathrm{C}$ (Kasting and Ackerman 1986; Robert and Chaussidon 2006; Tartèse et al. 2017). Again, the recent modelling by Krissansen-Totton et al. (2018) that also considers the input of seafloor weathering suggests relatively moderate temperatures between 0 and $50{ }^{\circ} \mathrm{C}$. Slightly higher temperatures have been derived from $\mathrm{O}$ and $\mathrm{Si}$ isotope studies. For instance, van den Boorn et al. (2007) suggest temperatures up to $55^{\circ} \mathrm{C}$ while Robert and Chaussidon (2006) propose even higher temperatures up to $80^{\circ} \mathrm{C}$, confirmed by Tartèse et al. (2017), who conclude that the high temperatures are the result of significant hydrothermal input. This hypothesis is supported by field observations and geochemical evidence (Hofmann and Harris 2008; Westall et al. 2015, 2018) with Westall et al. (2018) concluding that high temperatures were prevalent particularly at the rock/sediment/water interface, where hydrothermal effluent circulated.

\subsection{Earth-Moon System, Rotations and Tides}

The speed of rotation of the Earth at $4.4 \mathrm{Ga}$ is conservatively estimated to have been $20 \%$ faster (length of a Hadean Day being $\sim 17$ hours) and the moon was $\sim 15-20 \%$ closer (Zharkov 2000). The influence of the centrifugal force at the equator would have thus have been greater, increasing thereby the Coriolis effect. Lingam and Loeb (2017) estimate a tidal amplitude of around 20 meters, or rather less if the atmospheric pressure was much higher than it is today. Large-amplitude Rossby waves in an open ocean (Longuet-Higgins 1968) would have kept the ocean well-mixed through wave-induced upwelling (Uz et al. 2001); characterized as a "rototiller" mechanism (Dandonneau et al. 2003).

\subsection{Wind Speed and Wave Amplitude}

In the absence of land beyond any ephemeral volcanic windbreaks and, judging from measurements made in the 'Roaring Forties' of a continual wind speed of between 8 and 
$12 \mathrm{~m} \mathrm{~s}^{-1}$, waves amplitudes were likely to be 10 meters or higher over much of the ocean surface unless dampened by qualitatively higher atmospheric pressures than at present (Liu 2001). On the other hand, the presence of numerous Hadean shallow continental plateaus would have dampened this regime. Those early crustal remnants that are well-preserved show that the shallow water sedimentary sequences atop the Early Archaean plateaus are generally devoid of evidence of catastrophic tides. Indeed, they appear to have been characterized by relatively quiet tidal regimes suggesting deposition in largely protected basins on top of the plateau (Nijman and de Vries 2004, 2017; Westall et al. 2015, 2018).

\subsection{The Inconsequentiality of the Late Heavy Bombardment}

Much has been made of the Late Heavy Bombardment (LHB) with respect to its possible annihilation of early life (e.g. Maher and Stevenson 1988). The LHB hypothesis came into existence as a consequence of a 'bottle-neck' in the ages measured for lunar basalts returned to Earth by the Apollo astronauts: there seemed to be a cut-off point prior to $\sim 4.1 \mathrm{Ga}$ with the suggestion being that older lunar crust (and by corollary Hadean terrestrial crust) had been destroyed by an increase in the flux of asteroid impacts (Ryder et al. 2000; Bottke et al. 2012), modelled to be related to perturbations in the orbits of the giant outer planets (Kemp et al. 2010; Marchi et al. 2014). However, currently the 'bottleneck' lunar crustal ages appear to be the effect of sampling only mare basalts. This, combined with more recent modelling, suggests a monotonic decline in the flux of impactors throughout the Hadean-Archaean Eons (Boehnke and Harrison 2016; Zellner 2017). Abramov and Mojzsis (2009) modelled the limited effects that larger bolides would generally have on ocean temperatures (Abramov et al. 2013). Even supposing the most unlikely event of a sterilizing heat wave through the ocean, the very low thermal conductivity of ocean floor sediments would protect the 'deep biosphere', sparsely populated though it may have been, from heat death (Sleep 2012). We know from medical studies and planetary protection tests how difficult it is to completely eradicate microorganisms once they populate a given habitat, even more so when taking into account the myriad of smaller micro-habitats which could have acted as reservoirs in the event of large extinctions (Bloomfield and Miles 1979; Rummel 2001; Pugel et al. 2017; Tirumalai et al. 2018a, 2018b; Bradley et al. 2019).

\subsection{Hydrothermal Systems and Electron and Proton Availability}

As noted above, heat flow from the mantle to the surface on the early Earth was high, with average mantle temperatures being more than $300{ }^{\circ} \mathrm{C}$ higher than today (Van Kranendonk et al. 2015). In the absence of plate tectonics and linear spreading centers, abundant volcanoes and associated hydrothermal activity offered a relatively efficient escape for the internal heat. Even a billion years after the consolidation of the Earth, the Early Archaean sediments document the ubiquity and importance of hydrothermal fluids in the oceans (Hofmann and Harris 2008; Westall et al. 2015, 2018). Hydrothermal activity in the Hadean must have been commensurately higher.

Hot hydrothermal fluids percolating through the Earth's crust become enriched in numerous elements including transition elements, which precipitate out as they exhale and contact alkaline surface waters (Tosca et al. 2016). It was suggested that redox reactions between precipitated transition metal sulfides, such as iron monosulfide (FeS), could have provided the free energy and electrons for prebiotic synthesis through the generation of pyrite (Wächtershäuser 1988). Another approach also involving FeS and ferrous-ferric oxyhydroxide, but in the form of a putative membrane separating alkaline sulfide-bearing hydrothermal fluids from acidulous Fe-bearing ocean, had the effect of imposing both a redox 
and a $\mathrm{pH}$ gradient with a total potential approaching $1 \mathrm{~V}$, sufficient theoretically to drive the reduction of carbon dioxide (Russell and Hall 1997, 2006). These gradients are, and were, sustainable for at least 100,000 years (Ludwig et al. 2011). For example, the redox gradient across membrane-like metal sulfide precipitates produces about $0.5 \mathrm{~V}$ of energy (Russell and Hall 1997). These gradients included $\mathrm{pH}$ (ca. four units), temperature (ca. $60^{\circ} \mathrm{C}$ ) and redox potential (ca. $500 \mathrm{mV}$ ) that were sustainable over geological time-scales (Martin and Russell 2002). Furthermore, formed via Fischer Tropsch synthesis (e.g. Shock 1992; Sherwood Lollar et al. 2002; Shock et al. 2002 in crustal environments, or Camprubi et al. 2017 in hydrothermal environments) and serpentinization, the hydrothermal fluids also transported compounds of possible relevance for prebiotic chemistry, such as $\mathrm{CO}, \mathrm{H}_{2}, \mathrm{~N}_{2}$, along with reduced nitrogen $\left(\mathrm{NH}_{3}, \mathrm{CN}^{-}\right)$(Schulte and Shock 1995), reduced carbon $\left(\mathrm{CH}_{3} \mathrm{COO}^{-}, \mathrm{H}_{2} \mathrm{CO}\right.$, and short alkyl sulfides; but see Reeves et al. 2014), $\mathrm{CH}_{4}$ (Kelley 1996), and HS${ }^{-}$(Mielke et al. 2010).

Another potentially important aspect of hydrothermal systems concerns associated mineral precipitates. While amorphous silica and silica gels are the predominant hydrothermal precipitates that have been preserved from the early Archaean Earth (Hofmann and Harris 2008; Westall et al. 2015, 2018), barite and iron carbonates were also present. However, taking into consideration modern sulfate-poor, acidic, $\sim 400{ }^{\circ} \mathrm{C}$ hydrothermal springs, transition element precipitates, such as 'green rust' $\left(\sim\left[\mathrm{Fe}_{6 x}{ }^{2+} \mathrm{Fe}_{6(1-x)}{ }^{3+} \mathrm{O}_{12} \mathrm{H}_{2(7-3 x)}\right]^{2+} \cdot\left[\mathrm{CO}_{3}{ }^{2-}\right.\right.$. $\left.\left.3 \mathrm{H}_{2} \mathrm{O}\right]^{2-}\right)$, mackinawite $([\mathrm{Fe}>\mathrm{Ni}] \mathrm{S})$, and greigite $\left(\sim \mathrm{Fe}_{5} \mathrm{NiS}_{8}\right)$, may also have precipitated (Génin et al. 2008; Russell 2018). An early ( $\sim 4$ Ga) onset of sedimentary basins (Trail et al. 2018) fits well with the geological requirements of a putative hydrothermally-derived emergence of life, where the aforementioned minerals could have promoted the synthesis of organics and their complexification by minerally-mediated energy coupling (Fig. 1).

\subsection{Scenarios for the Origin of Life}

A wide variety of scenarios for the origin of life have been proposed. They range from submarine hydrothermal systems and sediments, through floating pumice rafts, beach or volcanic splash pool environments, nuclear geysers, to subaerial springs (see reviews in Dass et al. 2016; Westall et al. 2018). Hydrothermal systems were first suggested as a suitable location for the origin of life at the surface by Harvey (1924) and at the ocean floor by Corliss et al. (1981) and Baross and Hoffman (1985). They attracted attention because they are major sources of gases and dissolved elements and are characterized by numerous physical and chemical gradients due to interactions between hydrothermal fluids in the Earth's crust and the overlying oceanic and atmospheric environments. Over the last decades, many studies and models have supported the potential importance of hydrothermal systems for the emergence of life (Wächtershäuser 1990; Russell et al. 1990, 2010; Russell and Hall 1997, 2006, 2009; Martin and Russell 2002; Martin et al. 2008; Westall et al. 2018). Hydrothermal systems provide the necessary free-energy as well as a plethora of ingredients and microenvironments suitable for their reaction and the concentration of product. Russell and Hall (1997) described the possible synthesis of relatively complex reactants via FeS chemistry, and others have emphasized its high affinity for organophosphates (Whicher et al. 2018), cyanide (Woods 1984; Leja 1982), amines, and formaldehyde (Rickard et al. 2001).

Many of the minerals precipitated in and around hydrothermal systems would also have included ambient water that was confined and somewhat immobilized through hydrogen bonding, e.g. between 'brucite' layers (e.g. in $\left[\mathrm{Fe}_{4}{ }^{2+} \mathrm{Fe}_{2}{ }^{3+}(\mathrm{OH})_{12}\right]\left[\mathrm{CO}_{3}\right] \cdot 3 \mathrm{H}_{2} \mathrm{O}$, green rust; Russell 2018), or within pores in the mineral precipitates, e.g. silica gel or adjacent hydrothermal sediments (Ding et al. 2016; Westall et al. 2018). Moreover, many have noted the 


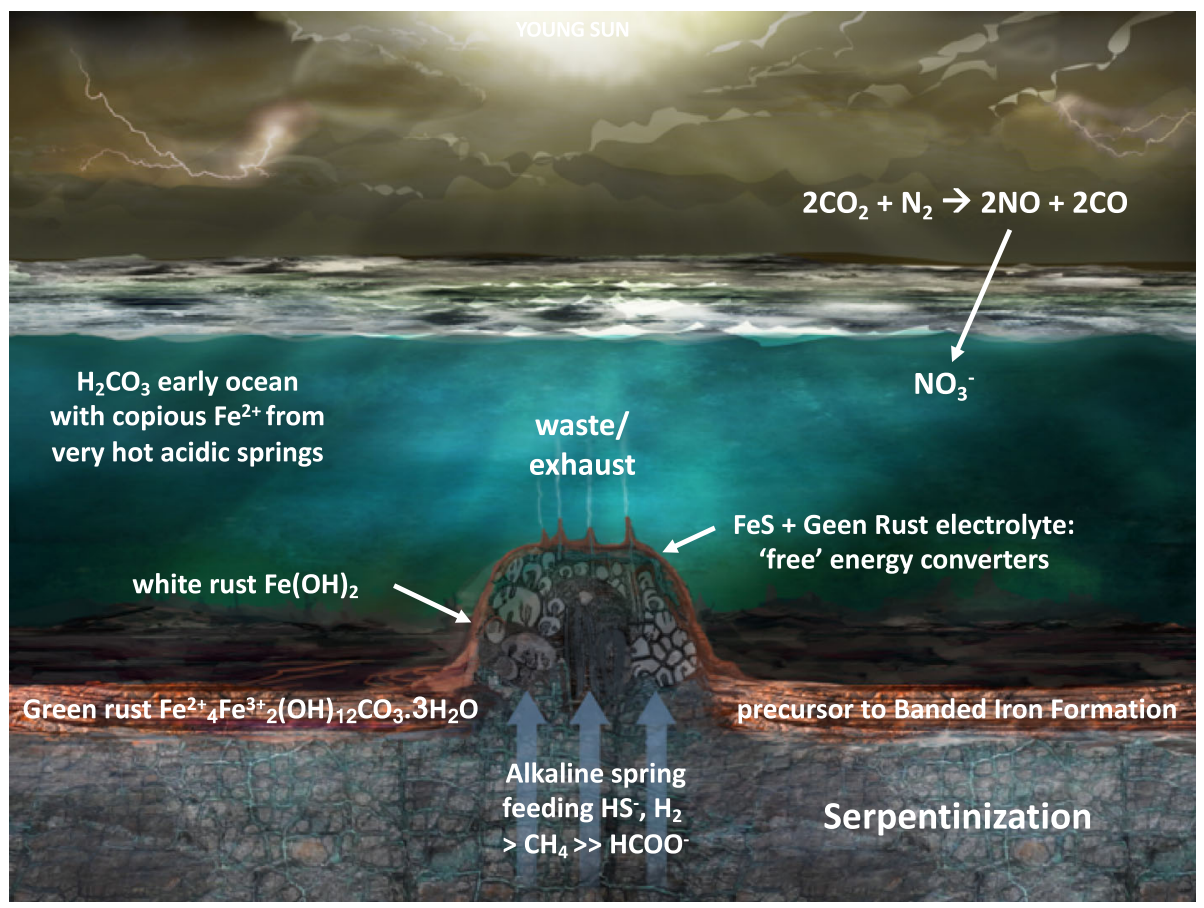

Fig. 1 Redox and pH disequilibria could be theoretically harnessed by Hadean mineral precipitates such as mackinawite, green rust, and silica gels in order to promote the synthesis and self-organization of relevant organic molecules. Analogous systems could be found on the icy moons of the Solar System. Recast from Branscomb and Russell (2018) with permission from John Wiley \& Sons Ltd

importance of mineral surfaces in and around hydrothermal systems (including hydrothermal sediments, cf. Westall et al. 2018) for condensing organic molecules, as well as having an effect on their conformation and complexification (Hazen et al. 2001; Hazen and Sverjensky 2010; Dass et al. 2016, 2018). The minerals making up the edifices and the volcanic sediments surrounding them, including olivine, pyroxenes, plagioclase feldspars, oxides, oxyhydroxides, sulfides, and amorphous volcanic glass, as well as their alteration products, namely clay minerals, sulfides, oxides, carbonates and zeolite, contained transition metals which would not only have served to enhance chirality, stabilized molecules, acted as catalysts for the chemical reactions, but some, e.g., green rust and mackinawite, could also have acted as free-energy transducers and electro-conformational coupling machines (Tsong and Astumian 1988; Hazen and Sverjensky 2010; Russell 2018). Since concentration or 'crowding' of organic molecules is an important aspect of prebiotic chemistry, molecules disseminated or dissolved in fluids could also be concentrated by the mineral surfaces (Dass et al. 2016, 2018; Westall et al. 2018). Other advantages of hydrothermal systems (sensu largo) include $\mathrm{pH}$, temperature, and ionic concentrations gradients that could harness proton and redox gradients to produce chemiosmotic energy, a free-energy source that could eventually be used by the earliest biochemical systems (Russell and Hall 1997, 2009; Russell et al. 2010; Westall et al. 2018). Note, however, that while temperatures within the Hadean vents were on the higher end to support prebiotic reactions, those in their vicinity, including porous volcanic sediments would have been more moderate (Westall et al. 2018). 
There is a certain amount of corroboration for the emergence of life in hydrothermal systems from genetic analyses (Weiss et al. 2016), which suggest that LUCA (the last universal common ancestor of life on Earth) lived in a hydrothermal environment, its closest relatives being methanogens and clostridium, using $\mathrm{H}_{2} \mathrm{~S}, \mathrm{H}_{2}$ and $\mathrm{CO}_{2}$, transition metals, and sulfur as nutrient sources, and where Fischer-Tropsch reactions and serpentinization produced $\mathrm{H}_{2}, \mathrm{CH}_{4}$ and reactive $\mathrm{C} 1$ type carbon molecules. The genetic code of the thermophilic LUCA likely arose in such a setting; Weiss et al. (2016) suggest that life arose in a single hydrothermal vent rather than different components being produced in different environments. Whether or not this was really the case (indeed, cells could have emerged in a number of environments around the globe), it is possible that various prebiotic molecules could have been formed in a variety of environments, ranging from subaerial springs (Damer and Deamer 2015), to coastal volcanic splash pools (Fox and Strasdeit 2013), to pumice rafts (Brasier et al. 2011), or submarine hydrothermal sediments. Dass et al. (2016) and Westall et al. (2018) reviewed the advantages and disadvantages of the various scenarios proposed for the emergence of life (as documented in Table 1) in terms of production of organic molecules, presence of complementary elements of relevance for catalyzing primitive metabolisms, availability of chemical energy for fueling reactions, availability of reactive mineral surfaces, potential for concentrating organic molecules, suitability of temperature for molecular complexification, temperature, $\mathrm{pH}$ and redox gradients, influence of fluid dynamics, plausibility of distribution on the Hadean Earth, and protection from impacts, radiation, etc. Of the scenarios proposed, nuclear geysers, pumice rafts, volcanic coastal splash pools, subaerial hot springs, submarine vents and hydrothermal sediments, the hydrothermal scenarios are the ones that present the most advantages, especially submarine vents and sediments.

\subsection{Implications for the Search of Life}

We do not fully understand how and why life emerged during the early Earth, and we are equally challenged on the geological conditions which made it possible. Yet, throughout this section we have discussed extensively about the importance of hydrothermalism for abiogenesis, as well as its ubiquity during the Hadean eon. Permeable volcanic and hydrothermal rocks and sediments, heat, and water are the three indispensable items for hydrothermal activity. We now know liquid water is pervasive in the Universe and it is remarkably abundant on planetary bodies such as the icy moons of the Solar System where it forms large or global sub-surficial oceans. Even though the reason(s) behind life's emergence is(are) probably universal, it is possible this event occurs through several mechanisms and crystalizes around different core molecules across the Universe. Despite this, when specifically assessing such prospects in oceanic worlds we should be looking for hydrothermal-sedimentary settings as the most likely candidates.

\section{The RNA World—Reality or Dogma?}

In his classic work 'What is life?' Schrödinger famously alluded to a thermodynamic interpretation of life. He proposed that the exchange of energy and matter with the environment, could lead to the reduction of thermodynamic entropy by living systems and the local accumulation of Gibbs free energy (Schrödinger 1944). Developments in molecular biology and evolutionary science offered new perspectives on this quest. Particularly, genetic sequencing offered the opportunity of opening a window into the biological past, something which was 


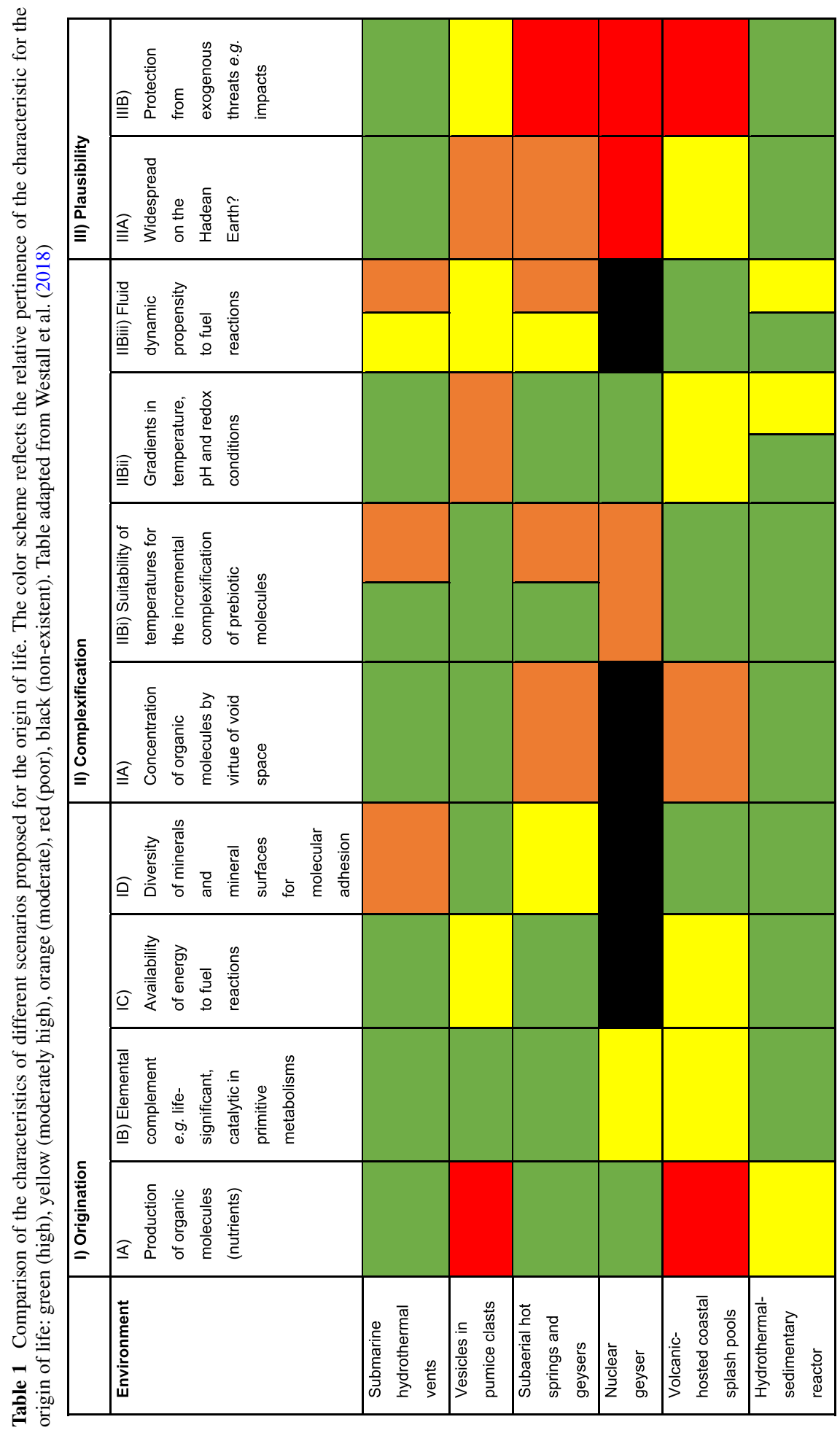


previously only possible by the study of fossils. Eventually and inevitably the question of the 'origins of life' would take center stage in this endeavor. To this end, the study of the origins and evolution of crucial biomolecules (such as RNA) constitutes a primary objective in the fields of astrobiology and exobiology.

\subsection{The 'Top-down' Approach-the Ribosome, the Last Universal Common Ancestor (LUCA), and the RNA World}

The organization of various biological forms and their interrelationships, vis-à-vis biochemical and molecular networks, is characterized by the interlinked processes of flow of information between the information-bearing macromolecular semantides, namely DNA and RNA, and proteins (Zuckerkandl and Pauling 1965). This flow takes place through transcription (of DNA to RNA) and translation (of the message from RNA to proteins) via the algorithm that is the genetic code. In the 1970s, the pursuit of exploring the stereochemical roots of the origins of the genetic code by Carl Woese (Woese 1968; Fox 2013) led to the observation that the signatures of the informational macromolecule, namely the ribosomal RNA, are universal and thus extremely well-conserved. The pioneering use of these molecular signatures to reclassify the phylogenetic relationships between various life forms resulted in the three-domain classification system, comprising the bacteria, archaea and eukarya (Woese and Fox 1977a, 1977b; Woese et al. 1990; Woese 2000; Sapp and Fox 2013). This molecular signature-based system replaced the earlier system that was based mostly on morphology for more than a century (Linné and Salvius 1758, 1759; Whittaker 1969; Margulis 1974).

The three-domain classification of cellular life represented a landmark event arguably equal in significance to that of solving the structure of DNA (Watson and Crick 1953). Following this, advances in sequencing technology generated large sets of genomic data from organisms spread across the three domains of life. This, in turn, could be exploited to refine the classification of gene systems and their relationships, levels of conservation and lateral transfer between domains, phyla/groups and species. In this process it became evident that in the hierarchical organization of molecular universality and levels of conservation, the genes involved in translation occupied the first slot. Central to the translation system, are the genes encoding the ribosomal RNA, the ribosomal proteins and associated factors, all of which ranked high in conservation and universality. Thus, the translational machinery was identified as one of the most ancient of systems in biology and was forming part of the core of the (hypothetical) Last Universal Common Ancestor (LUCA) (Gesteland and Atkins 1993; Woese 1998; Harris et al. 2003; Charlebois and Doolittle 2004; Vetsigian et al. 2006; Fournier et al. 2010; Di Giulio 2011, 2018; Williams et al. 2013; Hartman and Smith 2014; Bernier et al. 2018; Weiss et al. 2018; Coleman et al. 2019).

The translational apparatus itself, namely the ribosome, is a universal ribonucleoprotein complex of two (one large and one small) subunits (Smith et al. 2008; Fox 2010), described as a ratchet-like machine (Frank and Agrawal 2000) propelled by Brownian motion (Frank and Gonzalez 2010). The large subunit (LSU) houses the peptidyl transferase center (PTC) which was shown to catalyze peptide bond formation (Monro 1967) in the growing peptide chain, using the charged amino acid on the transfer RNA, decoding the message from the messenger RNA (Woese 2002; Beringer and Rodnina 2007; Fox 2010; Petrov et al. 2014b). The ribosome thus, links the genotype and phenotype (Noller 2012) and represents a universal molecular fossil with multiple layers of 'chronologically' separable domains (Bokov and Steinberg 2009; Hsiao et al. 2013b; Petrov et al. 2014a, b; Petrov et al. 2015; Lanier et al. 2016; Bernier et al. 2018). 
As structural studies on ribosomes continued to progress, the central role of the ribosomal RNA in the function of the ribosomes became increasingly evident. High resolution structural data further showed that the functional center for the peptide bond formation in the LSU is the RNA (Cate et al. 1999; Ban et al. 2000; Nissen et al. 2000; Harms et al. 2001; Schlunzen et al. 2001; Spahn et al. 2001; Yusupov et al. 2001; Hansen et al. 2002; Ramakrishnan 2002; Schuwirth et al. 2005; Selmer et al. 2006; Armache et al. 2010; Jenner et al. 2012; Anger et al. 2013). Furthermore, even though the ribosome requires several proteins for decoding the message from the mRNA to make the peptide (Brock et al. 1998; Ramakrishnan 2002), it was shown (as early as in 1964) that peptide synthesis initiation and subsequent steps in translation could also happen without these proteins (Nirenberg and Leder 1964; Pestka 1968; Lill et al. 1986). One study suggested that the ribosome could act as an entropy trap, creating the appropriate three-dimensional space molecular placements to ensure the exclusion of water and enabling peptide bond formation (Sievers et al. 2004). Thus, it is now generally accepted that the catalytic core of the ribosome is a ribozyme (Cech 2000; Muth et al. 2000; Nissen et al. 2000) and that such translation machinery is clearly very ancient (Hury et al. 2006). Recent efforts have also successfully delineated the components of the ribosome in a systems approach exploring the cavities within the ribosome (Rivas et al. 2013), as well as smaller motifs or centers of motion (Paci and Fox 2015, 2016).

\subsection{The Ribosome as a Window into the Ancient Pre-Biotic Past}

Given all of this, it is only conceivable that the 'top down' view of life leading towards LUCA's origins cannot be decoupled from the origins of the translational apparatus and thus of RNA itself (Woese 2001). With this as the backdrop, the discovery of RNAs that could catalyze reactions, lead to the idea of an RNA World where RNA molecules would have catalyzed reactions - such as their own replication — whilst these would have been coded by the sequence of nucleotides of the RNA molecule itself (Rich 1962; Woese 1967; Gilbert 1986; Lahav 1993; Orgel and Crick 1993;). This theory became popular quickly (Cech 1993, 2009, 2015; Gesteland and Atkins 1993; Woese 2001; Filipowicz 2017; Kawamura and Maurel 2017; Yeates et al. 2017) and it is rooted in multiple pieces of evidence. First, RNA possesses dual capabilities and serve both as a repository for genetic information (genotype) and as chemical catalysts (phenotype). Second, is the role of RNA in various aspects of the cellular machinery, including gene regulation (riboswitches, non-protein-coding regulatory RNAs, including microRNAs, sRNAs, scnRNAs and lncRNAs) (Lee et al. 1993; Ruvkun et al. 2004; Duharcourt et al. 2009; Ames and Breaker 2010; Wagner and Romby 2015; Dutta and Srivastava 2018; Li and Li 2018), and bacterial immune response (CRISPR/Cas) (Gholizadeh et al. 2017; Patterson et al. 2017). Lastly, the nucleotide co-enzymes are ribosebased, just like RNA.

Despite these observations, the notion of an extended RNA World in which RNAs catalyze many biochemical reactions as well as cell division remains controversial (James and Ellington 1995; Ma and Yu 2006). The key argument against the RNA World hypothesis has so far been the non-demonstration of the existence of a self-copying RNA replicase (Robertson and Joyce 2012; Ma 2014; Higgs and Lehman 2015). It is now considered plausible that the first RNA replicase may have originated as a peptide produced by a primitive ribosome that likely emerged from a replicase-free brief RNA World (Fox 2010, 2016a), which then continued to evolve (Fox and Naik 2004; Fox et al. 2012). There is yet another moot point: a putative molecular Darwinian bottleneck resulting from evolutionary biases and constraints in the prebiotic world has been proposed as a major factor leading to the asphalt paradox (Benner et al. 2012) with respect to the stability of the RNA world. The asphalt paradox 
refers to the observation that raw free energy applied to organic molecules tends to produce biologically useless tars, whilst life itself tends to evolve novel ways of using new sources of free energy.

Therefore, in the prebiotic RNA world, a rapid organization of the starting material into higher order complexity (proto-ribosome/primitive translation machinery) could have overcome the twin problems of maintaining stability in a hostile environment (that of a prebiotic Earth), as well as information processing. A novel model is lending further support to this hypothesis, in which an ancient RNA apparatus, lying embedded within the modern ribosome, has been proposed to have likely preceded the stable and (relatively) modern peptidyl transferase center (Krupkin et al. 2011).

\subsection{A View from the 'Bottom-up' - from Prebiotic Chemistry to the LUCA. Abiogenic Processes Leading to the Emergence of Life}

The emergence of life is undoubtedly married to the understanding of the sum total of geological events on the early Earth. As detailed in the previous section, the early history of Earth after its estimated formation around 4.54 billion years $(4.5 \mathrm{Ga})$ ago, was characterized by the energic bombardment of asteroids and other extraterrestrial objects, keeping Earth's water mostly in its gaseous state (Dalrymple 1991). A hydrosphere, a requirement for life as we know it, is estimated to have been formed $4.4 \mathrm{Ga}$ ago (Watson and Harrison 2005). How did a non-living chemical system, consisting of basic molecules, transition to the LUCA stage via the hypothetical RNA World? Could this question be addressed through the application of either Darwinian or non-Darwinian concepts? Could this shed light on whether the early events lead to an initial selection of prebiotic molecules? Could this selection have narrowed down molecules most 'ideal' for life? Could this then have been followed by molecular self-organization of such prebiotic molecules potentially leading to variation and selection, collectively termed molecular evolution?

In the 1920s, the classic Oparin-Haldane hypothesis proposed that life on Earth emerged through chemical evolution of abiogenic matter based on the assumption of a reducing atmosphere of an early habitable Earth (Oparin 1924; Haldane 1929). The hypothesis proposed that simple inorganics exploited chemical energy from natural sources to build larger building blocks in the famous 'primordial soup', very much akin to Charles Darwin's 'warm little pond' proposal (Darwin Correspondence Project, http://www.darwinproject.ac.uk/) (Peretó et al. 2009). This abiotic organization of molecules was proposed to have resulted in larger, more complex polymers.

On the footsteps of the Oparin-Haldane hypothesis, came the Miller-Urey experiment providing the first evidence that organic molecules arguably needed for life could be formed from inorganic components under reducing conditions. All that was required was an enclosed system comprising of a primordial soup analog of heated pool of water and a mixture of early Earth gases (that of water, ammonia, methane and nitrogen), with sparks of electricity providing 'lightning'-like energy (Miller 1953). The Oparin-Haldane hypothesis supported by the Miller-Urey experiment, was further vindicated with many experiments showing that organic building blocks can indeed form from inorganic precursors (Powner et al. 2009; McCollom 2013; Lazcano 2018). In one study, the Miller-Urey experiments could produce RNA nucleobases in discharges and laser-driven plasma impact simulations under reducing conditions with formamide as an intermediate (Ferus et al. 2017). One report makes a compelling argument for the occurrence of short-lived reducing atmospheres which could have supported the formation of organic matter (Genda et al. 2017; Parkos et al. 2018). However, the reducing atmosphere scenario of early Earth (on which the Oparin-Haldane 
hypothesis is based) have been challenged (Abelson 1966; Trail et al. 2011). The arguments are based on the observational models that the early atmosphere was mostly nitrogen gas with some $\mathrm{CO}_{2}$, where a lower yield of organic material is found (Folsome et al. 1981; Plankensteiner et al. 2006). Neutral atmospheric conditions appear to yield a fair amount of amino acids (Cleaves et al. 2008), but certainly at lower rates of production than if some methane is present. Photochemical production of HCN from even small fluxes of methane is efficient and likely was significant on the early Earth (Zahnle 1986; Tian et al. 2011), and most recent models suggest percent-levels of hydrogen would be present in the atmosphere before life arose (Tian et al. 2005; Wordsworth and Pierrehumbert 2013) likely bolstering the atmospheric production of organic material.

All of this does not make up the entire picture though. The carbon, oxygen and nitrogen on Earth were also sourced from the accretion of interstellar dust in the original solar nebula, in the form of organic compounds, a process that is still ongoing today (Chyba and Sagan 1992; Dworkin et al. 2001; Ehrenfreund et al. 2011). Thus, the accumulation of the organic compounds required for life to begin were not only possibly synthesized by geochemical processes, but could have also been delivered by meteoritic inputs (Meinschein et al. 1963; Anders 1989; Cooper et al. 2001; Sephton 2002; Pizzarello and Shock 2017), as confirmed by the finding of extraterrestrial carbon in early Earth sediments (Gourier et al. 2019). Such an available inventory could have undergone sorting, processing and selection (Lazcano 2016) to form the first heterotrophic protocell. Indeed, compounds extracted from the Murchison meteorite have been proposed as source material not only for membrane formation (Deamer et al. 1991; Deamer 2012), but also for facilitating electron transfer across membranes (Milshteyn et al. 2019).

\subsection{The Emergence of Life: In the Oceans or on Oceanic Edges?}

The Oparin-Haldane model of buildup of simple blocks of life is hypothesized to have occurred around the water's edge. This idea is being contested by those who argue in favor of deep oceanic origins. While no modern-style continental landmasses existed before 3.2 Ga, the preserved geological record from the Early Archaean (that can be translated probably back to the Hadean) documents small exposed landmasses on top of submerged ocean plateau-like protocontinents, something like volcanic Iceland surrounded by relatively protected collapse basins (cf. Nijman et al. 2017). It is fair to say, however, that our current understanding or knowledge of any kind of exposed terrestrial surface during those early days is hazy (Sleep 2018). Nevertheless, land/terrestrial hydrothermal vent systems that are components of volcanic landmasses in present day Earth are hypothesized to be analogs of similar geological features that likely arose out of Earth's first oceans (King and Adam 2014). In one novel hypothesis, it has been suggested that early Earth volcanic islands harboring Darwin's warm little ponds could have been the sites of early prebiotic chemistry, releasing the products into the oceans (Bada and Korenaga 2018).

Recent efforts have shown that a water-land interface could be plausible sites for the origins of life. For example, hydrothermal pool water was shown to support the assembly of a mixture of dodecanoic acid and glycerol monododecanoate into temperature tolerant and stable membranes at both acidic and alkaline $\mathrm{pH}$ ranges. On the other hand, recent studies suggest seawater does not support the formation of stable vesicles by amphiphiles (Milshteyn et al. 2018; Deamer et al. 2019). Nevertheless, it is worth noting that most of these studies have commonly used one type of amphiphilic molecule in order to assemble such vesicles. For instance, recent work shows that using mixtures of amphiphiles of differing tail lengths (Jordan et al. 2019b), or the addition of other types of amphiphiles such 
as isoprenoids (Jordan et al. 2019a) — a more realistic simulation of the 'dirty chemistry' world of prebiotic chemistry - can yield vesicles which are significantly more resistant to higher salinity and $\mathrm{pH}$ values. In any case, such land-water interface sites which are characterized by fluctuating fresh water hydrothermal pools could also support other reactions. These include polymerization, generation of a hydrogel of stable, communally supported membrane-bounded protocells (Damer 2016), molecular systems driven by cycles of hydration and dehydration, chemical evolution in dehydrated films on mineral surfaces, and encapsulation and combinatorial selection in a hydrated bulk phase (Damer and Deamer 2015). Such results are supportive of hydrothermal springs on primitive islands on the prebiotic Earth that are in line with the Oparin-Haldane idea of the edge of the ocean-land interface sites as candidate environments for biogenesis. However, this particular debate between the oceanic origins and the land-water interface origins of life is far from over, especially considering the huge UV flux to the surface of the early Earth (50-1000 W/m² according to Cockell and Raven 2004).

\subsection{Can a Primitive RNA World or RNA-Peptide World Generate Rapid Increases in Complexity?}

Based on multiple models of the early Earth and its impact history, it has been estimated that the appearance of RNA molecules could have occurred around $4.36 \pm 0.1$ billion years ago (Benner et al. 2019). In the face of different viewpoints of what the so-called RNA World might have been like — or whether it marked the start of the abiogenesis process or rather it represented a later (already quite complex) intermediate point-multiple efforts have been and are being made towards understanding the most probable order of molecular evolution events that could produce 'significant' quantities of RNA monomers under prebiotic conditions (Biscans 2018). The origins of the RNA polymers have been linked to several potential precursors such as ammonium cyanide (Oró 1960), 2-pyrimidinone (Bean et al. 2007), triaminopyrimidine (TAP), melamine, barbituric acid (BA), cyanuric acid (CA) (Menor-Salvan et al. 2009; Chen et al. 2014), formaldehyde (yielding ribose) (Decker et al. 1982; Larralde et al. 1995; Kim et al. 2011), ribose alternatives (Weber 1992; Eschenmoser 2011; Sagi et al. 2012), and formamide (Saladino et al. 2007, 2009, 2012a, 2012b; Pino et al. 2015). One proposal has suggested that the origin and early evolution of life took place in an environment containing previously synthesized building blocks. Following this argument, the chemical pathways and intermediate metabolites of extant biology would have been added to the emerging network of molecules in response to the adaptation needs of such early organisms (Wu and Sutherland 2019). This view is tantalizing, but it is worth noting this approach largely sacrifices the hopes of understanding the geological and biological forces which shaped early life into what would eventually become the LUCA.

Precursors have been shown to give rise to more complex structures through a variety of non-chemical processes (Ferris and Orgel 1966; Sanchez et al. 1967, 1968; Ferris et al. 1968; Sanchez and Orgel 1970; Fuller et al. 1972a,b; Orgel and Crick 1993; Ferris et al. 1996; Orgel 2004; Powner et al. 2009, 2010, 2011). Other efforts towards demonstrating the prebiotic synthesis of RNA have yielded promising results (Cafferty et al. 2016; Yeates et al. 2016; Costanzo et al. 2017; He et al. 2017; Mathis et al. 2017; Szilagyi et al. 2017; Taran et al. 2017; Wills and Carter 2018; Yeates et al. 2017). A significant effort resulted in the robust production of enantiopure RNA precursors from racemic starting materials under potential prebiotic conditions (Hein et al. 2011; Leu et al. 2011; Obermayer et al. 2011). The remarkable stability of RNA precursors, such as pentose aminooxazolines and oxazolidinone thiones, has also been demonstrated under the conditions of early Earth and UVirradiation levels (Janicki et al. 2018). Even neutral (as opposed to reducing) atmospheres 
could be conducive to the synthesis of carbonylated heterocycles from $\mathrm{N}$-heterocycles and their adducts (i.e. subunits of the proposed RNA precursor, peptide nucleic acids (PNAs)) on the early Earth (Rodriguez et al. 2019).

Once precursors leading to RNA monomers are available, polymerization could be potentially achieved through a combination of condensation and dehydration reactions (Hud et al. 2013), the ligation of random oligomers (Briones et al. 2009), possible reactions on inorganic surfaces/clays (Miyakawa et al. 2006; Joshi et al. 2009), or in lipid-bilayer lattices (Rajamani et al. 2008; Mungi and Rajamani 2015). A key step in RNA polymerization is the activation of nucleotides. 2-aminoimidazole and 2-aminooxazole have been proposed as good candidates for prebiotic nucleotide activation leading to non-enzymatic RNA replication. It has been proposed that the prebiotic synthesis of both these compounds share a common pathway in which simpler compounds such as glycolaldehyde, cyanamide, phosphate and ammonium react under low pH conditions (Fahrenbach et al. 2017). The rapidly fluctuating local environments on the prebiotic Earth could themselves have been ideal in aiding the requisite increases in complexity as demonstrated by the wet/dry cycles (Forsythe et al. 2015). A significant observation about RNA functional versatility lies in the fact that RNAs need not be large to exhibit functional activities. While there are multiple examples to support this, the example of a novel artificial RNA structurally mimicking a modern tRNA (Nagaswamy and Fox 2003; Di Giulio 2009), and a small 24 residue micro helix RNA that could be charged with alanine (Francklyn and Schimmel 1989), are two that illustrate this point. Given that prebiotic chemistry can potentially generate oligo ribonucleotides in the 15-40 size range, it is only likely that such similar small RNAs may have had biologically relevant properties in the prebiotic world.

In theoretical molecular evolution DNA and RNA-when subjected to self-organization - could eventually lead to the creation of clusters of mutants, each of which could be potentially identifiable by a certain representative (derived and defined) consensus sequence(s), termed the 'quasispecies' (Eigen et al. 1989; Schwille 2018). Such a clustering of subtypes provides ample space for evolutionary dynamics including selection and adaptation, leading to increase in complexity. The 'quasispecies' theory has been tested exploring the link between chemical kinetics and evolutionary dynamics, the generation of RNA oligomers by montmorillonite, and self-replicating peptides in a hyper cyclic network of symbiosis (Lee et al. 1997; Wattis and Coveney 1999; Emren et al. 2006; Huang and Ferris 2006; Kurtovic et al. 2007; Kurtovic and Mannervik 2009; Chen and Nowak 2012). Non-enzymatic RNA replication using only chemical processes is yet another option that has been adequately covered (Szostak 2012).

The mutation buildup approach has a drawback in that high rates of mutation could negatively impact the emergence of functional sequences in a prebiotic world (Higgs 1998; Rajamani et al. 2010; Leu et al. 2011). A novel alternate approach based on dynamic combinatorial chemistry (DCC) (Benner et al. 1996; Leal et al. 2006), proposes that when RNAs are subjected to a persistent equilibrium of ligation (recombination events rather than mutations) and cleavage, it would lead to naturally increasing RNA pools in variety and possibly complexity. This also suggests that this could happen in the absence of frequent point mutations caused by replication errors. Such pools of RNA may eventually gain resistance to degradation over time, thereby serving as the basis for an RNA World. Theoretical modelling (Walker et al. 2012) and experimental efforts (Arsène et al. 2018; Tirumalai et al. 2018a, 2018b), have adopted this approach, demonstrating that simultaneous ligation and degradation can rapidly produce RNAs of increasing diversity in the absence of a replicase. 


\subsection{Metals and the RNA World}

Metal ions play a wide plethora of roles in biology and were abundant on prebiotic Earth, which was characterized by high rates of leaching and solvation of the metals (Bengtson 1994; Westall et al. 2015). In contemporary biological systems, the association of RNA with transition metal ions is a widespread feature (Pyle 2002). Riboswitches that associate with $\mathrm{Mn}^{2+}, \mathrm{Ni}^{2+}$, and $\mathrm{Co}^{2+}$ (Furukawa et al. 2015; Price et al. 2015) and ribosomal RNA binding with $\mathrm{Pt}^{2+}$ (Plakos and DeRose 2017) are classic examples in this context. Magnesium which is frequently closely associated with phosphates and phosphate esters is an important metal in RNA metallobiochemistry (Gonzalez and Tinoco 2001) and an important player in the origins of life (Petrov et al. 2011; Westheimer 1987). Magnesium and potassium are important cations in RNA metallobiochemistry (Draper 2008; Gonzalez and Tinoco 2001); indeed, the early terrestrial basalts (komatiites) were richer in $\mathrm{Mg}$ than at present. Diffusely bound $\mathrm{Mg}$ ions stabilize the folded (tertiary) structures of RNA by accumulating in regions of high negative electrostatic potential. Single partially dehydrated $\mathrm{Mg}^{2+}$ stabilizes the tertiary structure of the rRNA and complex RNA folds (Cate et al. 1997; Misra and Draper 2001). Computational model predictions of two magnesium ions playing a role in the catalysis of the junction of two RNA strands via "a two $\mathrm{Mg}^{2+}$ ions" mechanism (Sgrignani and Magistrato 2012) have significant implications for the RNA world hypothesis. Magnesium has been shown to (i) form a framework critical for the ribosomal peptidyl transferase center (PTC) (Hsiao and Williams 2009), (ii) stabilizes ribosomal assembly (Petrov et al. 2012), (iii) regulates translational rates in bacteria (Pech et al. 2011), and (iv) alter base pairing in riboswitches (Zhao et al. 2011). In the vicinity of the PTC, the Mg divalent ion core has been suggested to be the RNA counterpart to the protein hydrophobic core, burying parts of the RNA molecule in the native structure and being critical for RNA tertiary structure formation (Cate et al. 1997). $\mathrm{Mg}^{2+}$ is thus inseparable from the overall compositional evolution of the ribosome and hence RNA.

In other studies, the roles of iron and manganese as magnesium substitutes under the anaerobic conditions that likely existed on the prebiotic Earth have been evaluated. Studies imply the association of $\mathrm{Fe}(\mathrm{II})$, the most common form of $\mathrm{Fe}$ on the anoxic planet, with functional RNA during the early anoxygenic period of Earth's history. The advent of oxygen is thought to have led to $\mathrm{Fe}$ (II) being replaced by $\mathrm{Mg}^{2+}$ (Hsiao et al. 2013a). Further studies have demonstrated the potential roles of $\mathrm{Fe}^{2+}$ and $\mathrm{Mn}^{2+}$ as $\mathrm{Mg}^{2+}$ substitutes during the early stages of the ribosomal evolution when both $\mathrm{Fe}^{2+}$ and $\mathrm{Mn}^{2+}$ were abundant in the absence of free oxygen (Athavale et al. 2012; Bray et al. 2018).

\subsection{Molecular Mutualism or Symbiosis Between Polymers of Nucleotides and Peptides}

“... Polynucleotide and polypeptide are molecules in mutualism. RNA synthesizes protein in the ribosome and protein synthesizes RNA in polymerases. RNA and protein are codependent, and trade proficiencies..." (Lanier et al. 2017). The limitations to the RNA 'only' or RNA 'first' world theories-imposed by the relatively poor catalytic ability as well as stability of RNAs by themselves (Lilley 2003) — have led to the emerging idea of the co-evolution of both RNA and peptide polymers in a synergistic manner. Scientists van der Gulik and Speijer have made a compelling argument that the RNA world could not have been possible without amino acids playing a role in the same (van der Gulik and Speijer 2015). This leads us back to the idea of a proto-ribosome preceding the LUCA (Fox 2016b; Fox and Naik 
2004; Bowman et al. 2015). In one novel hypothetical scenario, ancient versions of transfer RNAs (tRNA) could enable the origin of the first genes (mRNA), while a proto-PTC (rRNA) and proto-tRNAs formed a proto-translation system, followed by the emergence of metabolic pathways (de Farias et al. 2016). In addition to what was mentioned earlier about the protoribosome, it has been shown that a quantum mechanical theoretical model of such a system based on coordinates of known crystal structures of existing ribosomes, fits well with energetic stability of such a proto-ribosome structure and its attachment to substrates (Huang et al. 2013). Mutual partnership interactions between ancestral oligonucleotides/ribozymes and oligopeptides in an ancient pre-LUCA scenario, supporting the emergence of biology, are gaining traction (Taylor 2006; Wolf and Koonin 2007). Much of this is supported by structural evidence for simple, stereo chemically coded, reciprocally catalytic peptide/RNA complexes, thereby overriding the need for one type of polymer to possess both catalytic and informational properties (Yarus 1998; Li et al. 2013; Carter 2015; Carter and Wills 2018; Wills and Carter 2018; Puthenvedu et al. 2018; Yarus 2018). RNA, peptides and lipids could have aggregated to give rise to molecular 'sociality' leading to the emergence of the first primitive form of life (Ray 1992).

Thomas R. Cech in his 2012 paper eloquently described two RNA worlds (Cech 2012). In the earlier primordial hypothetical RNA world, RNA was genotype and phenotype. In the other, more recent, version of the RNA world, RNA catalyzes, mediates and participates in a multitude of reactions and cellular processes. Extending his description to the current ideas, it is conceivable that a primitive RNA world was likely a RNA-peptide world which transitioned to a proto-ribosome encapsulated within a proto-membrane to the LUCA, in a manner analogous to the 'punctuated equilibrium' states proposed by evolutionary biologist Stephen J. Gould (Gould 1983, 1986; Gould and Eldredge 1993).

As it stands now, certain key questions do not have concrete answers. Firstly, there is the question as to how populations of prebiotic molecules underwent selection leading to filtering out some of the same, and the fine-tuning of this selection process (Islam et al. 2017). From this stage, selection arguably lead to choosing RNA as the primary information carrying starting material (Whitaker and Powner 2018), with peptides forming a mutually supporting role for the next step in kick-starting life. At the second level, is the question as to how did the RNA world or RNA-peptide world get to the LUCA stage? The larger 'origins of life' questions are gradually evolving towards a more systemic approach that involves simultaneous roles of multiple components and their respective pathways in a coevolving network towards biocomplexity (de la Escosura et al. 2015; Le Vay and Mutschler 2019; Runnels et al. 2018). Bhowmik and Krishnamurthy (2019) have made a compelling case for the possibility of the concurrent emergence of both RNA and DNA from what they refer to as a "prebiotic clutter" of chemicals. Stephen J. Gould hypothesized that if we were to 'replay life's tape' by going back in time, the replay would most probably be different (Gould 1989). Thus, prebiotic molecules, including nucleic acids, peptides and lipids interacting in a playback scenario might lead to something different than the LUCA. Even if one were to consider a similar set of parameters in extraterrestrial bodies like Mars, Titan, Europa, Enceladus, Ganymede (and their likes) leading to formation of precursors similar to Earth's 'life' precursors, the process of evolution would have led to or could lead to something different than what is observed on Earth. One could say that both Gould and Schrödinger would perhaps agree on this.

\subsection{Extraterrestrial RNA Worlds?}

Even if often the existence of an RNA World is not directly referred to in hypotheses for the emergence of life focusing on metabolism, at some point in their chronology it is common 
for the invocation of a prevalent role of RNA or RNA-like molecules. Most "genetics first" hypotheses require surficial synthesis of nucleotides or nucleobases, regardless of whether this occurs de novo or by recycling extra-terrestrial organics delivered from space. This is mostly because the need of UV radiation and/or wet-dry cycling, two features which are difficult to be found at oceanic depths (although the necessity of decreased water activity could be overcome by reactions on mineral surfaces, such as silica gel (Dass et al. 2018)). The global oceans present in icy moons such as Europa and Enceladus are covered in a thick ice shell which would impede any UV radiation down into their respective oceans. Wet-dry cycles and UV-mediated chemistry could still occur in the upper layers of the ice shell, so putative nucleotides synthesized there could still be useful for abiogenesis if a mechanism for some type of ice subduction is (or was) taking place. This idea, however, does not take into account the huge radiation fields of the giant planets which would effectively destroy the more complex prebiotic organics necessary for cell-building at the surficial ice layers. Nucleotide synthesis in the surface of other icy moons such as Titan seems more plausible due to the physical remodeling of its landscape and associated chemical activity. Despite this, there are doubts as to how such nucleotides could migrate down to Titan's subsurface watery oceans in order for RNA World-type (bio)chemistry to take place (more on this in Sect. 5 of this article).

Nevertheless, the putative (perhaps past) presence of some sort or RNA World in the oceans of Europa and Enceladus is anything but impossible. It is reasonable to consider that nucleotides could be non-enzymatically synthesized in chemical pathways independent of wet-dry cycling and UV radiation, which are two alleged abiogenic reaction promoters that modern-and arguably ancient-life does not use (Harrison and Lane 2018). Reduced nitrogen species have already been detected in the plumes of Enceladus (Waite et al. 2009), which suggests that the hydrothermally-derived reactivity present at the oceanic floor could also yield the nucleotides (or at least the nucleobases) required for an RNA World-like scenario.

\section{Lessons from Biology-What Does the Tree of Life Tell Us About Its Emergence?}

\subsection{The Historical Universal Tree of Life}

The first significant attempt at a phylogenetic tree of prokaryotes, historically, was published by Orla-Jensen (1909) (Fig. 2) and based on the concept that the earliest organisms on Earth were chemolithoautotrophs since they would have had to inhabit an environment devoid of light and organic nutrients. In many ways similar to present hydrothermal vent origin of life models, in his scheme, evolution proceeded from the original lithotrophic stock to give rise to bacteria having diverse nutritional requirements and increasingly complex niches (Orla-Jensen 1909). Our present view of prokaryotic evolution was significantly shaped by the pioneering work of Carl R. Woese and George E. Fox (Woese and Fox 1977a, 1977b) that was based on the analyses of universally conserved nucleic acid sequences (particularly those of the small subunit rRNA gene; Pace 1997). Indeed, phylogenetic analyses of the 16S and 18S rRNA genes universally present in all cellular life became subsequently an integral tool for microbial taxonomists. In many ways, the rRNA tree of life has become a foundation on which rests much of our modern view of microbiology and, in particular, our view of the evolutionary history of microorganisms. However, in spite of its impact and successes, the comparison of the small submit rRNA has inherent limitations. First, phylogenetic analyses 
1. Sporosarcina

2. Sporospirillum

3. Nitrosomonas nitrator

4. Indolococcus

5. Thermobscillus

6. Peptonococcus

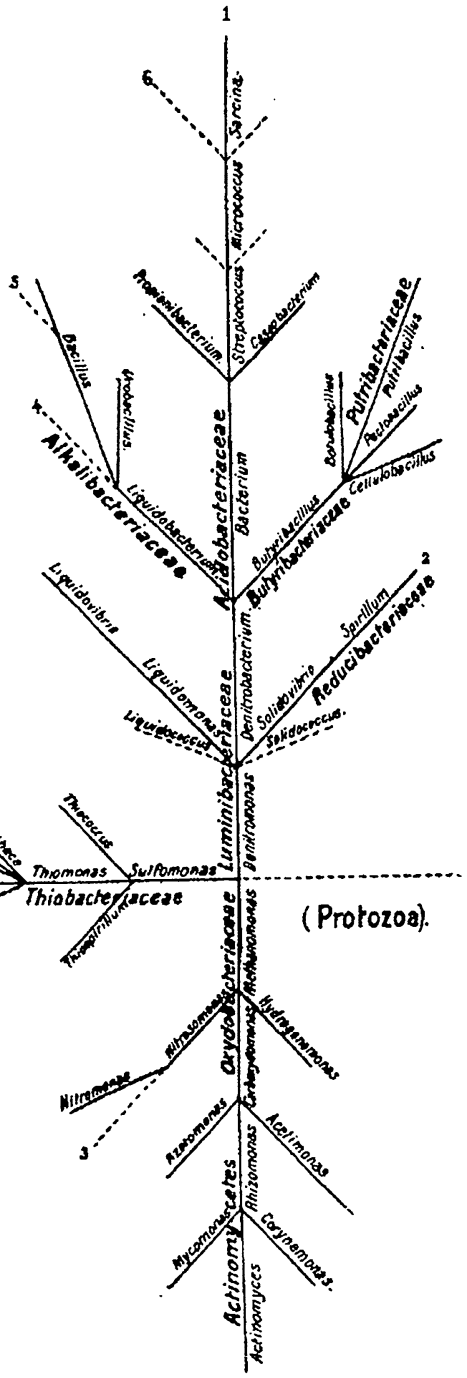

(Eumyceres)

Fig. 2 Early 20th century microbial tree (Orla-Jensen 1909)

of single gene sequences, such as the rRNA gene, lack sufficient information to confidently resolve the divergence patterns of the major microbial lineages that diverged very early in life's history. Second, although this is true for any phylogenetic analysis, misalignments as well as varying evolutionary rates and compositional biases between distinct lineages can adversely impact the recovered phylogenetic tree and result in incorrect topologies (Felsenstein 1981; Gribaldo and Philippe 2002; Heaps et al. 2014). Third, at its best, the 16S rRNA tree represents the evolutionary history of this particular marker gene and may or may not be reflective of the phylogenetic history of microorganisms, which is known to be shaped by both vertical and horizontal components of evolution (Koonin 2016) with different protein families displaying independent histories. The recognition that substantial horizontal gene 
transfer (HGT) has occurred between microorganisms raised concerns that genes might be transferred with high enough frequency as to seriously challenge the notion of a universal tree of life (e.g. Doolittle 1999; Gogarten et al. 2002). However, using a variety of phylogenetic and phylogenomic approaches, it became subsequently clear that, in spite of frequent HGT, a central trend of predominantly vertical evolution is discernible and leaves the notion of a tree of life (e.g. House 2009, Puigbò et al. 2009, 2010). In fact, reconciliation methods have shown that HGT may even reinforce these central trends in the tree of life (Abby et al. 2012), which to some extent is similar to the basic structure of the small subunit rRNA tree and broadly validates original inferences about microbial history (e.g. Fitz Gibbon and House 1999; Snel et al. 1999).

\subsection{The Importance of a Rooted and Supported Tree of Life for Understanding Early Evolution}

While life most likely originated and diversified long before the existence of the last universal common ancestor (LUCA), extrapolating back from the current genomic and taxonomic diversity to LUCA can help to provide insights into the nature of this elusive ancestor. In this regard, it is important to locate the root in the current tree of life as this is essential for reconstructing the early evolutionary history of life (Williams et al. 2015). However, both the root as well as the exact topology of the tree of life remain a matter of ongoing research as lack of data and challenges with regard to phylogenetic reconstructions have thus far hampered to unambiguously elucidate the identity of early diverging lineages. For instance, previous work has shown that bacterial hyperthermophiles such as Aquificales and Thermotogales can artificially be attracted to the root of the tree due to phylogenetic artifacts (Williams et al. 2015) (Fig. 3A). Furthermore, it remains to be determined, whether the root is indeed placed between Archaea on one side and Bacteria on the other side or falls within Bacteria (Cavalier-Smith 2006; Lake et al. 2009; Dagan et al. 2010; Williams et al. 2015, Weiss et al. 2018). Finally, it is currently debated whether life should be divided into three major domains, i.e. Archaea, Bacteria and Eukaryotes, as originally suggested by Woese and co-workers (e.g. Woese et al. 1990) or into two primary domains of life, i.e. Archaea and Bacteria, and one secondary domain of life (Eukaryotes) (Williams et al. 2013). The latter view is based on the notion that Eukaryotes likely originated from a symbiosis between an archaeal host and a bacterial endosymbiont (e.g. reviewed in Lopez-Garcia and Moreira 2015: Martin et al. 2015), a scenario that has gained recent support from the discovery of the Asgard archaea, which form a monophyletic group with Eukaryotes in phylogenetic analyses and encode various eukaryotic signature proteins (Spang et al. 2015; ZarembaNiedzwiedzka et al. 2017; Eme et al. 2018). Nevertheless, independently of a consensus on how to best categorize the different types of extant cellular life forms, which to some extent is a matter of definition, it is most commonly assumed (though not by everybody) that prokaryotic life predated eukaryotic life (Weiss et al. 2018). As such, most inferences on the nature of LUCA are based on information retained in archaeal and bacterial genomes (e.g. Weiss et al. 2016).

\subsection{An Expanded Microbial Tree}

Recently, the genomic exploration of various environments has yielded an expanded view of the large microbial diversity that comprises major lineages in the tree of life (Hug et al. 2016) (Fig. 3). Thus far, it remains unresolved whether (hyper-)thermophilic groups indeed represent early diverging lineages. For instance, preliminary phylogenetic analyses using 


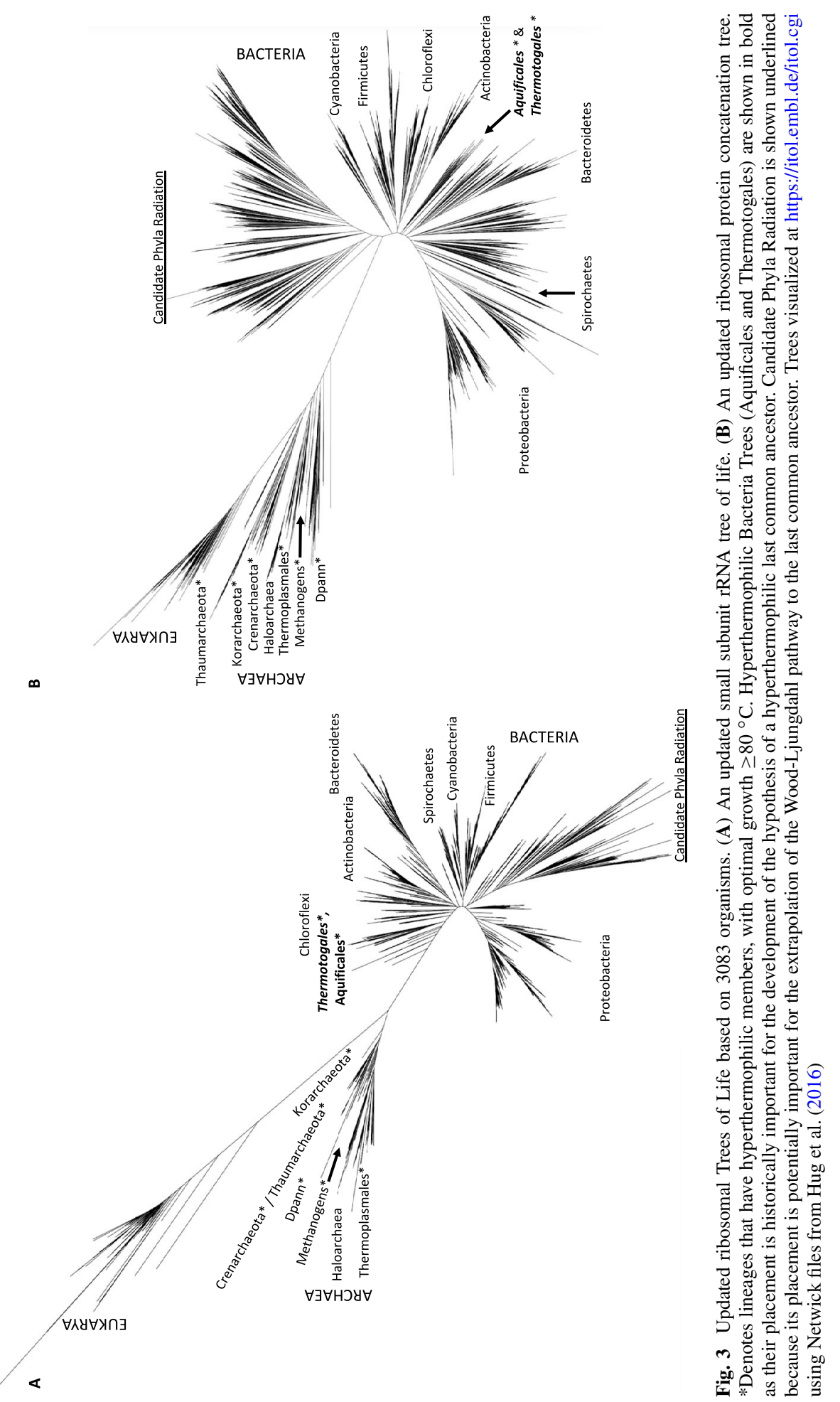


concatenated ribosomal proteins in place of $16 \mathrm{~S}$ rRNA genes (Fig. 3B) indicate that a large radiation of predominantly uncultured mesophilic taxa, which are comprised of potentially symbiotic organisms with small cells and genomes and are referred to as the bacterial candidate phyla radiation (CPR) and the DPANN archaea, diversify near the base of the Bacteria and Archaea respectively (Brown et al. 2015; Castelle et al. 2015; Hug et al. 2016; Castelle and Banfield 2018). In contrast, the hyperthermophilic Aquificales and Thermotogales, as well as the Deinococcus-Thermus phylum, now fall within a more derived, larger cluster of major microbial groups as was suggested previously using more sophisticated models of evolution (Williams et al. 2015). If the root is placed between Bacteria and Archaea, this recent data does not, at face value, indicate a thermophilic common ancestor of Bacteria. However, both the placement of the root as well as the identity of early diverging lineages has to be confirmed using this updated dataset of microbial diversity in combination with more complex models of evolution, which are better suited to prevent phylogenetic artifacts such as long branch attraction (Bergsten 2005). These artifacts are expected to particularly affect microbial lineages comprised predominantly of symbiotic members such as the CPR bacteria and DPANN archaea, as genomes of known symbionts are often compositionally biased and characterized by faster evolutionary rates (Dombrowski et al. 2019). Various attempts in this direction are currently being made but this is clearly a challenging undertaking due to large computational demands of using complex evolutionary models on big datasets. Yet, the further improvement of models of evolution and phylogenetic algorithms (including molecular dating approaches such as recently employed by Wolfe and Fournier 2018 and Davín et al. 2018) in combination with ever increasing computational resources will certainly help to further refine the tree of life and get a better supported location of the root.

\subsection{What Was the Nature of LUCA?}

Given the large uncertainty of the topology and root of the tree of life, the nature of LUCA remains an open question that has to be further addressed in the coming years. Below we summarize some findings from recent publications, which provide initial insights into the genomic potential of this elusive ancestor. First of all, Weiss and co-workers have recently undertaken an attempt to reconstruct the genomic repertoire of LUCA and thereby shed light onto its carbon and energy metabolism as well as the environment in which it may have thrived (Weiss et al. 2016 and reviewed in Weiss et al. 2018). For instance, the inferred presence of the hallmark gene of hyperthermophiles (coding for the reverse gyrase) indicated that LUCA was adapted to a life in a hydrothermal setting. However, a recent re-analysis of the evolutionary history of reverse gyrases has led to the suggestion that the LUCA genome did not contain this gene (Catchpole and Forterre 2019). The latter study is consistent with findings derived from the use of compositional information from 16S rRNA genes and proteins as so-called molecular thermometers, which have pointed out that, while the ancestors of Bacteria and Archaea were thermophilic (Boussau et al. 2008) and thermophilic or hyperthermophilic (Groussin and Gouy 2011; Williams et al. 2017), respectively, LUCA may have been a mesophilic organism (Boussau et al. 2008). Clearly, this seemingly contrasts with previous hypotheses on a thermophilic last common ancestor (Di Giulio 2003). However, they may still be compatible with a hydrothermal origin of life (e.g. Russell et al. 1988; Wächtershäuser 1988; Shock 1990; Pace 1991; Russell and Hall 1997; Schwartzman and Lineweaver 2004; Wächtershäuser 2006; Ooka et al. 2018), as discussed earlier in this article, considering that the first and last universal common ancestor(s) may have been very different. Furthermore, these inferences have their limitations and a more precise estimate 
on the optimal growth temperature of LUCA and its habitat preference remain to be established.

The reconstruction of the LUCA proteome by Weiss and co-workers has also led to the conclusion that this elusive ancestor was an anaerobic organism capable of growth on $\mathrm{H}_{2}$ and $\mathrm{CO}_{2}$ fixation via the Wood-Ljungdahl pathway (WLP) (Weiss et al. 2016). In line with this, the reconstruction of the evolutionary history of the key enzyme of the WLP, the carbon monoxide dehydrogenase/acetyl-CoA synthase (CODH/ACS), has led to the suggestion that it may represent one of the oldest enzymatic complexes (Adam et al. 2018). Furthermore, the last archaeal common ancestor (LACA) is likely to have encoded a CODH/ACS (Williams et al. 2017). Even if the presence of this enzyme complex in early Archaea and Bacteria may not unequivocally allow the determination of whether LUCA was an autotrophic organism using the WLP for carbon fixation (Adam et al. 2018), its suggested presence in the deep nodes in the tree of life is in agreement with previous work that has pointed out the WLP as the most ancient carbon fixation pathway known (e.g. Ferry and House 2005; Fuchs 2011; Martin and Sousa 2016; Weiss et al. 2016; Camprubi et al. 2017). While it may be noteworthy that the potentially deep branching CPR bacteria and DPANN archaea do not encode the WLP (Spang et al. 2017; Adam et al. 2018), the placement of these lineages remains to be verified. Furthermore, even if it would be confirmed that members of these lineages branch deep in the tree of life, their genomes may be secondarily reduced and the absence of key metabolic pathways including the WLP does not, at face value, exclude its presence in LACA. This is consistent with the notion that the Altiarchaea, which may in fact belong to the DPANN archaea (Dombrowski et al. 2019), do encode the WLP (Probst et al. 2014).

Other authors have suggested the likely early evolution of the reductive tricarboxylic acid cycle (rTCA) (Wächtershäuser 1990), but the limited phylogenetic distribution of the key enzyme of the rTCA (ATP citrate lyase or citryl-CoA synthetase) that distinguishes it from the oxidative TCA (which uses citrate synthase), has previously casted doubt on its occurrence in early chemolithoautotrophs (Camprubi et al. 2017). Recently, it was however found that citrate synthase can operate in reverse and thus allows the use of this cycle in both the reductive and oxidative direction (Nunoura et al. 2018). Clearly this finding adds new information to the discussion as to which carbon fixation pathway evolved first, whether any or both were encoded by LUCA and in which direction they operated. In fact, both the TCA and the WLP may have a non-enzymatic origin, testifying to their potential emergence long before LUCA (Ralser 2018; Varma et al. 2018).

Beyond carbon fixation, genomic approaches do support a chemosynthetic last common ancestor with both RNA and protein-based biochemistry. Specifically, the last common ancestor may have had a cell membrane (Jékely 2006; Koga 2011; Lombard et al. 2012; Sojo et al. 2014; Coleman et al. 2019), RNA and phosphodiester-based energy coupling (e.g. Werner and Grohmann 2011), as well as thioester-based intermediary metabolism (Goldford et al. 2017; Weiss et al. 2018), but may not have used a strictly DNA genome (Mushegian and Koonin 1996; Leipe et al. 1999; Forterre 2002; Poole and Logan 2005). Similarly, the last common ancestor appears to have had an ATP synthase for the conversion of the proton motive force into available chemical energy (e.g. Weiss et al. 2016), albeit with important caveats regarding lack of completeness of the ATP synthase extrapolated to be present in the last common ancestor (Werner and Grohmann 2011). These observations seemingly indicate that LUCA is more recent than the evolution electron transport energetics, and to a degree support emergence of life models that propose $\mathrm{pH}$ gradients as a prebiotic source of energy (e.g. Lane et al. 2010; Ducluzeau et al. 2014; Camprubi et al. 2017; Ooka et al. 2018). 


\subsection{Mind the Gap}

Given the large uncertainties with respect to the topology and root of the tree of life as well as the methodological challenges connected with the reconstruction of the earliest states of cellular life, all of these inferences remain tentative. Furthermore, these considerations would apply to Earth-based abiogenesis and, on their own, tell us little about abiogenesis as a Universe-wide phenomenon. Finding evidence for methanogen-like life in an exo-oceanic world (e.g. Enceladus) would not, on its own, tell us much about how life actually originated there. Nonetheless, it is undeniable that if life could be found on such a planet, this-coupled to the phylogenetic inference LUCA could have been a methanogenic chemolithoautotroph (Weiss et al. 2016) — could be interpreted as evidence supporting the idea of a universal push toward abiogenesis as a result of planetary-scale redox disequilibria (Russell et al. 2014), which would apply to most olivine-rich planetary bodies containing liquid water.

In any case, a deeper issue arises from this discussion: there is a knowledge gap between LUCA and the prebiotic chemistry/proto-metabolism from which it eventually descended. In other words, even if a consensus on the physiology of LUCA could be reached, would its biochemistry be somewhat homologous to the non-enzymatic (geo)chemistry from its primordial origins? This issue has divided the 'origins' field for decades with some authors defending there is actually no real gap because adaptation would have bridged any apparent chemical discontinuities between prebiotic chemistry and biochemistry (e.g. Jia et al. 2019; $\mathrm{Wu}$ and Sutherland 2019). Others defend some degree of homology must apply since biology tends to follow the path of least resistance (e.g. Harrison and Lane 2018; Preiner et al. 2018; Muchowska et al. 2019). These different viewpoints partially stem from the classical scientific disciplines of the authors, with (bio)chemistry focusing more on structure and function (i.e. nucleic acid synthesis and replication), and biology and physics putting the emphasis on understanding the forces (e.g. selection pressures) shaping each of the transitions, aiming to bridge the aforementioned gap.

\section{Implications for the Search for Life Elsewhere}

\subsection{Life (Somewhat) Close to Life as We Know It}

Whatever the scenario of the emergence of life, the last steps towards the "self-sustaining chemical system capable of Darwinian evolution" (citing NASA's definition of life) on Earth was probably made up of complex organic compounds, under energy flow, far from equilibrium, and using liquid water. Since their discovery in the late 1970s, hydrothermal vent environments have been considered a very plausible environment for the emergence of life (see Sect. 2 and, for example, Martin et al. 2008). They, and the porous volcanic sediments surrounding them, provide a natural geochemical reactor, with temperature and pressure values and gradients allowing the prebiotic formation of a wide variety of organic materials of biological interest. They also provide a natural far-from-equilibrium setting that favors the emergence of energy-dissipating (and eventually self-replicating) systems. This view has recently been challenged by some biochemists (Jackson 2016, 2017) and prebiotic chemists (Pascal 2016; Sutherland 2017, but see responses by Branscomb and Russell 2018, and Branscomb and Russell 2019). Notwithstanding these critiques, hydrothermal vent environments remain strong contenders and they offer a series of useful constraints in the search for extraterrestrial life, especially when considering the case of icy moons in the Solar System (Russell et al. 2014). Indeed, many of these moons have an internal ocean of water, which 
makes these planetary bodies interesting for astrobiology. This is particularly the case when the subsurface ocean rests on a rocky bottom allowing for direct rock-water interaction, especially in the presence of submarine volcanic activity. This is most probably the case with Europa and Enceladus (McKay et al. 2008; Russell et al. 2017). However, it should be noted that other moons may have experienced such conditions in their early history. This is the case of Titan, which currently has an internal ocean of salty water sandwiched between thick layers of water ice (see 'Ice-Ocean Exchange Processes in the External Solar System' chapter). Models of Titan's evolution suggest that during the first tens of millions of years after its formation it had an ocean in direct contact with a dense atmosphere and above a rocky surface. Thus, Titan could have very early on possessed conditions favorable to the emergence of life and it cannot be discarded that this ocean may still harbor life today (Fortes 2000).

The different scenarios proposed for the origin of life on Earth and the processes involved in it are of crucial interest and can be used as valuable guides in the search for extraterrestrial life (hence, this book). Obviously, this does not mean we should only seek life as it is today on Earth. On the contrary, we must consider that the first living system on Earth was not LUCA, our last common ancestor. Instead, LUCA was the last organism, which already operated in the world of genes and proteins, to exist before the first split-which we have evidence for-in the tree of life. There could have existed a simpler world of RNA which predated LUCA, a scenario in which the same macromolecules played the role of replication and catalysis (see Sect. 3). Today, experimental studies conducted to reproduce in the laboratory some of the last chemical steps in the formation of replication biomolecules have shown the difficulty of obtaining DNA-polynucleotides or even RNA-polynucleotides. Thus, even if a world of RNA existed before LUCA, there could have also been a pre-RNA world, where nucleotide-like monomers were simpler, easier to form and more robust than pentose nucleotides.

Several avenues have been explored in this area. One of the first publications on this subject was presented by Nielsen et al. (1991), with the use of pseudo-peptides (polyamides) instead of sugars in the skeleton of DNA/RNA macromolecular analogues. According to the authors, this polyamide nucleic acids would later become a peptide nucleic acid or PNA. PNA can form a double strand with itself and with DNA or RNA, which supports the idea that it could have acted as a replication molecule (Nielsen et al. 1991). Additionally, it can be easily synthesized under prebiotic conditions (Nelson et al. 2000). Thus, the pre-RNA world could have been a peptide nucleic acid world: a PNA world. Many studies have been conducted by Eschenmoser, who has explored the replacement of ribose in nucleotides by other sugars such as glucose producing pyranosyl RNA or pRNA (Eschenmoser 1999), or by tetrose producing (threose nucleic acids) TNA (Fig. 4) (Eschenmoser 2004). More recently, the use of a simpler sugar, glycol, has been studied. It has been shown that the corresponding glycolic nucleic acid can form helical molecules, opening the possibility of a world of GNA (Chen et al. 2009; Johnson et al. 2011). Even a living world chemically closer to LUCA, but with the involvement of amyloid: an ANA world (amyloid nucleic acid) with nucleic acids bound to the amyloid protein has been considered (Braun et al. 2011).

Therefore, it is of interest to consider these different possibilities and our still sizeable ignorance in this field when seeking for life-whether extent or extinct-in extraterrestrial environments. Indeed, if life appeared in other planetary environments by following a chemical evolution similar to that of the Earth, but perhaps without reaching a 'fully living' state, an 'exo-LUCA' may be (or has been if life has since disappeared) similar to one of these hypothetical pre-RNA worlds. This is particularly true for Mars, whose geological history is similar to that of the Earth, including the period when life appeared on Earth. Therefore, 


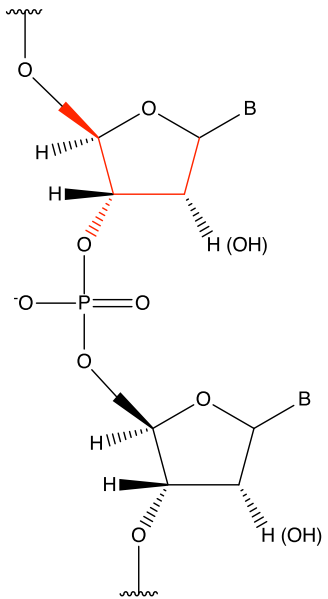

DNA (RNA)

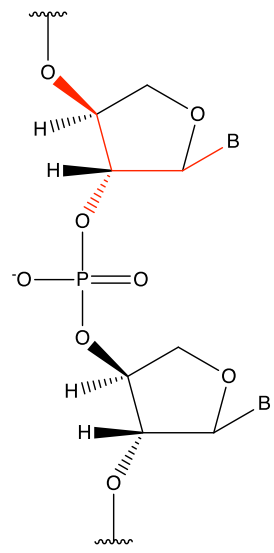

TNA

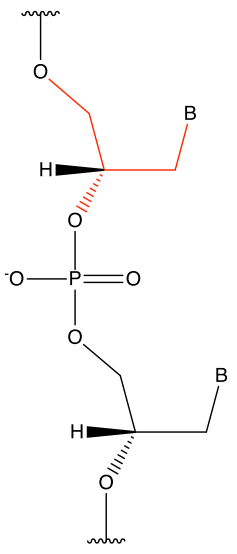

GNA

Fig. 4 Structures of DNA, RNA, TNA and GNA. Backbone analogies in red. Adapted from Chen et al. (2009)

the search for extraterrestrial life in planetary exploration missions must be as open as possible, using instruments capable of detecting the signatures of this exotic life. For example, in the case of molecular bio-signatures and in situ rover-mediated missions, instrumentation should be able to analyze a very wide range of compounds and not be specific to terrestrial bio-signatures. And these biosignatures must, by definition, have derived from a far-fromequilibrium setting (Dorn et al. 2011).

\subsection{Prokaryotic Life Elsewhere?}

Can we predict how life might look elsewhere in the Universe? This is clearly a complex question to tackle but assessing the uniqueness (or not) of the conditions found on the early Earth could help us have a better perspective. Hence, we summarize some astronomical considerations which arguably apply universally:

(i) The relative abundance of natural elements is relatively homogenous throughout the universe due to their formation shortly after the Big Bang (i.e. $\mathrm{H}, \mathrm{He}$ ), later in heavy stars, during supernovas, and during collisions of the remains of heavy stars.

(ii) Carbon is arguably the element better fit for acting as the backbone of life due to its unique bond-forming properties, resulting in thousands of molecules through $\mathrm{C}-\mathrm{C}$ bonds and $\mathrm{C}-\mathrm{X}$ bonds $(\mathrm{X}=\mathrm{O}, \mathrm{N}, \mathrm{S}, \mathrm{P}$ and halogens) required to run the complex cellular machinery. These bonds seem to display the 'optimal' level of stability so that these are not too stable as to become extremely unreactive (which would slow metabolism considerably), nor too labile as to hinder complexification by excessively favoring hydrolyses.

(iii) Water is present in substantial amounts throughout the universe due to its formation in interstellar clouds and its transport to disks, planetesimals, planets and moons (van Dishoeck et al. 2014).

(iv) Compounds crucial for life such as phosphorous oxoacids are also omnipresent in the universe due to their formation in interstellar clouds and dust particles from phosphine 
and water, and their transport through disks and planetesimals to planets and moons (Turner et al. 2018).

(v) Nitrates are formed on habitable planets by the reaction of nitrogen, carbon dioxide and water upon lightning in their atmospheres (Wolf 2017). Nitrates in reducing environments (e.g. alkaline hydrothermal vents or underlying serpentinizing rocks) could result in the synthesis of ammonia which could be incorporated into organic molecules via reductive aminations (Harrison and Lane 2018).

(vi) If life emerged on Earth at alkaline hydrothermal environments by hydrogenating $\mathrm{CO}_{2}$, or more generally in hydrothermally-influenced environments such as hydrothermally-percolated sediments, it is probable it could also do so in other planets and moons where tectonics (plate or plume) or gravitational forces (e.g. Enceladus) promote the production of hydrogen through serpentinization and iron/nickel sulfides and iron oxyhydroxides (e.g. green rust) as catalysts. These minerals are some of the most abundant on the Solar System.

(vii) It is possible life emerged on Earth in other ways (e.g. surficial hydrothermalism or tidal pools). However, the latter environments are unlikely to have occurred on the icy satellites in contrast to the subsea hydrothermal settings (Waite et al. 2017). Nevertheless, we cannot rule out that life could emerge in other planetary bodies following these alternative pathways, but, if this were the case, it would be a waste of resources for fund-limited space exploration efforts in the near future (Choblet et al. 2019). It is clear that Mars contained a much higher quantity of liquid water in the past than at present, but any current evidence for extant or extinct Martian life would likely lie in subsoil reservoirs. We do not intend to discourage space exploration in Mars or other planetary bodies-all space exploration is useful—but, given the pecuniary constraints of modern economies, the possibility of exploring non-extinct exo-oceans where we have evidence for current organosynthesis represents, to us, an opportunity we should not miss.

Taking all this into consideration, we may hypothesize that prokaryotic-like life (close to life as we know it) will be present throughout the universe (Fig. 5). Most of it would presumably be in a prokaryotic form, since the emergence of eukaryotes on Earth is arguably the result of an endosymbiotic event (i.e. the merging of a bacterium and an archaea), whichas far as we know-occurred only once over a period of $4 \mathrm{Ga}$. This rare occurrence suggests that the presence of some sort of (eukaryotic-like) intelligent life elsewhere would be rare. Therefore, the search for life should focus on a search for prokaryotic-like microbes or their biochemical signatures.

\subsection{Life Far from Life as We Know It-the Case for Titan}

The Cassini-Huygens mission made many detailed observations of Titan and revealed several astrobiological aspects of Saturn's largest satellite. Titan presents some analogies to the Earth, including the presence of liquid bodies on its surface (but composed of liquid methane-ethane mixtures) and, most importantly, a very complex organic chemistry (Fig. 6). This chemistry is often considered 'prebiotic' (Raulin et al. 2012 and refs. included) and includes several of the low molecular weight organic compounds that could have played key roles in terrestrial prebiotic chemistry, such as $\mathrm{HCN}$ or $\mathrm{HC}_{3} \mathrm{~N}$. It begins in the upper atmosphere of the satellite, with the coupled chemistry of methane and dinitrogen, induced by the energetic electrons of Saturn's magnetosphere and UV solar radiation. This allows for the formation of high molecular weight organic anions in the ionosphere; these produce macromolecular species with a chemical composition similar to that of laboratory tholins (Cable 


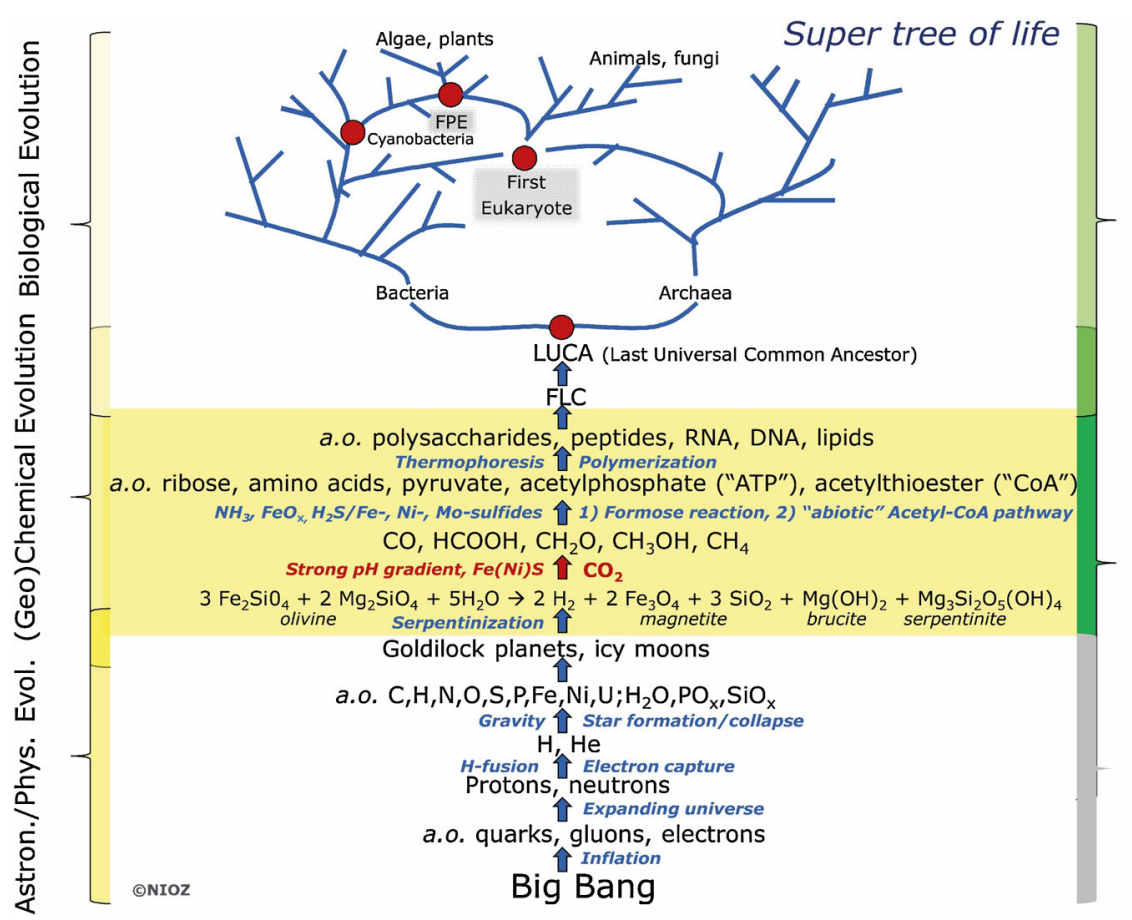

Fig. 5 Supertree of life on Earth based on the alkaline hydrothermal vent theory. Note that the astronomical and physical evolution and part of the (geo)chemical evolution is universal and may result in a first living cell $(F L C)$ to some extent similar to the one that emerged on Earth. FPE = first photosynthetic eukaryote

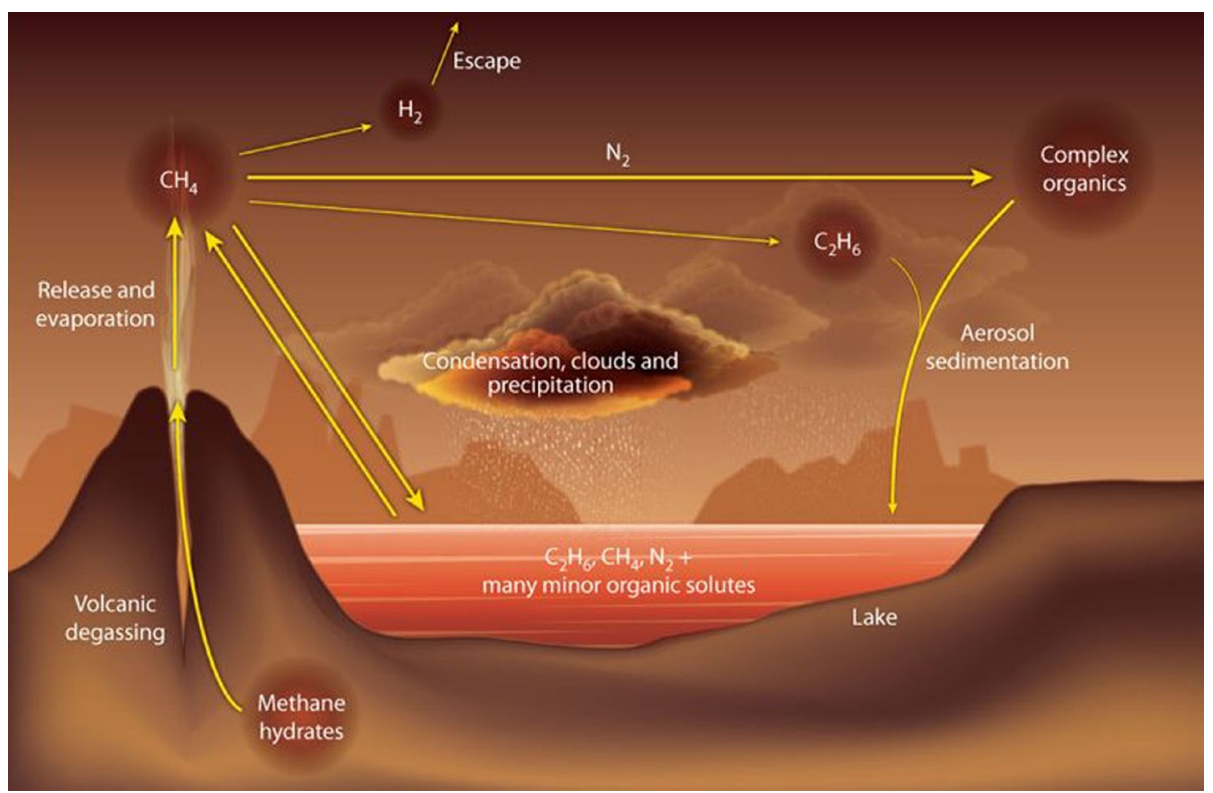

Fig. 6 Methane-ethane cycle on Titan and implication to Titan's lakes. Modeling of atmospheric $\mathrm{H}_{2}$ escape cannot explain the $\mathrm{H}_{2}$ depletion at Titan's surface. Credit: Nature journal, Raulin (2008) 
et al. 2012 and refs. included) and form organic hazes. The haze particles act as condensation nuclei inducing the condensation of low molecular weight organic compounds in the lower atmosphere. The particles deposited on the surface are therefore made of a refractory organic nucleus, composed mainly of $\mathrm{C}, \mathrm{N}$ and $\mathrm{H}$ atoms, covered with volatile organic compounds also made of $\mathrm{C}, \mathrm{N}$ and $\mathrm{H}$ atoms (Israël et al. 2005). Therefore, there is a continuous flow of organic matter on the surface of Titan. Depending on the surface condition, these particles may evolve differently.

During sedimentation on (still hypothetical) cryovolcanic zones, particles can interact with cryolava and its water content. They can chemically evolve to more complex organics, including compounds of biological (terrestrial) interest such as urea, amino acids, purines and pyrimidines (Brassé et al. 2017). A similar evolution can occur in transitional water basins produced by large impactors capable of melting surface water ice and forming "Titan impact oases" (O'Brien et al. 2005). However, even if the potential surface organic chemistry induced by Titan's (hypothetical) water pools can allow the formation of more complex organic compounds at the surface, these complex organics produced are still very far from life as we know it. Admittedly, the disequilibrium produced by Titan rain or by the flow of organic sedimentary aerosols on the surface does not seem significant enough (or of the 'right type'; Branscomb and Russell 2018) to allow evolution of these organics towards life, especially considering the low temperatures $(<100 \mathrm{~K})$ and the time scale of these pools of liquid water (about 1000 years maximum). In addition, it remains unclear how these surface organic materials could reach the deep internal ocean of Titan and follow a complex chemical evolution in its liquid waters over a long period of time.

However, the discovery of permanent bodies of liquid methane and ethane on Titan's surface has led to envisage the possibility of exotic life in these exotic lakes. Huygens' data showed the presence of an anomalous depletion of $\mathrm{H}_{2}, \mathrm{C}_{2} \mathrm{H}_{2}$ and $\mathrm{C}_{2} \mathrm{H}_{6}$ at Titan's surface. McKay and Smith (2005) have envisaged that such a depletion could be due to the biological activity of an exotic methanogenic life, despite the very low temperature ( $\sim 93 \mathrm{~K})$. The reaction of hydrogenation of acetylene into methane is indeed very exergonic with a $\Delta \mathrm{G}$ of $-334 \mathrm{~kJ} / \mathrm{mol}$, however, the apparent activation energy of this reaction is high. The measurement of the rate constant of this reaction for cyanobacteria (Jensen and Cox 1983) indicates $36 \mathrm{~kJ} / \mathrm{mol}$ above $21^{\circ} \mathrm{C}$ and $166 \mathrm{~kJ} / \mathrm{mol}$ below $21^{\circ} \mathrm{C}$. Even with the lowest value of $\mathrm{Ea}$, a decrease from $293 \mathrm{~K}$ to $93 \mathrm{~K}$ corresponds to a reduction of a rate constant by $5 \times 10^{13}$. There is thus an obvious need for a superpowerful Titanian enzyme-which is of course yet unknown - to enable such type of metabolism in Titan's lakes.

Could life have emerged in these lakes? During sedimentation on Titan's lakes, a very small fraction of the atmospheric organic aerosols may dissolve in the lake's hydrocarbons solvent. The remainder is likely to sediment down to its bottom. These lakes, made of very non-polar liquid at low temperatures, should be chemically very stable. The "accumulation of poorly soluble species at the deposit margin and a central layer of evaporites enriched in more soluble species, such as acetylene and butane" has recently been modeled (Cordier et al. 2016). Thus, only a significant physical evolution due to evaporation cycles, with the production of organic evaporates is expected. The chemical evolution of Titan's lakes would require high energy sources, capable of overcoming the activation energy barrier. High energy cosmic rays could play such a role, but their flux at Titan's surface is extremely low. Atmospheric impactors could also induce chemical changes, but it is likely that their frequency is also too low to allow them to play a significant role.

These lakes contain a large number of dissolved organics, at low concentration (ppm level) for several of them, and without significant concentration of oxygenated compounds. Nevertheless, the possibility of a biochemistry without oxygen has been considered by several authors. They suggest that replacing $\mathrm{C}=\mathrm{O}$ by $\mathrm{C}=\mathrm{NH}$ can produce "ammono" analogues 
such as $\alpha$-aminoamidines and amonopeptides (Raulin and Owen 2002), or cyanoanalogues such as cyanosugars, cyanolipids and cyanoproteins (Lv et al. 2017). But, until now, this has only been "chemistry on paper". The formation of a membrane alternative in such an oxygen-free world has also been considered by Stevenson et al. (2015). These authors studied the possible formation of a new type of membrane, made up of small N-organics, capable of forming vesicles in liquid methane at low temperatures. They call these 3D structures "azotosomes" as an analogue of liposome. Using molecular modeling they studied the ability of several simple nitriles to form azotozomes. Their theoretical study shows that the best results are obtained with acrylonitrile (vinyl cyanide), where azotosome vesicles with a diameter of $90 \AA$ are formed. Two years later, the detection of this nitrile in Titan's middle atmosphere by ALMA observation was published by Palmer et al. (2017). Based on the vertical column density of acrylonitrile derived from this detection, the authors estimate that there is sufficient dissolved nitrile to form about $10^{7}$ azotozome $/ \mathrm{cm}^{3}$ in Titan's sea Ligeaia Mare. It should be noted that azotozome formation has only been demonstrated by molecular modeling, and there is no experimental evidence to date. In addition, in the case of Titan's lakes, many other compounds are dissolved in the methane (and ethane) dominated solvent, including other nitriles that may interact with acrylonitrile and inhibit the formation of these-still hypothetical-membranes. Finally, even if such structures are present in Titan's lakes, it is still far from life, which requires replicating and energy-dissipating catalytic entities. Rahma et al. (2016) showed by theoretical calculations that polyimines could drive photochemistry and potentially have a catalytic role on Titan's surface. Indeed, polyimine is one of the polymers of HCN. It could form in Titan's atmosphere and be present on its surface. However, its potential catalytic role has only been studied by theoretical molecular chemistry, hence without considering the possible influence of the many other species present.

In any case, the nature of a possible replicating molecule in such an exotic world is still a mystery. Therefore, such an exotic life based on a CHN biochemistry with liquid methane-ethane mixture as solvent and operating at very low temperature still looks highly speculative.

\section{Conclusions}

In this article we aim to provide the reader with as broad an overview as possible of the field of the emergence of life. Our primary goal was to extrapolate the conclusions drawn in each section in order to discuss the possibilities of life elsewhere, which should allow us to better guide future space exploration missions. In our first section, where we discussed the geochemical and geophysical conditions of the Hadean Earth, we concluded that we are unfortunately still far from having a clear picture of what such a primordial environment was like. Despite this, we suggest that hydrothermal environments were widely distributed during that period, and that such conditions promote the synthesis of organic molecules and their self-organization in what can be seen as early proto-metabolic networks, which would eventually result in the origin of the first protocells. The conditions required for this type of hydrothermal processes are the presence of fresh mafic minerals (e.g. olivine) in contact with liquid water. These requirements are very likely currently met in the icy moons of the Solar System, making them prime candidates for astrobiological exploration. In our second section about the famous RNA World, we discussed how most genetics-first proposals usually invoke the prebiotic synthesis of nucleotides via UV irradiation and surficial wet-dry cycling, and that these requirements would usually be deemed unlikely in the subsurface 
oceans of oceanic icy moons. Despite this, we concluded that the synthesis of nucleotides could have proceeded in alternative chemical pathways allowing for a (probably dirty) RNA World-type scenario even in this type of planetary bodies. In our third section, we delved into the tree of life and discussed the knowns and unknowns of the nature of the elusive LUCA. We also noted that there may have been a large temporal and chemical gap between the last and first universal ancestors, and that it is debated to what extend the knowledge of the characteristics of these cellular entities help in closing the gap between biochemistry and prebiotic (geo)chemistry. Finally, in our last section we discussed the possibility and nature of extraterrestrial life, which might exist in a form close to what Earth-based life represents, or indeed rather far from it. In the former case, we expect life emerging in planetary bodies with similar compositions to Earth (i.e. mafic rocks in contact with liquid water) to be somewhat similar to terrestrial prokaryotes since it would have been shaped by very similar geochemical-and later biochemical—forces. In case of the latter, in truly chemically-wise alien planetary bodies, such as Titan's surface, it is possible life is comprised of exotic (to us) organics, even though the universal physical push for the emergence of dissipative structures would still arguably be the main forcing motor.

In any case, it is clear that we are still far from an answer on how life emerged on Earth, let alone on life's place within the Universe. The ideas exposed in this article exemplify how hard it is to make the fields of geology, biology, chemistry and planetary sciences converge into one holistic narrative. Perhaps we are still too far from one complete narrative. If this is the case, trying to construct a cohesive story with the somewhat meager evidence we have so far could lead to hampering our future progress by the systematic exclusion of important pieces of evidence, which may currently seem to collide with the overall narrative. This is often one of the major criticisms of the submarine hydrothermal hypothesis, which in our view is one of the most promising hypotheses explaining the putative emergence of life in oceanic icy moons. As explained above, this ambitious approach aims to drive the aforementioned disciplines together to explain the emergence of life as comprehensive set of events, ultimately connecting geochemistry with biochemistry. Unfortunately, there is still a lack of experimental evidence on some of its important features: most notably on the non-enzymatic reduction of $\mathrm{CO}_{2}$ by $\mathrm{H}_{2}$ by tapping into naturally occurring $\mathrm{pH}$ gradients, and the synthesis of nucleic acids under Hadean deep-sea conditions. The reverse hazard also applies: by following promising — but often narrow-lines of research we could be hindering future progress due to skewed and potentially flawed foundations. This is certainly one of the main criticisms to the (pure) RNA World and primordial soup hypotheses. These lines of thought focus most of their efforts on achieving a self-replicating catalytic coding molecule (something not yet experimentally demonstrated). It is clear that RNA, or other coding polymers, were of central importance for the emergence of life. Despite this, the idea that a self-replicating polymer can, on its own, "invent" even a simple network of energy-dissipating reactions (i.e. metabolism) represents a substantial leap of faith with little evidence to back it up. In any case, these criticisms are indeed applicable to both main contenders, and extend to all other proposals.

Despite this, there are reasons for optimism. Never before have so many research groups all over the globe and from across most disciplines been focusing on origins-related questions. So much that, at times, it is difficult to discern what is abiogenically-relevant from what is not. During the second half of the twentieth century, research focused on synthetic pathways leading to organic molecules. Now we know that, despite its intricacies, the synthetic part is the less complicated to address, and that many organic molecules can be nonenzymatically synthesized in numerous scenarios. With the improvement of molecular biology techniques, the focus transitioned into biochemical studies on the replicating/catalytic 
properties of RNA and RNA-like molecules. Recently, emphasis has shifted towards furthering our understanding of non-enzymatic autocatalytic sets, since it is suspected that RNA may not have been able to orchestrate proto-metabolism on its own. In relation to this last point, it is becoming clearer that focusing on stochastic (or 'dirty') chemistry, where most relevant reactions coexist under similar reaction conditions, might represent a more accurate view of relevant prebiotic chemistry (Dass et al. 2016; Guttenberg et al. 2017), rather than the classic synthetic chemistry approach, which heavily relies on more unnatural sequences of very specific reaction conditions.

Nonetheless, there is clearly an elephant in the room: we are missing evidence of the existence of extraterrestrial life and its nature. With it, it would certainly be more meaningful to extrapolate conclusions regarding life's universal traits, which would help us to puzzle out its emergence (on Earth and elsewhere). It is therefore important that the direction of future space exploration missions takes into account lessons learnt from the emergence of Earth's life in order to better discriminate where and what to look for keeping in mind that the physical, astronomical and geochemical processes related to life seem to be rather universal.

Acknowledgements We would like to thank Ewine van Dishoeck for her useful insights and suggestions.

Publisher's Note Springer Nature remains neutral with regard to jurisdictional claims in published maps and institutional affiliations.

Open Access This article is licensed under a Creative Commons Attribution 4.0 International License, which permits use, sharing, adaptation, distribution and reproduction in any medium or format, as long as you give appropriate credit to the original author(s) and the source, provide a link to the Creative Commons licence, and indicate if changes were made. The images or other third party material in this article are included in the article's Creative Commons licence, unless indicated otherwise in a credit line to the material. If material is not included in the article's Creative Commons licence and your intended use is not permitted by statutory regulation or exceeds the permitted use, you will need to obtain permission directly from the copyright holder. To view a copy of this licence, visit http://creativecommons.org/licenses/by/4.0/.

\section{References}

S.S. Abby, E. Tannier, M. Gouy, V. Daubin, Lateral gene transfer as a support for the tree of life. Proc. Natl. Acad. Sci. USA 109, 4962-4967 (2012)

P.H. Abelson, Chemical events on the primitive Earth. Proc. Natl. Acad. Sci. USA 55(6), 1365-1372 (1966)

O. Abramov, S.J. Mojzsis, Microbial habitability of the hadean Earth during the late heavy bombardment. Nature 459, 419-422 (2009)

O. Abramov, D.A. Kring, S.J. Mojzsis, The impact environment of the Hadean Earth. Chem. Erde 73(3), 227-248 (2013)

P.S. Adam, G. Borrel, S. Gribaldo, Evolutionary history of carbon monoxide dehydrogenase/acetyl-CoA synthase, one of the oldest enzymatic complexes. Proc. Natl. Acad. Sci. USA 115, E1166-E1173 (2018) https://doi.org/10.1073/pnas.1716667115

T.D. Ames, R.R. Breaker, Bacterial riboswitch discovery and analysis, in The Chemical Biology of Nucleic Acids, ed. by G. Mayer (Wiley, Chichester, 2010), Chap. 20

E. Anders, Pre-biotic organic matter from comets and asteroids. Nature 342(6247), 255-257 (1989)

A.M. Anger, J.P. Armache, O. Berninghausen, M. Habeck, M. Subklewe, D.N. Wilson, R. Beckmann, Structures of the human and Drosophila 80S ribosome. Nature 497(7447), 80-85 (2013)

J.P. Armache, A. Jarasch, A.M. Anger, E. Villa, T. Becker, S. Bhushan, F. Jossinet, M. Habeck, G. Dindar, S. Franckenberg, V. Marquez, T. Mielke, M. Thomm, O. Berninghausen, B. Beatrix, J. Soding, E. Westhof, D.N. Wilson, R. Beckmann, Cryo-EM structure and rRNA model of a translating eukaryotic 80S ribosome at 5.5-A resolution. Proc. Natl. Acad. Sci. USA 107(46), 19748-19753 (2010)

N.T. Arndt, Archean komatiites, in Archean Crustal Evolution, ed. by K.C. Condie (Elsevier, Amsterdam, 1994), pp. 11-44

N.T. Arndt, E.G. Nisbet, Processes on the young Earth and the habitats of early life. Annu. Rev. Earth Planet. Sci. 40, 521-549 (2012) 
S. Arsène, S. Ameta, N. Lehman, A.D. Griffiths, P. Nghe, Coupled catabolism and anabolism in autocatalytic RNA sets. Nucleic Acids Res. 46(18), 9660-9666 (2018)

R.D. Astumian, Stochastically pumped adaptation and directional motion of molecular machines. Proc. Natl. Acad. Sci. USA 115, 9405-9413 (2018)

S.S. Athavale, A.S. Petrov, C. Hsiao, D. Watkins, C.D. Prickett, J.J. Gossett, L. Lie, J.C. Bowman, E. O’Neill, C.R. Bernier, N.V. Hud, R.M. Wartell, S.C. Harvey, L.D. Williams, RNA folding and catalysis mediated by iron (II). PLoS ONE 7(5), e38024 (2012)

J. Bada, J. Korenaga, Exposed areas above sea level on Earth $>3.5$ Gyr ago: implications for prebiotic and primitive biotic chemistry. Life 8(4), 55 (2018)

N. Ban, P. Nissen, J. Hansen, P.B. Moore, T.A. Steitz, The complete atomic structure of the large ribosomal subunit at 2.4 A resolution. Science 289(5481), 905-920 (2000)

L.M. Barge, S.S.S. Cardoso, J.H.E. Cartwright, G.J.T. Cooper, L. Cronin, A. De Wit, I.J. Doloboff, B. Escribano, R.E. Goldstein, F. Haudin, D.E.H. Jones, A.L. Mackay, J. Maselko, J.J. Pagano, J. Pantaleone, M.J. Russell, C.I. Sainz-Díaz, O. Steinbock, D.A. Stone, Y. Tanimoto, N.L. Thomas, From chemical gardens to chemobrionics. Chem. Rev. 115, 8652-8703 (2015)

J.A. Baross, S.E. Hoffman, Submarine hydrothermal vents and associated gradient environments as sites for the origin and evolution of life. Orig. Life Evol. Biosph. 15, 327-345 (1985)

H.D. Bean, Y. Sheng, J.P. Collins, F.A. Anet, J. Leszczynski, N.V. Hud, Formation of a beta-pyrimidine nucleoside by a free pyrimidine base and ribose in a plausible prebiotic reaction. J. Am. Chem. Soc. 129(31), 9556-9557 (2007)

J.H. Bédard, A catalytic delamination-driven model for coupled genesis of Archaean crust and subcontinental lithospheric mantle. Geochim. Cosmochim. Acta 70, 1188-1214 (2006)

J.H. Bédard, Stagnant lids and mantle overturns: implications for Archaean tectonics, magmagenesis, crustal growth, mantle evolution, and the start of plate tectonics. Geosci. Front. 9, 19-49 (2018)

S. Bengtson, Early Life on Earth (Columbia University Press, New York, 1994)

S.A. Benner, T.M. Jermann, J.G. Opitz, S.A. Raillard, T.R. Zankel, K. Trautwein-Fritz, J. Stackhouse, M.I. Ciglic, M. Haugg, N. Trabesinger-Ruf, E.G. Weinhold, Developing new synthetic catalysts. How nature does it. Acta Chem. Scand. 50(3), 243-248 (1996)

S.A. Benner, H.J. Kim, M.A. Carrigan, Asphalt, water, and the prebiotic synthesis of ribose, ribonucleosides, and RNA. Acc. Chem. Res. 45(12), 2025-2034 (2012)

S.A. Benner, E.A. Bell, E. Biondi, R. Brasser, T. Carell, K. Hyo-Joong, S.J. Mojzsis, A. Omran, M.A. Pasek, D. Trail, When did life likely emerge on Earth in an RNA-first process? Chem. Syst. Chem. (2019). https://doi.org/10.1002/syst.201900035

D.N. Beratan, C. Liu, A. Migliore, N.F. Polizzi, S.S. Skourtis, P. Zhang, Y. Zhang, Charge transfer in dynamical biosystems, or the treachery of (static) images. Acc. Chem. Res. 48, 474-481 (2014)

I.A. Berg, D. Kockelkorn, W.H. Ramos-Vera, R.F. Say, J. Zarzycki, M. Hügler, B.E. Alber, G. Fuchs, Autotrophic carbon fixation in archaea. Nat. Rev. Microbiol. 8(6), 447 (2010)

J. Bergsten, A review of long-branch attraction. Cladistics 21, 163-193 (2005)

M. Beringer, M.V. Rodnina, The ribosomal peptidyl transferase. Mol. Cell 26(3), 311-321 (2007)

J.D. Bernal, The physical basis of life. Proc. Phys. Soc. 62, 537-555 (1949)

C.R. Bernier, A.S. Petrov, N.A. Kovacs, P.I. Penev, L.D. Williams, Translation: the universal structural core of life. Mol. Biol. Evol. 35(8), 2065-2076 (2018)

S. Bhowmik, R. Krishnamurthy, The role of sugar-backbone heterogeneity and chimeras in the simultaneous emergence of RNA and DNA. Nat. Chem. 11, 1009-1018 (2019)

A. Biscans, Exploring the emergence of RNA nucleosides and nucleotides on the early Earth. Life 8(4), 57 (2018)

S.F. Bloomfield, G.A. Miles, The antibacterial properties of sodium dichloroisocyanurate and sodium hypochlorite formulations. J. Appl. Bacteriol. 1, 65 (1979)

P. Boehnke, T.M. Harrison, Illusory late heavy bombardments. Proc. Nat. Acad. Sci. 113(39), 10802-10806 (2016)

K. Bokov, S.V. Steinberg, A hierarchical model for evolution of 23S ribosomal RNA. Nature 457, 977 (2009)

W.F. Bottke, D. Vokrouhlicky, D. Minton, D. Nesvorny, A. Morbidelli, R. Brasser, B. Simonson, H.F. Levison, An Archaean heavy bombardment from a destabilized extension of the asteroid belt. Nature $\mathbf{4 8 5}$, 78-81 (2012)

C. Bounama, S. Franck, W. von Bloh, The fate of the Earth's ocean. Hydrol. Earth Syst. Sci. 5, 569-575 (2001)

B. Boussau, S. Blanquart, A. Necsulea, N. Lartillot, M. Gouy, Parallel adaptations to high temperatures in the Archaean eon. Nature 456, 942-945 (2008)

J.C. Bowman, N.V. Hud, L.D. Williams, The ribosome challenge to the RNA world. J. Mol. Evol. 80(3), 143-161 (2015) 
J.A. Bradley, J.P. Amend, D.E. LaRowe, Survival of the fewest: microbial dormancy and maintenance in marine sediments through deep time. Geobiology 17, 43-59 (2019)

E. Branscomb, M.J. Russell, Frankenstein or a submarine alkaline vent: who is responsible for abiogenesis? Part 2: As life is now, so it must have been in the beginning? BioEssays 40(8), e1700182 (2018)

E. Branscomb, M.J. Russell, Why the submarine alkaline vent is the most reasonable explanation for the emergence of life. BioEssays 41, 1800208 (2019)

E. Branscomb, T. Biancalani, N. Goldenfeld, M.J. Russell, Escapement mechanisms and the conversion of disequilibria; the engines of creation. Phys. Rep. 677, 1-60 (2017)

M.D. Brasier, R. Matthewman, S. McMahon, D. Wacey, Pumice as a remarkable substrate for the origin of life. Astrobiology 11, 725-735 (2011)

C. Brassé, A. Buch, C. Coll, F. Raulin, Low-temperature alkaline $\mathrm{pH}$ hydrolysis of oxygen-free Titan tholins: carbonates' impact. Astrobiology 17(1), 8-26 (2017)

S. Braun, C. Humphreys, E. Fraser, A. Brancale, M. Bochtler, T.C. Dale, Amyloid-associated nucleic acid hybridisation. PLoS ONE 6(5), e19125 (2011)

M.S. Bray, T.K. Lenz, J.W. Haynes, J.C. Bowman, A.S. Petrov, A.R. Reddi, N.V. Hud, L.D. Williams, J.B. Glass, Multiple prebiotic metals mediate translation. Proc. Natl. Acad. Sci. 115(48), 12164-12169 (2018)

C. Briones, M. Stich, S.C. Manrubia, The dawn of the RNA World: toward functional complexity through ligation of random RNA oligomers. RNA 15(5), 743-749 (2009)

S. Brock, K. Szkaradkiewicz, M. Sprinzl, Initiation factors of protein biosynthesis in bacteria and their structural relationship to elongation and termination factors. Mol. Microbiol. 29(2), 409-417 (1998)

C.T. Brown, L.A. Hug, B.C. Thomas, I. Sharon, C.J. Castelle, A. Singh, M.J. Wilkins, K.C. Wrighton, K.H. Williams, J.F. Banfield, Unusual biology across a group comprising more than $15 \%$ of domain Bacteria. Nature 523, 208-11 (2015)

M.L. Cable, S.M. Hörst, R. Hodyss, P.M. Beauchamp, M.A. Smith, P.A. Willis, Titan tholins: simulating Titan organic chemistry in the Cassini-Huygens era. Chem. Rev. 112, 1882-1909 (2012)

B.J. Cafferty, D.M. Fialho, J. Khanam, R. Krishnamurthy, N.V. Hud, Spontaneous formation and base pairing of plausible prebiotic nucleotides in water. Nat. Commun. 7, 11328 (2016)

A.G. Cairns-Smith, Genetic Takeover: and the Mineral Origins of Life (Cambridge University Press, Cambridge, 1982)

E. Camprubi, S.F. Jordan, R. Vasiliadou, N. Lane, Iron catalysis at the origin of life. IUBMB Life 69(6), 373-381 (2017)

C.W. Carter Jr., What RNA world? Why a peptide/RNA partnership merits renewed experimental attention. Life 5(1), 294-320 (2015)

C.W. Carter Jr., P.R. Wills, Interdependence, reflexivity, fidelity, impedance matching, and the evolution of genetic coding. Mol. Biol. Evol. 35(2), 269-286 (2018)

C.J. Castelle, J.F. Banfield, Major new microbial groups expand diversity and alter our understanding of the tree of life. Cell 172, 1181-1197 (2018)

C.J. Castelle, K.C. Wrighton, B.C. Thomas, L.A. Hug, C.T. Brown, M.J. Wilkins, K.R. Frischkorn, S.G. Tringe, A. Singh, L.M. Markillie, R.C. Taylor, K.H. Williams, J.F. Banfield, Genomic expansion of domain archaea highlights roles for organisms from new phyla in anaerobic carbon cycling. Curr. Biol. 25, 690-701 (2015)

R. Catchpole, P. Forterre, Positively twisted: the complex evolutionary history of Reverse Gyrase suggests a non-hyperthermophilic Last Universal Common Ancestor. BioRxiv 524215 (2019)

J.H. Cate, R.L. Hanna, J.A. Doudna, A magnesium ion core at the heart of a ribozyme domain. Nat. Struct. Biol. 4(7), 553-558 (1997)

J.H. Cate, M.M. Yusupov, G.Z. Yusupova, T.N. Earnest, H.F. Noller, X-ray crystal structures of 70S ribosome functional complexes. Science 285(5436), 2095-2104 (1999)

T. Cavalier-Smith, Rooting the tree of life by transition analyses. Biol. Direct 1, 1-19 (2006)

A.J. Cavosie, J.W. Valley, S.A. Wilde, The oldest terrestrial mineral record: a review of 4400 to 3900 ma detrital zircons from Jack Hills, Western Australia. Dev. Precambrian Geol. 15, 91-111 (2007)

T.R. Cech, The efficiency and versatility of catalytic RNA: implications for an RNA world. Gene 135(1-2), 33-36 (1993)

T.R. Cech, Structural biology. The ribosome is a ribozyme. Science 289(5481), 878-879 (2000)

T.R. Cech, Evolution of biological catalysis: ribozyme to RNP enzyme. Cold Spring Harbor Symp. Quant. Biol. 74, 11-16 (2009)

T.R. Cech, The RNA worlds in context. Cold Spring Harbor Perspect. Biol. 4(7), A006742 (2012)

T.R. Cech, RNA world research-still evolving. RNA 21(4), 474-475 (2015)

R.L. Charlebois, W.F. Doolittle, Computing prokaryotic gene ubiquity: rescuing the core from extinction. Genome Res. 14(12), 2469-2477 (2004) 
I.A. Chen, M.A. Nowak, From prelife to life: how chemical kinetics become evolutionary dynamics. Acc. Chem. Res. 45(12), 2088-2096 (2012)

J.J. Chen, C-H. Tsai, X. Cai, T. Allen, A.T. Horhota, L.W. McLaughlin, J.W. Szostak, Enzymatic primerextension with glycerol-nucleoside triphosphates on DNA templates. PLoS ONE 4(3), 4949 (2009)

M.C. Chen, B.J. Cafferty, I. Mamajanov, I. Gallego, J. Khanam, R. Krishnamurthy, N.V. Hud, Spontaneous prebiotic formation of a beta-ribofuranoside that self-assembles with a complementary heterocycle. J. Am. Chem. Soc. 136(15), 5640-5646 (2014)

G. Choblet, O. Cadek, C. Freissinet, G. Jones, A. Le Gall, S. MacKenzie, M. Neveu, K. Olsson-Francis, J. Saur, J. Schmidt, Y. Sekine, G. Tobie, S. Vance, L. Barge, M. Behounkova, A. Buch, E. Camprubi, M. Hedman, V. Lainey, A. Lucchetti, G. Mitri, F. Nimmo, M. Panning, F. Postberg, T. Shibuya, C. Sotin, O. Soucek, C. Szopa, U. Tomohiro, T. Van Hoolst, (2019) Enceladus as a potential oasis for life: Science goals and investigations for future explorations (a white paper submitted in response to ESA's Voyage 2050 call). https://www.cosmos.esa.int/documents/1866264/3219248/ChobletG_Enceladus-ESAVoyage-2050_final.pdf/bd402C07-fb49-5fd2-09C2-8ce8cfc4fc3b?t=1565184629813

M. Chojnacki, Spectral evidence for hydrated salts in recurring slope lineae on Mars. Nat. Geosci. 8(11), 829 (2015)

C. Chyba, C. Sagan, Endogenous production, exogenous delivery and impact-shock synthesis of organic molecules: an inventory for the origins of life. Nature 355, 125-132 (1992)

U.S. Clanton, D.S. McKay, G. Waits, R. Fuhrman, Sublimate morphology on 74001 and 74002 orange and black glassy droplets, in Lunar and Planetary Science Conference Proceedings, vol. 9 (1978), pp. 19451957

H.J. Cleaves, J.H. Chalmers, A. Lazcano, S.L. Miller, J.L. Bada, A reassessment of prebiotic organic synthesis in neutral planetary atmospheres. Orig. Life Evol. Biosph. 38(2), 105-115 (2008)

C.E. Cleland, C.F. Chyba, Defining "life". Orig. Life Evol. Biosph. 32(4), 387-393 (2002)

C.S. Cockell, J.A. Raven, Zones of photosynthetic potential on Mars and the early Earth. Icarus 169(2), 300-310 (2004)

G.A. Coleman, R.D. Pancost, T.A. Williams, Investigating the origins of membrane phospholipid biosynthesis genes using outgroup-free rooting. Genome Biol. Evol. 11(3), 883-898 (2019)

G. Cooper, N. Kimmich, W. Belisle, J. Sarinana, K. Brabham, L. Garrel, Carbonaceous meteorites as a source of sugar-related organic compounds for the early Earth. Nature 414(6866), 879-883 (2001)

D. Cordier, T. Cornet, J.W. Barnes, S.M. MacKenzie, T. Le Bahers, D. Nna-Mvondo, P. Rannou, A.G. Ferreira, Structure of Titan's evaporates. Icarus 270, 41-56 (2016)

J.B. Corliss, J.A. Baross, S.E. Hoffman, An hypothesis concerning the relationships between submarine hot springs and the origin of life on Earth. Oceanol. Acta 4, 59-69 (1981)

G. Costanzo, A. Giorgi, A. Scipioni, A.M. Timperio, C. Mancone, M. Tripodi, M. Kapralov, E. Krasavin, H. Kruse, J. Sponer, J.E. Sponer, V. Ranc, M. Otyepka, S. Pino, E. Di Mauro, Non-enzymatic oligomerization of $3^{\prime}, 5^{\prime}$ cyclic CMP induced by proton- and UV-irradiation hints at a non-fastidious origin of RNA. ChemBioChem 18(15), 1535-1543 (2017)

T. Dagan, M. Roettger, D. Bryant, W. Martin, Genome networks root the tree of life between prokaryotic domains. Genome Biol. Evol. 2, 379-392 (2010)

G.B. Dalrymple, The Age of the Earth (Stanford University Press, Stanford, 1991)

B. Damer, A field trip to the Archaean in search of Darwin's warm little pond. Life 6(2), 21 (2016)

B.F. Damer, D.W. Deamer, Coupled phases and combinatorial selection in fluctuating hydrothermal pools: a scenario to guide experimental approaches to the origin of cellular life. Life 5, 872-887 (2015)

Y. Dandonneau, A. Vega, H. Loisel, Y. Du Penhoat, C. Menkes, Oceanic Rossby waves acting as a "hay rake" for ecosystem floating by-products. Science 302(5650), 1548-1551 (2003)

R. Dasgupta, M.M. Hirschmann, Melting in the Earth's deep upper mantle caused by carbon dioxide. Nature 440, 659-662 (2006)

A.V. Dass, K. Hickman-Lewis, A. Brack, T.P. Kee, F. Westall, Stochastic prebiotic chemistry within realistic geological systems. Chem. Select. 1, 4906-4926 (2016)

A.V. Dass, M. Jaber, A. Brack, F. Foucher, T.P. Kee, T. Georgelin, F. Westall, Potential role of inorganic confined environments in prebiotic phosphorylation. Life 2018(8), 7 (2018)

A.A. Davín, E. Tannier, T.A. Williams, B. Boussau, V. Daubin, G.J. Szöllősi, Gene transfers can date the tree of life. Nat. Ecol. Evol. 2(5), 904-909 (2018)

S. de Farias, T. Rêgo, M. José, TRNA core hypothesis for the transition from the RNA world to the ribonucleoprotein world. Life 6(2), 15 (2016)

A. de la Escosura, C. Briones, K. Ruiz-Mirazo, The systems perspective at the crossroads between chemistry and biology. J. Theor. Biol. 381, 11-22 (2015)

C.E.J. de Ronde, D.M.deR. Channer, K. Faure, C.J. Bray, E.T.C. Spooner, Fluid chemistry of Archean seafloor hydrothermal vents; implications for the composition of circa 3.2 Ga seawater. Geochim. Cosmochim. Acta 61, 4025-4042 (1997) 
D. Deamer, Membranes, Murchison, and Mars: an encapsulated life in science. Astrobiology 12(6), 616-617 (2012)

D. Deamer, S.I. Kuzina, A.I. Mikhailov, E.I. Maslikova, S.A. Seleznev, Origin of amphiphilic molecules and their role in primary structure formation. J. Evol. Biochem. Physiol. 27(3), 212-217 (1991)

D. Deamer, B. Damer, V. Kompanichenko, Hydrothermal chemistry and the origin of cellular life. Astrobiology (2019). https://doi.org/10.1089/ast.2018.1979

P. Decker, H. Schweer, R. Pohlamnn, Bioids: X. Identification of formose sugars, presumable prebiotic metabolites, using capillary gas chromatography/gas chromatography-mas spectrometry of nbutoxime trifluoroacetates on OV-225. J. Chromatogr. A 244(2), 281-291 (1982)

M. Di Giulio, The universal ancestor was a thermophile or a hyperthermophile: tests and further evidence. J. Theor. Biol. 221(3), 425-436 (2003)

M. Di Giulio, A comparison among the models proposed to explain the origin of the tRNA molecule: a synthesis. J. Mol. Evol. 69(1), 1-9 (2009)

M. Di Giulio, The last universal common ancestor (LUCA) and the ancestors of archaea and bacteria were progenotes. J. Mol. Evol. 72(1), 119-126 (2011)

M. Di Giulio, The universal ancestor, the deeper nodes of the tree of life, and the fundamental types of primary cells (cellular domains). J. Theor. Biol. 460, 142-143 (2018)

Y. Ding, B. Batista, O. Steinbock, J.H. Cartwright, S.S. Cardoso, Wavy membranes and the growth rate of a planar chemical garden: enhanced diffusion and bioenergetics. Proc. Natl. Acad. Sci. USA 113, 91829186 (2016)

N. Dombrowski, J.H. Lee, T.A. Williams, P. Offre, A. Spang, Genomic diversity, lifestyles and evolutionary origins of DPANN archaea. FEMS Microbiol. Lett. 366 (2019)

W.F. Doolittle, Phylogenetic classification and the universal tree. Science 284(5423), 2124-2128 (1999)

E.D. Dorn, K.H. Nealson, C. Adami, Monomer abundance distribution patterns as a universal biosignature: examples from terrestrial and digital life. J. Mol. Evol. 72, 283-295 (2011)

D.E. Draper, RNA folding: thermodynamic and molecular descriptions of the roles of ions. Biophys. J. 95, 5489-5495 (2008)

A.L. Ducluzeau, B. Schoepp-Cothenet, F. Baymann, M.J. Russell, W. Nitschke, Free energy conversion in the LUCA: quo vadis? Biochim. Biophys. Acta (BBA)-Bioenerg. 1837(7), 982-988 (2014)

S. Duharcourt, G. Lepere, E. Meyer, Developmental genome rearrangements in ciliates: a natural genomic subtraction mediated by non-coding transcripts. Trends Genet. 25(8), 344-350 (2009)

T. Dutta, S. Srivastava, Small RNA-mediated regulation in bacteria: a growing palette of diverse mechanisms. Gene 656, 60-72 (2018)

J. Dworkin, D. Deamer, S. Sandford, L. Allamandola, Self-assembling amphiphilic molecules: synthesis in simulated interstellar/precometary ices. Proc. Natl. Acad. Sci. USA 98(3), 815-819 (2001)

P. Ehrenfreund, M. Spaans, N.G. Holm, The evolution of organic matter in space. Philos. Trans. R. Soc., Math. Phys. Eng. Sci. 369(1936), 538-554 (2011).

M. Eigen, J. McCaskill, P. Schuster, The molecular quasi-species. Adv. Chem. Phys. 75, 149-263 (1989)

M.Y. El-Naggar, G. Wanger, K.M. Leung, T.D. Yuzvinsky, G. Southam, J. Yang, W.M. Lau, K.H. Nealson, Y.A. Gorby, Electrical transport along bacterial nanowires from Shewanella oneidensis MR-1. Proc. Natl. Acad. Sci. 107, 18127-18131 (2010)

L.T. Elkins-Tanton, Linked magma ocean solidification and atmospheric growth for Earth and Mars. Earth Planet. Sci. Lett. 271, 181-191 (2008)

L. Eme, A. Spang, J. Lombard, C.W. Stairs, T.J.G. Ettema, Archaea and the origin of eukaryotes. Nat. Rev. Microbiol. 16, 120 (2018)

L.O. Emren, S. Kurtovic, A. Runarsdottir, A.K. Larsson, B. Mannervik, Functionally diverging molecular quasi-species evolve by crossing two enzymes. Proc. Natl. Acad. Sci. USA 103(29), 10866-10870 (2006)

A. Eschenmoser, Chemical etiology of nucleic acid structure. Science 284, 2118-2124 (1999)

A. Eschenmoser, The TNA-family of nucleic acid systems: properties and prospects. Orig. Life Evol. Biosph. 34, 277-306 (2004)

A. Eschenmoser, Etiology of potentially primordial biomolecular structures: from vitamin B12 to the nucleic acids and an inquiry into the chemistry of life's origin: a retrospective. Angew. Chem., Int. Ed. Engl. 50(52), 12412-12472 (2011)

A.C. Fahrenbach, C. Giurgiu, C.P. Tam, L. Li, Y. Hongo, M. Aono, J.W. Szostak, Common and potentially prebiotic origin for precursors of nucleotide synthesis and activation. J. Am. Chem. Soc. 139(26), 87808783 (2017)

P.G. Falkowski, Tracing oxygen's imprint on Earth's metabolic evolution. Science 311(5768), 1724-1725 (2006)

J. Felsenstein, Evolutionary trees from DNA sequences: a maximum likelihood approach. J. Mol. Evol. 17, 368-376 (1981) 
J.P. Ferris, L.E. Orgel, Studies on prebiotic synthesis. I. Aminomalononitrile and 4-amino-5-cyanoimidazole. J. Am. Chem. Soc. 88(16), 3829-3831 (1966)

J.P. Ferris, A. Sanchez, L.E. Orgel, Studies in prebiotic synthesis. 3. Synthesis of pyrimidines from cyanoacetylene and cyanate. J. Mol. Biol. 33(3), 693-704 (1968)

J.P. Ferris, A.R. Hill Jr., R. Liu, L.E. Orgel, Synthesis of long prebiotic oligomers on mineral surfaces. Nature 381(6577), 59-61 (1996)

J.G. Ferry, C.H. House, The stepwise evolution of early life driven by energy conservation. Mol. Biol. Evol. 23(6), 1286-1292 (2005)

M. Ferus, F. Pietrucci, A.M. Saitta, A. Knizek, P. Kubelik, O. Ivanek, V. Shestivska, S. Civis, Formation of nucleobases in a Miller-Urey reducing atmosphere. Proc. Natl. Acad. Sci. USA 114(17), 4306-4311 (2017)

W. Filipowicz, Traversing the RNA world. J. Biol. Chem. 292(20), 8122-8135 (2017)

C.M. Fisher, J.D. Vervoort, Using the magmatic record to constrain the growth of continental crust-the Eoarchean zircon Hf record of Greenland. Earth Planet. Sci. Lett. 488, 79-91 (2008)

S.T. Fitz Gibbon, C.H. House, Whole genome-based phylogenetic analysis of free-living microorganisms. Nucleic Acids Res. 27(21), 4218-4222 (1999)

C.E. Folsome, A. Brittain, A. Smith, S. Chang, Hydrazines and carbohydrazides produced from oxidized carbon in Earth's primitive environment. Nature 294, 64 (1981)

J.G. Forsythe, S.S. Yu, I. Mamajanov, M.A. Grover, R. Krishnamurthy, F.M. Fernandez, N.V. Hud, Estermediated amide bond formation driven by wet-dry cycles: a possible path to polypeptides on the prebiotic Earth. Angew. Chem., Int. Ed. Engl. 54(34), 9871-9875 (2015)

P. Forterre, The origin of DNA genomes and DNA replication proteins. Curr. Opin. Microbiol. 5(5), 525-532 (2002)

A.D. Fortes, Exobiological implications of a possible ammonia-water ocean inside Titan. Icarus 146, 444$452(2000)$

G.P. Fournier, J.E. Neumann, J.P. Gogarten, Inferring the ancient history of the translation machinery and the genetic code via recapitulation of ribosomal subunit assembly orders. PLoS ONE 5(3), e9437 (2010)

G.E. Fox, Origin and evolution of the ribosome. Cold Spring Harb. Perspect. Biol. 2(9), A003483 (2010)

G.E. Fox, Carl R. Woese, 1928-2012. Astrobiology 13(12), 1201-1202 (2013)

G.E. Fox, Origins and early evolution of the ribosome, in Evolution of the Protein Synthesis Machinery and Its Regulation, ed. by G.H.R. Jagus 1st edn. (Springer, Berlin, 2016a), pp. 31-60

G.E. Fox, Origins and early evolution of the ribosome, in Evolution of the Protein Synthesis Machinery and Its Regulation, ed. by G. Hernández, R. Jagus (Springer, Cham, 2016b), pp. 31-60

G.E. Fox, A.K. Naik, The evolutionary history of the ribosome, in The Genetic Code and the Origin of Life, ed. by L.R. de Pouplana. Landes Bioscience (2004), pp. 92-105

S. Fox, H. Strasdeit, A possible prebiotic origin on volcanic islands of oligopyrrole-type photopigments and electron transfer cofactors. Astrobiology 13, 578-595 (2013)

G.E. Fox, Q. Tran, A. Yonath, An exit cavity was crucial to the polymerase activity of the early ribosome. Astrobiology 12(1), 57-60 (2012)

C. Francklyn, P. Schimmel, Aminoacylation of RNA minihelices with alanine. Nature 337(6206), 478-481 (1989)

J. Frank, R.K. Agrawal, A ratchet-like inter-subunit reorganization of the ribosome during translocation. Nature 406(6793), 318-322 (2000)

J. Frank, R.L. Gonzalez Jr., Structure and dynamics of a processive Brownian motor: the translating ribosome. Annu. Rev. Biochem. 79, 381-412 (2010)

D.J. Frost, U. Mann, Y. Asahara, D.C. Rubie, The redox state of the mantle during and just after core formation. Philos. Trans. R. Soc. A 366, 4315-4337 (2008)

G. Fuchs, Alternative pathways of carbon dioxide fixation: insights into the early evolution of life? Annu. Rev. Microbiol. 65, 631-658 (2011)

W.D. Fuller, R.A. Sanchez, L.E. Orgel, Studies in prebiotic synthesis. VI. Synthesis of purine nucleosides. J. Mol. Biol. 67(1), 25-33 (1972a)

W.D. Fuller, R.A. Sanchez, L.E. Orgel, Studies in prebiotic synthesis: VII. Solid-state synthesis of purine nucleosides. J. Mol. Evol. 1(3), 249-257 (1972b)

K. Furukawa, A. Ramesh, Z. Zhou, Z. Weinberg, T. Vallery, W.C. Winkler, R.R. Breaker, Bacterial riboswitches cooperatively bind $\mathrm{Ni}^{(2+)}$ or $\mathrm{Co}^{(2+)}$ ions and control expression of heavy metal transporters. Mol. Cell 57(6), 1088-1098 (2015)

H. Genda, Origin of Earth's oceans: an assessment of the total amount, history and supply of water. Geochem. J. 50(1), 27-42 (2016)

H. Genda, R. Brasser, S.J. Mojzsis, The terrestrial late veneer from core disruption of a lunar-sized impactor. Earth Planet. Sci. Lett. 480, 25-32 (2017) 
J.M. Génin, A. Renard, C. Ruby, Fougerite Fe II-III oxyhydroxycarbonate in environmental chemistry and nitrate reduction, in ICAME 2007 (Springer, Berlin, 2008), pp. 913-919

R. Gesteland, J. Atkins, The RNA World (Cold Spring Harbor Laboratory Press, Cold Spring Harbor, 1993)

P. Gholizadeh, M. Aghazadeh, M. Asgharzadeh, H.S. Kafil, Suppressing the CRISPR/Cas adaptive immune system in bacterial infections. Eur. J. Clin. Microbiol. Infect. Dis. 36(11), 2043-2051 (2017)

W. Gilbert, Origin of life: the RNA world. Nature 319(6055), 618 (1986)

C.R. Glein, J.A. Baross, J.H. Waite Jr., The pH of Enceladus' ocean. Geochim. Cosmochim. Acta 162, 202219 (2015)

J.P. Gogarten, W.F. Doolittle, J.G. Lawrence, Prokaryotic evolution in light of gene transfer. Mol. Biol. Evol. 19(12), 2226-22238 (2002)

J.E. Goldford, H. Hartman, T.F. Smith, D. Segrè, Remnants of an ancient metabolism without phosphate. Cell 168(6), 1126-1134 (2017)

V.M. Goldschmidt, Geochemical aspects of the origin of complex organic molecules on Earth, as precursors to organic life. New Biol. 12, 97-105 (1952)

R.L. Gonzalez Jr., I. Tinoco Jr., Identification and characterization of metal ion binding sites in RNA. Methods Enzymol. 338, 421-443 (2001)

S.J. Gould, Punctuated equilibrium and the fossil record. Science 219(4584), 439-440 (1983)

S.J. Gould, Punctuated equilibrium: empirical response. Science 232(4749), 439 (1986)

S.J. Gould, Wonderful Life: The Burgess Shale and the Nature of History (Norton, New York, 1989)

S.J. Gould, N. Eldredge, Punctuated equilibrium comes of age. Nature 366(6452), 223-227 (1993)

D. Gourier, L. Binet, T. Calligaro, S. Capelli, H. Vezin, J.G. Bréhéret, K. Hickman-Lewis, P. Gautret, F. Foucher, K.A. Campbell, F. Westall, Extraterrestrial organic matter preserved in 3.33 Ga sediments from Barberton, South Africa. Geochim. Cosmochim. Acta 258, 207-225 (2019)

M.G. Green, P.J. Sylvester, R. Buick, Growth and recycling of early Archaean continental crust: geochemical evidence from the Coonterunah and Warrawoona groups, Pilbara Craton, Australia. Tectonophysics 322, 69-88 (2000)

S. Gribaldo, H. Philippe, Ancient phylogenetic relationships. Theor. Popul. Biol. 61(4), 391-408 (2002)

M. Groussin, M. Gouy, Adaptation to environmental temperature is a major determinant of molecular evolutionary rates in archaea. Mol. Biol. Evol. 28, 2661-2674 (2011)

N. Guttenberg, N. Virgo, K. Chandru, C. Scharf, I. Mamajanov, Bulk measurements of messy chemistries are needed for a theory of the origins of life. Philos. Trans. R. Soc., Math. Phys. Eng. Sci. 375, 20160347 (2017)

J. Haldane, The Origin of Life. Rationalist Annual (1929)

K.P. Hand, R.W. Carlson, Europa's surface color suggests and ocean rich with sodium chloride. Geophys. Res. Lett. 42, 3174-3178 (2015)

J.L. Hansen, T.M. Schmeing, P.B. Moore, T.A. Steitz, Structural insights into peptide bond formation. Proc. Natl. Acad. Sci. USA 99(18), 11670-11675 (2002)

J. Harms, F. Schluenzen, R. Zarivach, A. Bashan, S. Gat, I. Agmon, H. Bartels, F. Franceschi, A. Yonath, High resolution structure of the large ribosomal subunit from a mesophilic eubacterium. Cell 107(5), 679-688 (2001)

J.K. Harris, S.T. Kelley, G.B. Spiegelman, N.R. Pace, The genetic core of the universal ancestor. Genome Res. 13(3), 407-412 (2003)

S. Harrison, N. Lane, Life as a guide to prebiotic nucleotide synthesis. Nat. Commun. 9, 5176 (2018)

T.M. Harrison, A.K. Schmitt, M.T. McCulloch, O.M. Lovera, Early ( $\geq 4.5 \mathrm{Ga}$ ) formation of terrestrial crust: $\mathrm{Lu}-\mathrm{Hf}, \mathrm{d}^{18} \mathrm{O}$, and Ti thermometry results for hadean zircons. Earth Planet. Sci. Lett. 268(3), 476-486 (2008)

H. Hartman, T. Smith, The evolution of the ribosome and the genetic code. Life 4(2), 227 (2014)

R.B. Harvey, Enzymes of thermal algae. Science 60, 481-482 (1924)

R.M. Hazen, D.A. Sverjensky, Mineral surfaces, geochemical complexities, and the origins of life. Cold Spring Harb. Perspect. Biol. 2(2010), A002162 (2010)

R.M. Hazen, T.R. Filley, G.A. Goodfriend, Selective adsorption of L- and D-amino acids on calcite: implications for biochemical homochirality. Proc. Natl. Acad. Sci. USA 98, 5487-5490 (2001)

C. He, I. Gallego, B. Laughlin, M.A. Grover, N.V. Hud, A viscous solvent enables information transfer from gene-length nucleic acids in a model prebiotic replication cycle. Nat. Chem. 9(4), 318-324 (2017)

S.E. Heaps, T.M. Nye, R.J. Boys, T.A. Williams, T.M. Embley, Bayesian modelling of compositional heterogeneity in molecular phylogenetics. Stat. Appl. Genet. Mol. Biol. 13, 589-609 (2014)

J.E. Hein, E. Tse, D.G. Blackmond, A route to enantiopure RNA precursors from nearly racemic starting materials. Nat. Chem. 3(9), 704-706 (2011)

S. Helmreich, Life is a verb: inflections of artificial life in cultural context. Artif. Life 13, 189-201 (2007)

P.G. Higgs, Compensatory neutral mutations and the evolution of RNA. Genetica 102-103(1-6), 91-101 (1998) 
P.G. Higgs, N. Lehman, The RNA World: molecular cooperation at the origins of life. Nat. Rev. Genet. 16(1), 7-17 (2015)

M.M. Hirschmann, T. Tenner, C. Aubaud, A.C. Withers, Dehydration melting of nominally anhydrous mantle: the primacy of partitioning. Phys. Earth Planet. Inter. 176, 54-68 (2009)

A. Hofmann, C. Harris, Stratiform alteration zones in the Barberton greenstone belt: a window into subseafloor processes 3.5-3.3 Ga ago. Chem. Geol. 257, 224-242 (2008)

H.D. Holland, The Chemical Evolution of the Atmosphere and Oceans (Princeton University Press, Princeton, 1984)

C.H. House, The tree of life viewed through the contents of genomes. Methods Mol. Biol. 532, 141-161 (2009)

C. Hsiao, L.D. Williams, A recurrent magnesium-binding motif provides a framework for the ribosomal peptidyl transferase center. Nucleic Acids Res. 37(10), 3134-3142 (2009)

C. Hsiao, I.C. Chou, C.D. Okafor, J.C. Bowman, E.B. O’Neil, S.S. Athavale, A.S. Petrov, N.V. Hud, R.M. Wartell, S.C. Harvey, L.D. Williams, RNA with iron(II) as a cofactor catalyses electron transfer. Nat. Chem. 5(6), 525-528 (2013a)

C. Hsiao, T.K. Lenz, J.K. Peters, P.Y. Fang, D.M. Schneider, E.J. Anderson, T. Preeprem, J.C. Bowman, E.B. O’Neill, L. Lie, S.S. Athavale, J.J. Gossett, C. Trippe, J. Murray, A.S. Petrov, R.M. Wartell, S.C. Harvey, N.V. Hud, L.D. Williams, Molecular paleontology: a biochemical model of the ancestral ribosome. Nucleic Acids Res. 41(5), 3373-3385 (2013b)

W. Huang, J.P. Ferris, One-step, regioselective synthesis of up to 50-mers of RNA oligomers by montmorillonite catalysis. J. Am. Chem. Soc. 128(27), 8914-8919 (2006)

L. Huang, M. Krupkin, A. Bashan, A. Yonath, L. Massa, Protoribosome by quantum kernel energy method. Proc. Natl. Acad. Sci. USA 110(37), 14900-14905 (2013)

N.V. Hud, B.J. Cafferty, R. Krishnamurthy, L.D. Williams, The origin of RNA and "my grandfather's axe". Chem. Biol. 20(4), 466-474 (2013)

L.A. Hug, B.J. Baker, K. Anantharaman, C.T. Brown, A.J. Probst, C.J. Castelle, C.N. Butterfield, A.W. Hernsdorf, Y. Amano, K. Ise, Y. Suzuki, N. Dudek, D.A. Relman, K.M. Finstad, R. Amundson, B.C. Thomas, J.F. Banfield, A new view of the tree of life. Nat. Microbiol. 1(5), 16048 (2016)

J. Hury, U. Nagaswamy, M. Larios-Sanz, G.E. Fox, Ribosome origins: the relative age of 23S rRNA domains. Orig. Life Evol. Biosph. 36(4), 421 (2006)

S. Islam, D.-K. Bučar, M.W. Powner, Prebiotic selection and assembly of proteinogenic amino acids and natural nucleotides from complex mixtures. Nat. Chem. 9, 584 (2017)

G. Israël, C. Szopa, F. Raulin, M. Cabane, H.B. Niemann, S.K. Atreya, S.J. Bauer, J.-F. Brun, E. Chassefière, P. Coll, E. Condé, D. Coscia, A. Hauchecorne, P. Millian, M.-J. Nguyen, T. Owen, W. Riedler, R.E. Samuelson, J.-M. Siguier, M. Steller, R. Sternberg, C. Vidal-Madjar, Evidence for the presence of complex organic matter in Titan's aerosols by in situ analysis. Nature 438, 796-799 (2005)

J.B. Jackson, Natural pH gradients in hydrothermal alkali vents were unlikely to have played a role in the origin of life. J. Mol. Evol. 83(1-2), 1-11 (2016)

J.B. Jackson, The "Origin-of-Life Reactor" and reduction of $\mathrm{CO}_{2}$ by $\mathrm{H}_{2}$ in inorganic precipitates. J. Mol. Evol. 85(1-2), 1-7 (2017)

K.D. James, A.D. Ellington, The search for missing links between self-replicating nucleic acids and the RNA world. Orig. Life Evol. Biosph. 25(6), 515-530 (1995)

M.J. Janicki, S.J. Roberts, J. Sponer, M.W. Powner, R.W. Gora, R. Szabla, Photostability of oxazoline RNAprecursors in UV-rich prebiotic environments. Chem. Commun. 54(95), 13407-13410 (2018)

G. Jékely, Did the last common ancestor have a biological membrane? Biol. Direct 1(1), 35 (2006)

L. Jenner, S. Melnikov, N. Garreau de Loubresse, A. Ben-Shem, M. Iskakova, A. Urzhumtsev, A. Meskauskas, J. Dinman, G. Yusupova, M. Yusupov, Crystal structure of the 80S yeast ribosome. Curr. Opin. Struct. Biol. 22(6), 759-767 (2012)

B.B. Jensen, R.P. Cox, Direct measurements of steady-state kinetics of cyanobacterial N2 uptake by membrane-leak mass spectrometry and comparisons between nitrogen fixation and acetylene reduction. Appl. Environ. Microbiol. 45(4), 1331-1337 (1983)

T.Z. Jia, K. Chandru, Y. Hongo, R. Afrin, T. Usui, K. Myojo, H.J. Cleaves, Membraneless polyester microdroplets as primordial compartments at the origins of life. Proc. Natl. Acad. Sci. USA 116(32), 15830-15835 (2019)

A.T. Johnson, M.K. Schlegel, E. Meggers, L-O. Essen, O. Wiest, On the structure and dynamics of duplex GNA. J. Org. Chem. 76(19), 7964-7974 (2011)

F.S. Jordan, E. Nee, N. Lane, Isoprenoids enhance the stability of fatty acid membranes at the emergence of life potentially leading to an early lipid divide. Interface Focus 9, 20190067 (2019a)

F.S. Jordan, H. Rammu, I.N. Zheludev, A.M. Hartley, A. Maréchal, N. Lane, Promotion of protocell selfassembly from mixed amphiphiles at the origin of life. Nat. Ecol. Evol. (2019b). https://doi.org/10.1038/ s41559-019-1015-y 
P.C. Joshi, M.F. Aldersley, J.W. Delano, J.P. Ferris, Mechanism of montmorillonite catalysis in the formation of RNA oligomers. J. Am. Chem. Soc. 131(37), 13369-13374 (2009)

B.S. Kamber, The evolving nature of terrestrial crust from the Hadean, through the Archaean, into the Proterozoic. Precambrian Res. 258, 48-82 (2015)

M.B. Kamenetsky, A.V. Sobolev, V.S. Kamenetsky, R. Maas, L.V. Danyushevsky, R. Thomas, N.P. Pokhilenko, N.V. Sobolev, Kimberlite melts rich in alkali chlorides and carbonates: a potent metasomatic agent in the mantle. Geology 32(10), 845-848 (2004)

J.F. Kasting, T.P. Ackerman, Climatic consequences of very high carbon dioxide levels in the Earth's early atmosphere. Science 234(4782), 1383-1385 (1986)

K. Kawamura, M.C. Maurel, Walking over 4 Gya: chemical evolution from photochemistry to mineral and organic chemistries leading to an RNA world. Orig. Life Evol. Biosph. 47(3), 281-296 (2017)

D.S. Kelley, Methane-rich fluids in the oceanic crust. J. Geophys. Res., Solid Earth 101(B2), 2943-2962 (1996)

A.I.S. Kemp, S.A. Wilde, C.J. Hawkesworth, C.D. Coath, A. Nemchin, R.T. Pidgeon, J.D. Vervoort, S.A. DuFrane, Hadean crustal evolution revisited: new constraints from $\mathrm{Pb}-\mathrm{Hf}$ isotope systematics of the Jack Hills zircons. Earth Planet. Sci. Lett. 296, 45-56 (2010)

N. Khawaja, F. Postberg, J. Hillier, F. Klenner, S. Kempf, L. Nolle, R. Reviol, Z. Zou, R. Srama, Low-mass nitrogen-, oxygen-bearing, and aromatic compounds in Enceladean ice grains. Mon. Not. R. Astron. Soc. 489(4), 5231-5243 (2019)

H.J. Kim, A. Ricardo, H.I. Illangkoon, M.J. Kim, M.A. Carrigan, F. Frye, S.A. Benner, Synthesis of carbohydrates in mineral-guided prebiotic cycles. J. Am. Chem. Soc. 133(24), 9457-9468 (2011)

S.D. King, C. Adam, Hotspot swells revisited. Phys. Earth Planet. Inter. 235, 66-83 (2014)

Y. Koga, Early evolution of membrane lipids: how did the lipid divide occur? J. Mol. Evol. 72, 274-282 (2011)

E.V. Koonin, Horizontal gene transfer: essentiality and evolvability in prokaryotes, and roles in evolutionary transitions. F1000 Res 5, 1805 (2016)

J. Korenaga, N.J. Planavsky, D.A. Evans, Global water cycle and the coevolution of the Earth's interior and surface environment. Philos. Trans. R. Soc. a 375 (2017)

J. Krissansen-Totton, G.N. Arney, D.C. Catling, Constraining the climate and ocean pH of the early Earth with a geological carbon cycle model. Proc. Natl. Acad. Sci. USA 115, 4105-4110 (2018)

M. Krupkin, D. Matzov, H. Tang, M. Metz, R. Kalaora, M.J. Belousoff, E. Zimmerman, A. Bashan, A. Yonath, A vestige of a prebiotic bonding machine is functioning within the contemporary ribosome. Philos. Trans. R. Soc. Lond. B, Biol. Sci. 366(1580), 2972-2978 (2011)

C.G. Kurland, The RNA dreamtime: modern cells feature proteins that might have supported a prebiotic polypeptide world but nothing indicates that RNA world ever was. BioEssays 32, 866-871 (2010)

S. Kurtovic, B. Mannervik, Identification of emerging quasi-species in directed enzyme evolution. Biochemistry 48(40), 9330-9339 (2009)

S. Kurtovic, A. Runarsdottir, L.O. Emren, A.K. Larsson, B. Mannervik, Multivariate-activity mining for molecular quasi-species in a glutathione transferase mutant library. Protein Eng. Des. Sel. 20(5), 243256 (2007)

M. Kusakabe, G.Z. Tanyileke, S.A. McCord, S.G. Schladow, Recent pH and $\mathrm{CO}_{2}$ profiles at Lakes Nyos and Monoun, Cameroon: implications for the degassing strategy and its numerical simulation. J. Volcanol. Geotherm. Res. 97, 241-260 (2000)

N. Lahav, The RNA-world and co-evolution hypotheses and the origin of life: implications, research strategies and perspectives. Orig. Life Evol. Biosph. 23(5-6), 329-344 (1993)

J.A. Lake, R.G. Skophammer, C.W. Herbold, J.A. Servin, Genome beginnings: rooting the tree of life. Philos. Trans. R. Soc. Lond. B, Biol. Sci. 364, 2177-2185 (2009)

H. Lammer, A. Stökl, N.V. Erkaev, E.A. Dorfi, P. Odert, M. Güdel, Y.N. Kulikov, K.G. Kislyakova, M. Leitzinger, Origin and loss of nebula-captured hydrogen envelopes from 'sub'-to 'super-Earths' in the habitable zone of Sun-like stars. Mon. Not. R. Astron. Soc. 439(4), 3225-3238 (2014)

N. Lane, J.F. Allen, W. Martin, How did LUCA make a living? Chemiosmosis in the origin of life. BioEssays 32, 271-280 (2010)

K.A. Lanier, S.S. Athavale, A.S. Petrov, R. Wartell, L.D. Williams, Imprint of ancient evolution on rRNA folding. Biochemistry 55(33), 4603-4613 (2016)

K.A. Lanier, A.S. Petrov, L.D. Williams, The central symbiosis of molecular biology: molecules in mutualism. J. Mol. Evol. 85(1-2), 8-13 (2017)

R. Larralde, M.P. Robertson, S.L. Miller, Rates of decomposition of ribose and other sugars: implications for chemical evolution. Proc. Natl. Acad. Sci. USA 92(18), 8158-8160 (1995)

A. Lazcano, Alexandr I. Oparin and the origin of life: a historical reassessment of the heterotrophic theory. J. Mol. Evol. 83(5-6), 214-222 (2016)

A. Lazcano, Prebiotic evolution and self-assembly of nucleic acids. ACS Nano 12(10), 9643-9647 (2018) 
K. Le Vay, H. Mutschler, The difficult case of an RNA-only origin of life. Emerg. Top. Life Sci. 3(5), 469-475 (2019). https://doi.org/10.1042/ETLS20190024

N.A. Leal, M. Sukeda, S.A. Benner, Dynamic assembly of primers on nucleic acid templates. Nucleic Acids Res. 34(17), 4702-4710 (2006)

S. Leduc, in The Mechanism of Life, London, Rebman (1911)

R.C. Lee, R.L. Feinbaum, V. Ambros, The C. elegans heterochronic gene lin-4 encodes small RNAs with antisense complementarity to lin-14. Cell 75(5), 843-854 (1993)

D.H. Lee, K. Severin, Y. Yokobayashi, M.R. Ghadiri, Emergence of symbiosis in peptide self-replication through a hypercyclic network. Nature 390(6660), 591-594 (1997)

D.D. Leipe, L. Aravind, E.V. Koonin, Did DNA replication evolve twice independently? Nucleic Acids Res. 27(17), 3389-3401 (1999)

J. Leja, Surface Chemistry of Froth Flotation (Plenum Press, New York, 1982)

E. Lellouch, G. Paubert, J.I. Moses, N.M. Schneider, D.F. Strobel, Volcanically-emitted sodium chloride as a source for Io's neutral clouds and plasma torus. Nature 421, 45-47 (2003)

K. Leu, B. Obermayer, S. Rajamani, U. Gerland, I.A. Chen, The prebiotic evolutionary advantage of transferring genetic information from RNA to DNA. Nucleic Acids Res. 39(18), 8135-8147 (2011)

X. Li, N. Li, in LncRNAs on Guard. Int. Immunopharmacol, vol. 65 (2018), pp. 60-63

L. Li, C. Francklyn, C.W. Carter Jr., Aminoacylating urzymes challenge the RNA world hypothesis. J. Biol. Chem. 288(37), 26856-26863 (2013)

B.L. Ligon, Louis Pasteur: a controversial figure in a debate on scientific ethics. Semin. Pediatr. Infect. Dis. 13(2), 134-141 (2002)

R. Lill, J.M. Robertson, W. Wintermeyer, Affinities of tRNA binding sites of ribosomes from Escherichia coli. Biochemistry 25(11), 3245-3255 (1986)

D.M.J. Lilley, The origins of RNA catalysis in ribozymes. Trends Biochem. Sci. 28(9), 495-501 (2003)

M. Lingam, A. Loeb, Implications of tides for life on exoplanets (2017). ArXiv preprint. arXiv:1707.04594

Cv. Linné, L. Salvius, Caroli Linnaei.., Systema Naturae per Regna Tria Naturae: Secundum Classes, Ordines, Genera, Species, Cum Characteribus, Differentiis, Synonymis, Locis. Holmiae, vol v.1 (Impensis Direct. Laurentii Salvii, Stockholm, 1758)

Cv. Linné, L. Salvius, Caroli Linnaei... Systema naturae per regna tria naturae: secundum classes, ordines, genera, species, cum characteribus, differentiis, synonymis, locis, Holmiae, vol. v.2, (Impensis Direct. Laurentii Salvii, Stockholm, 1759)

W.T. Liu, Wind over troubled water. Backscatter 12(2), 14 (2001)

J. Lombard, P. López-García, D. Moreira, The early evolution of lipid membranes and the three domains of life. Nat. Rev. Microbiol. 10, 507-515 (2012)

M.S. Longuet-Higgins, The eigenfunctions of Laplace's tidal equation over a sphere. Philos. Trans. R. Soc. Lond. A 262(1132), 511-607 (1968)

P. Lopez-Garcia, D. Moreira, Open questions on the origin of eukaryotes. Trends Ecol. Evol. 30, 697-708 (2015)

K.A. Ludwig, C.C. Shen, D.S. Kelley, H. Cheng, R.L. Edwards, U-Th systematics and ${ }^{230}$ th ages of carbonate chimneys at the Lost City Hydrothermal Field. Geochim. Cosmochim. Acta 75, 1869-1888 (2011)

K-P. Lv, L. Norman, Y-L. Li, Oxygen-free biochemistry: the putative CHN foundation for exotic life in a hydrocarbon world? Astrobiology 17(11), 1173-1181 (2017)

W. Ma, The origin of life: a problem of history, chemistry, and evolution. Chem. Biodivers. 11(12), 19982010 (2014)

W. Ma, C. Yu, Intramolecular RNA replicase: possibly the first self-replicating molecule in the RNA world. Orig. Life Evol. Biosph. 36(4), 413-420 (2006)

G. Macleod, C. McKeown, A.J. Hall, M.J. Russell, Hydrothermal and oceanic pH conditions of possible relevance to the origin of life. Orig. Life Evol. Biosph. 24(1), 19-41 (1994)

K.A. Maher, D.J. Stevenson, Impact frustration of the origin of life. Nature 331, 612-614 (1988)

A.M. Makarieva, V.G. Gorshkov, B.L. Li, Energetics of the smallest: do bacteria breathe at the same rate as whales? Proc. R. Soc. Lond. B, Biol. Sci. 272, 2219-2224 (2005)

S. Marchi, W.F. Bottke, L.T. Elkins-Tanton, M. Bierhaus, K. Wuennemann, A. Morbidelli, D.A. Kring, Widespread mixing and burial of Earth's hadean crust by asteroid impacts. Nature 511, 578-582 (2014)

L. Margulis, Five-kingdom classification and the origin and evolution of cells, in Evolutionary Biology, vol. 7, ed. by T. Dobzhansky, M.K. Hecht, W.C. Steere (Springer, Boston, 1974), pp. 45-78

W.F. Martin, M.J. Russell, On the origins of cells: a hypothesis for the evolutionary transitions from abiotic geochemistry to chemoautotrophic prokaryotes, and from prokaryotes to nucleated cells. Philos. Trans. R. Soc. Lond. B, Biol. Sci. 358(1429), 59-85 (2002)

W.F. Martin, F.L. Sousa, Early microbial evolution: the age of anaerobes. Cold Spring Harb Perspect Biol. 8, A018127 (2016) 
R.S. Martin, T.A. Mather, D.M. Pyle, Volcanic emissions and the early Earth atmosphere. Geochim. Cosmochim. Acta 71, 3673-3685 (2007)

W.F. Martin, J. Baross, D. Kelley, M.J. Russell, Hydrothermal vents and the origin of life. Nat. Rev. Microbiol. 6, 805-814 (2008)

W.F. Martin, S. Garg, V. Zimorski, Endosymbiotic theories for eukaryote origin. Philos. Trans. R. Soc. Lond. B, Biol. Sci. 370, 20140330 (2015)

B. Marty, The origins and concentrations of water, carbon, nitrogen and noble gases on Earth. Earth Planet. Sci. Lett. 313(314), 56-66 (2012)

B. Marty, K. Altwegg, H. Balsiger, A. Bar-Nun, D.V. Bekaert, J.-J. Berthelier, A. Bieler, C. Briois, U. Calmonte, M. Combi, J. De Keyser, B. Fiethe, S.A. Fuselier, S. Gasc, T.I. Gombosi, K.C. Hansen, M. Hässig, A. Jäckel, E. Kopp, A. Korth, L. Le Roy, U. Mall, O. Mousis, T. Owen, H. Rème, M. Rubin, T. Sémon, C.-Y. Tzou, J.H. Waite, P. Wurz, Xenon isotopes in 67P/Churyumov-Gerasimenko show that comets contributed to Earth's atmosphere. Science 356, 1069-1072 (2017)

H. Massol, K. Hamano, F. Tian, M. Ikoma, Y. Abe, E. Chassefière, A. Davaille, H. Genda, M. Güdel, Y. Hori, F. Leblanc, Formation and evolution of protoatmospheres. Space Sci. Rev. 205(1-4), 153-211 (2016)

C. Mathis, S.N. Ramprasad, S.I. Walker, N. Lehman, Prebiotic RNA network formation: a taxonomy of molecular cooperation. Life 7(4), E38 (2017)

T.M. McCollom, Miller-Urey and beyond: what have we learned about prebiotic organic synthesis reactions in the past 60 years? Annu. Rev. Earth Planet. Sci. 41(1), 207-229 (2013)

C.P. McKay, H.D. Smith, Possibilities for methanogenic life in liquid methane on the surface of Titan. Icarus 178, 274-276 (2005)

C.P. McKay, C.C. Porco, T. Altheide, W.L. Davis, T.A. Kral, The possible origin and persistence of life on Enceladus and detection of biomarkers in the plume. Astrobiology 8(5), 909-919 (2008)

W.G. Meinschein, B. Nagy, D.J. Hennessy, Evidence in meteorites of former life: the organic compounds in carbonaceous chondrites are similar to those found in marine sediments. Ann. N.Y. Acad. Sci. 108, 553-579 (1963)

C. Menor-Salvan, D.M. Ruiz-Bermejo, M.I. Guzman, S. Osuna-Esteban, S. Veintemillas-Verdaguer, Synthesis of pyrimidines and triazines in ice: implications for the prebiotic chemistry of nucleobases. Chemistry 15(17), 4411-4418 (2009)

R.E. Mielke, M.J. Russell, P.R. Wilson, S. McGlynn, M. Coleman, R. Kidd, I. Kanik, Design, fabrication and test of a hydrothermal reactor for origin-of-life experiments. Astrobiology 10, 799-810 (2010)

S.L. Miller, A production of amino acids under possible primitive Earth conditions. Science 117(3046), 528529 (1953)

D. Milshteyn, B. Damer, J. Havig, D. Deamer, Amphiphilic compounds assemble into membranous vesicles in hydrothermal hot spring water but not in seawater. Life 8(2), E11 (2018)

D. Milshteyn, G. Cooper, D. Deamer, Chemiosmotic energy for primitive cellular life: proton gradients are generated across lipid membranes by redox reactions coupled to meteoritic quinones. Sci. Rep. 9(1), 12447 (2019)

V.K. Misra, D.E. Draper, A thermodynamic framework for $\mathrm{Mg}^{2+}$ binding to RNA. Proc. Natl. Acad. Sci. 98, 12456 (2001)

P. Mitchell, The origin of life and the formation and organizing functions of natural membranes, in Proceedings of the First International Symposium on the Origin of Life on the Earth, ed. by R.L.M. Synge (Pergamon Press, New York, 1959), pp. 437-443

S. Miyakawa, P.C. Joshi, M.J. Gaffey, E. Gonzalez-Toril, C. Hyland, T. Ross, K. Rybij, J.P. Ferris, Studies in the mineral and salt-catalyzed formation of RNA oligomers. Orig. Life Evol. Biosph. 36(4), 343-361 (2006)

S.J. Mojzsis, T.M. Harrison, R.T. Pidgeon, Oxygenisotope evidence from ancient zircons for liquid water at the Earth's surface 4300 Myr ago. Nature 409, 178-181 (2001)

R.E. Monro, Catalysis of peptide bond formation by $50 \mathrm{~S}$ ribosomal subunits from Escherichia coli. J. Mol. Biol. 26(1), 147-151 (1967)

W.B. Moore, A.A.G. Webb, Heat-pipe earth. Nature 501(7468), 501-505 (2013)

J.P. Morgan, W.J. Morgan, Two-stage melting and the geochemical evolution of the mantle: a recipe for mantle plum-pudding. Earth Planet. Sci. Lett. 170(3), 215-239 (1999)

K.B. Muchowska, E. Chevallot-Beroux, J. Moran, Recreating ancient metabolic pathways before enzymes. Bioorg. Med. Chem. 27(12), 2292-2297 (2019)

C.V. Mungi, S. Rajamani, Characterization of RNA-like oligomers from lipid-assisted nonenzymatic synthesis: implications for origin of informational molecules on early Earth. Life 5(1), 65-84 (2015)

A.R. Mushegian, E.V. Koonin, A minimal gene set for cellular life derived by comparison of complete bacterial genomes. Proc. Natl. Acad. Sci. 93(19), 10268-10273 (1996)

G.W. Muth, L. Ortoleva-Donnelly, S.A. Strobel, A single adenosine with a neutral pKa in the ribosomal peptidyl transferase center. Science 289(5481), 947-950 (2000) 
U. Nagaswamy, G.E. Fox, RNA ligation and the origin of tRNA. Orig. Life Evol. Biosph. 33(2), 199-209 (2003)

K.E. Nelson, M. Levy, S.L. Miller, Peptide nucleic acids rather than RNA may have been the first genetic molecule. Proc. Natl. Acad. Sci. 97(8), 3868-3871 (2000)

P.E. Nielsen, M. Egholm, R.H. Berg, O. Buchardt, Sequence-selective recognition of DNA by strand displacement with a thymine-substituted polyamide. Science 254, 1497-1500 (1991)

W. Nijman, S.T. de Vries, Early archean crustal collapse structures and sedimentary basin dynamics, in The Precambrian Earth: Tempos and Events, ed. by P.G. Eriksson, W. Altermann, D.R. Nelson, W.U. Mueller, O. Catuneau (Elsevier, Amsterdam, 2004), pp. 139-154

W. Nijman, A. Kloppenburg, S.T. de Vries, Archaean basin margin geology and crustal evolution: an East Pilbara traverse. J. Geol. Soc. 174, 1090-1112 (2017)

M. Nirenberg, P. Leder, RNA codewords and protein synthesis. The effect of trinucleotides upon the binding of sRNA to ribosomes. Science 145(3639), 1399-1407 (1964)

P. Nissen, J. Hansen, N. Ban, P.B. Moore, T.A. Steitz, The structural basis of ribosome activity in peptide bond synthesis. Science 289(5481), 920-930 (2000)

A. Nissenbaum, Scavenging of soluble organic matter from the prebiotic oceans. Orig. Life 7, 413-416 (1976)

W. Nitschke, M.J. Russell, Hydrothermal focusing of chemical and chemiosmotic energy, supported by delivery of catalytic Fe, Ni, Mo/W, Co, S and Se, forced life to emerge. J. Mol. Evol. 69, 481 (2009)

H.F. Noller, Evolution of protein synthesis from an RNA world. Cold Spring Harb. Perspect. Biol. 4(4), a003681 (2012)

T. Nunoura, Y. Chikaraishi, R. Izaki, T. Suwa, T. Sato, T. Harada, K. Mori, Y. Kato, M. Miyazaki, S. Shimamura, K. Yanagawa, A. Shuto, N. Ohkouchi, N. Fujita, Y. Takaki, H. Atomi, K. Takai, A primordial and reversible TCA cycle in a facultatively chemolithoautotrophic thermophile. Science 359(6375), 559563 (2018)

B. Obermayer, H. Krammer, D. Braun, U. Gerland, Emergence of information transmission in a prebiotic RNA reactor. Phys. Rev. Lett. 107(1), 018101 (2011)

D.P. O'Brien, R.D. Lorenz, J.I. Lunine, Numerical calculations of the longevity of impact oases on Titan. Icarus 173, 243-253 (2005)

L. Ojha, M.B. Wilhelm, S.L. Murchie, A.S. McEwen, J.J. Wray, J. Hanley, M. Massé, K.P. Hand, Halogens on and within the ocean worlds of the outer Solar System, in The Role of Halogens in Terrestrial and Extraterrestrial Geochemical Processes (Springer, Cham, 2018), pp. 997-1016

C. O'Neill, V. Debaille, W. Griffin, Deep earth recycling in the Hadean and constraints on surface tectonics. Am. J. Sci. 313(9), 912-932 (2013)

H. Ooka, S.E. McGlynn, R. Nakamura, Electrochemistry at deep-sea hydrothermal vents: utilization of the thermodynamic driving force towards the autotrophic origin of life. ChemElectroChem 6(5), 1316-1323 (2018)

J. Oró, Synthesis of adenine from ammonium cyanide. Biochem. Biophys. Res. Commun. 2(6), 407-412 (1960)

A. Oparin, Origin of Life. Moscovskij Rabochij Moscow (1924).

L.E. Orgel, Prebiotic chemistry and the origin of the RNA world. Crit. Rev. Biochem. Mol. Biol. 39(2), 99-123 (2004)

L.E. Orgel, F.H. Crick, Anticipating an RNA world. Some past speculations on the origin of life: where are they today? FASEB J. 7(1), 238-239 (1993)

S. Orla-Jensen, Die hauptlinien des naturlichen bakteriensystems. Zentralbl. Bakteriol. Parasitenkd. Infektionskr. Hyg., Abt. II(22), 305-346 (1909)

N.R. Pace, Origin of life-facing up to the physical setting. Cell 65(4), 531-533 (1991)

N.R. Pace, A molecular view of microbial diversity and the biosphere. Science 276(5313), 734-740 (1997)

M. Paci, G.E. Fox, Major centers of motion in the large ribosomal RNAs. Nucleic Acids Res. 43(9), 46404649 (2015)

M. Paci, G.E. Fox, Centers of motion associated with EF-Tu binding to the ribosome. RNA Biol. 13(5), 524-530 (2016)

M.Y. Palmer, M.A. Cordiner, C.A. Nixon, S.B. Charnley, N.A. Teanby, Z. Kisiel, P.G.J. Irwin, M.J. Mumma, ALMA detection and astrobiological potential of vinyl cyanide on Titan. Sci. Adv. 28(3), e1700022 (2017)

D. Parkos, A. Pikus, A. Alexeenko, H.J. Melosh, HCN production via impact ejecta reentry during the late heavy bombardment. J. Geophys. Res., Planets 123(4), 892-909 (2018)

R. Pascal, Physicochemical requirements inferred for chemical self-organization hardly support an emergence of life in the deep oceans of icy moons. Astrobiology 16(5), 328-334 (2016)

L. Pasteur, Mémoire sur les corpuscules organisés qui existent dans l'atmosphère. Mallet-Bachelier (1862) 
A.G. Patterson, M.S. Yevstigneyeva, P.C. Fineran, Regulation of CRISPR-Cas adaptive immune systems. Curr. Opin. Microbiol. 37, 1-7 (2017)

M. Pech, Z. Karim, H. Yamamoto, M. Kitakawa, Y. Qin, K.H. Nierhaus, Elongation factor 4 (EF4/LepA) accelerates protein synthesis at increased $\mathrm{Mg}^{2+}$ concentrations. Proc. Natl. Acad. Sci. USA 108(8), 3199-3203 (2011)

J. Peretó, J.L. Bada, A. Lazcano, Charles Darwin and the origin of life. Orig. Life Evol. Biosph. 39(5), 395406 (2009)

S. Pestka, Studies on the formation of transfer ribonucleic acid-ribosome complexes: III. The formation of peptide bonds by ribosomes in the absence of supernatant ennzymes. J. Biol. Chem. 243(10), 2810-2820 (1968)

J.W. Peters, A.F. Miller, A.K. Jones, P.W. King, M.W. Adams, Electron bifurcation. Curr. Opin. Chem. Biol. 31, 146-152 (2016)

A.S. Petrov, J.C. Bowman, S.C. Harvey, L.D. Williams, Bidentate RNA-magnesium clamps: on the origin of the special role of magnesium in RNA folding. RNA 17(2), 291-297 (2011)

A.S. Petrov, C.R. Bernier, C. Hsiao, C.D. Okafor, E. Tannenbaum, J. Stern, E. Gaucher, D. Schneider, N.V. Hud, S.C. Harvey, L.D. Williams, RNA-magnesium-protein interactions in large ribosomal subunit. J. Phys. Chem. B 116(28), 8113-8120 (2012)

A.S. Petrov, C.R. Bernier, B. Gulen, C.C. Waterbury, E. Hershkovits, C. Hsiao, S.C. Harvey, N.V. Hud, G.E. Fox, R.M. Wartell, L.D. Williams, Secondary structures of rRNAs from all three domains of life. PLoS ONE 9(20), e88222 (2014a)

A.S. Petrov, C.R. Bernier, C. Hsiao, A.M. Norris, N.A. Kovacs, C.C. Waterbury, V.G. Stepanov, S.C. Harvey, G.E. Fox, R.M. Wartell, N.V. Hud, L.D. Williams, Evolution of the ribosome at atomic resolution. Proc. Natl. Acad. Sci. USA 111(28), 10251-10256 (2014b)

A.S. Petrov, B. Gulen, A.M. Norris, N.A. Kovacs, C.R. Bernier, K.A. Lanier, G.E. Fox, S.C. Harvey, R.M. Wartell, N.V. Hud, L.D. Williams, History of the ribosome and the origin of translation. Proc. Natl. Acad. Sci. USA 112(50), 15396-15401 (2015)

S. Pino, J.E. Sponer, G. Costanzo, R. Saladino, E. Di Mauro, From formamide to RNA, the path is tenuous but continuous. Life 5(1), 372-384 (2015)

S. Pizzarello, E. Shock, Carbonaceous chondrite meteorites: the chronicle of a potential evolutionary path between stars and life. Orig. Life Evol. Biosph. 47(3), 249-260 (2017)

K. Plakos, V.J. DeRose, Mapping platinum adducts on yeast ribosomal RNA using high-throughput sequencing. Chem. Commun. 53(95), 12746-12749 (2017)

K. Plankensteiner, H. Reiner, B.M. Rode, Amino acids on the rampant primordial Earth: electric discharges and the hot salty ocean. Mol. Divers. 10(1), 3-7 (2006)

A.M. Poole, D.T. Logan, Modern mRNA proofreading and repair: clues that the last universal common ancestor possessed an RNA genome? Mol. Biol. Evol. 22(6), 1444-1455 (2005)

M.J. Poston, R.W. Carlson, K.P. Hand, Spectral behavior of irradiated sodium chloride crystals under Europalike conditions. J. Geophys. Res., Planets 122(12), 2644-2654 (2017)

M.W. Powner, B. Gerland, J.D. Sutherland, Synthesis of activated pyrimidine ribonucleotides in prebiotically plausible conditions. Nature 459(7244), 239-242 (2009)

M.W. Powner, J.D. Sutherland, J.W. Szostak, Chemoselective multicomponent one-pot assembly of purine precursors in water. J. Am. Chem. Soc. 132(46), 16677-16688 (2010)

M.W. Powner, J.D. Sutherland, J.W. Szostak, The origins of nucleotides. Synlett 22(14), 1956-1964 (2011)

M. Preiner, J.C. Xavier, F.L. Sousa, V. Zimorski, A. Neubeck, S.Q. Lang, H.C. Greenwell, K. Kleinermanns, H. Tuysuz, T.M. McCollom, N.G. Holm, W.F. Martin, Serpentinization: connecting geochemistry, ancient metabolism and industrial hydrogenation. Life 22(8), 4 (2018)

I.R. Price, A. Gaballa, F. Ding, J.D. Helmann, A. Ke, $\mathrm{Mn}^{(2+)}$-sensing mechanisms of yybP-ykoY orphan riboswitches. Mol. Cell 57(6), 1110-1123 (2015)

A.J. Probst, T. Weinmaier, K. Raymann, A. Perras, J.B. Emerson, T. Rattei, G. Wanner, A. Klingl, I.A. Berg, M. Yoshinaga, B. Viehweger, K.U. Hinrichs, B.C. Thomas, S. Meck, A.K. Auerbach, M. Heise, A. Schintlmeister, M. Schmid, M. Wagner, S. Gribaldo, J.F. Banfield, C. Moissl-Eichinger, Biology of a widespread uncultivated archaeon that contributes to carbon fixation in the subsurface. Nat. Commun. 26(5), 5497 (2014)

D.E.B. Pugel, J.D. Rummel, C. Conley, Brushing your spacecraft's teeth: a review of biological reduction processes for planetary protection missions, in IEEE Aerospace Conference (2017), pp. 1-10

P. Puigbò, Y.I. Wolf, E.V. Koonin, Search for a 'Tree of Life' in the thicket of the phylogenetic forest. J. Biol. 8, 59 (2009)

P. Puigbò, Y.I. Wolf, E.V. Koonin, The tree and net components of prokaryote evolution. Genome Biol. Evol. 2, 745-756 (2010)

D. Puthenvedu, I. Majerfeld, M. Yarus, Non-Watson-Crick RNA synthesis suited to origin functions. RNA 24(1), 90-97 (2018) 
A. Pyle, Metal ions in the structure and function of RNA. JBIC, J. Biol. Inorg. Chem. 7(7), 679-690 (2002)

M. Rahma, J. Lunine, D.A. Usher, D. Shalloway, Polymorphism and electronic structure of polyimine and its potential significance for prebiotic chemistry on Titan. Proc. Natl. Acad. Sci. 113(29), 8121-8126 (2016)

S. Rajamani, A. Vlassov, S. Benner, A. Coombs, F. Olasagasti, D. Deamer, Lipid-assisted synthesis of RNAlike polymers from mononucleotides. Orig. Life Evol. Biosph. 38(1), 57-74 (2008)

S. Rajamani, J.K. Ichida, T. Antal, D.A. Treco, K. Leu, M.A. Nowak, J.W. Szostak, I.A. Chen, Effect of stalling after mismatches on the error catastrophe in nonenzymatic nucleic acid replication. J. Am. Chem. Soc. 132(16), 5880-5885 (2010)

M. Ralser, An appeal to magic? The discovery of a non-enzymatic metabolism and its role in the origins of life. Biochem. J. 475(16), 2577-2592 (2018)

V. Ramakrishnan, Ribosome structure and the mechanism of translation. Cell 108(4), 557-572 (2002)

F. Raulin, Organic lakes on Titan. Nature 454, 587-589 (2008)

F. Raulin, T. Owen, Organic chemistry and exobiology on Titan. Space Sci. Rev. 104(1-2), 377-394 (2002)

F. Raulin, C. Brassé, O. Poch, P. Coll, Prebiotic chemistry on Titan. Chem. Soc. Rev. 41, 5380-5393 (2012)

T. Ray, An approach to the synthesis of life, in Artificial Life II, ed. by C.G. Langton (Addison-Wesley, Redwood City, 1992), pp. 371-408

E.P. Reeves, J.M. McDermott, J.S. Seewald, The origin of methanethiol in mid ocean ridge hydrothermal fluids. Proc. Natl. Acad. Sci. USA 111, 5474-5479 (2014)

A. Rich (ed.), On the Problems of Evolution and Biochemical Information Transfer. Horizons in Biochemistry (Academic Press, New York, 1962)

D. Rickard, I.B. Butler, A. Oldroyd, A novel iron sulphide mineral switch and its implications for Earth and planetary science. Earth Planet. Sci. Lett. 189, 85-91 (2001)

M. Rivas, Q. Tran, G.E. Fox, Nanometer scale pores similar in size to the entrance of the ribosomal exit cavity are a common feature of large RNAs. RNA 19(10), 1349-1354 (2013)

F. Robert, M. Chaussidon, A palaeotemperature curve for the Precambrian oceans based on silicon isotopes in cherts. Nature 443(7114), 969 (2006)

M.P. Robertson, G.F. Joyce, The origins of the RNA world. Cold Spring Harb. Perspect. Biol. 4(5), A003608 (2012)

L.E. Rodriguez, C.H. House, K.E. Smith, M.R. Roberts, M.P. Callahan, Nitrogen heterocycles form peptide nucleic acid precursors in complex prebiotic mixtures. Sci. Rep. 9(1), 9281 (2019)

K. Ruiz-Mirazo, J. Peretó, A. Moreno, A universal definition of life: autonomy and open-ended evolution. Orig. Life Evol. Biosph. 34(3), 323-346 (2004)

J.D. Rummel, Planetary exploration in the time of astrobiology: protecting against biological contamination. Proc. Natl. Acad. Sci. USA 98, 2128-2131 (2001)

C.M. Runnels, K.A. Lanier, J.K. Williams, J.C. Bowman, A.S. Petrov, N.V. Hud, L.D. Williams, Folding, assembly, and persistence: the essential nature and origins of biopolymers. J. Mol. Evol. 86(9), 598-610 (2018)

M.J. Russell, Green rust: the simple organizing 'seed' of all life? Life 8, 35 (2018)

M.J. Russell, A.J. Hall, The emergence of life from iron monosulphide bubbles at a submarine hydrothermal redox and pH front. Mem. Geol. Soc. Lond. 154, 377-402 (1997)

M.J. Russell, A.J. Hall, The onset and early evolution of life, in Evolution of Early Earth's Atmosphere, Hydrosphere, and Biosphere-Constraints from Ore Deposits, ed. by S.E. Kesler, H. Ohmoto. Geological Society of America, Memoir, vol. 198 (2006), pp. 1-32

M.J. Russell, A.J. Hall, A hydrothermal source of energy and materials at the origin of life, in Chemical Evolution II: From Origins of Life to Modern Society (Am. Chem. Soc., Washington, 2009), pp. 45-62

M.J. Russell, I. Kanik, Why does life start, what does it do, where will it be, and how might we find it. J. Cosmol. 5, 1008-1039 (2010)

M.J. Russell, A.J. Hall, A.G. Cairns-Smith, P.S. Braterman, Submarine hot springs and the origin of life. Nature 336, 117 (1988)

M.J. Russell, A.J. Hall, A.P. Gize, Pyrite and the origin of life. Nature 344, 387 (1990)

M.J. Russell, A.J. Hall, W.F. Martin, Serpentinization as a source of energy at the origin of life. Geobiology 8, 355-371 (2010)

M.J. Russell, L.M. Barge, R. Bhartia, D. Bocanegra, P.J. Bracher, E. Branscomb, R. Kidd, S.E. McGlynn, D.H. Meier, W. Nitschke, T. Shibuya, S. Vance, L. White, I. Kanik, The drive to life on wet and icy worlds. Astrobiology 14, 308-343 (2014)

M.J. Russell, K.P. Hand, A.E. Murray, The possible emergence of life and differentiation of a shallow biosphere on irradiated icy worlds: the example of Europa. Astrobiology 17, 1265-1273 (2017)

G. Ruvkun, B. Wightman, I. Ha, The 20 years it took to recognize the importance of tiny RNAs. Cell 116(2 Suppl), S93-S96 (2004), 92 p following S96 
G. Ryder, C. Koeberl, S.J. Mojzsis, Heavy bombardment on the Earth at $~ 3.85 \mathrm{Ga}$ : the search for petrographic and geochemical evidence, in Origin of the Earth and Moon, ed. by R.M. Canup, K. Righter (University of Arizona Press, Tucson, 2000), pp. 475-492

V.N. Sagi, V. Punna, F. Hu, G. Meher, R. Krishnamurthy, Exploratory experiments on the chemistry of the "glyoxylate scenario": formation of ketosugars from dihydroxyfumarate. J. Am. Chem. Soc. 134(7), 3577-3589 (2012)

R. Saladino, C. Crestini, F. Ciciriello, G. Costanzo, E. Di Mauro, Formamide chemistry and the origin of informational polymers. Chem. Biodivers. 4(4), 694-720 (2007)

R. Saladino, C. Crestini, F. Ciciriello, S. Pino, G. Costanzo, E. Di Mauro, From formamide to RNA: the roles of formamide and water in the evolution of chemical information. Res. Microbiol. 160(7), 441-448 (2009)

R. Saladino, G. Botta, S. Pino, G. Costanzo, E. Di Mauro, Genetics first or metabolism first? The formamide clue. Chem. Soc. Rev. 41(16), 5526-5565 (2012a)

R. Saladino, C. Crestini, S. Pino, G. Costanzo, E. Di Mauro, Formamide and the origin of life. Phys. Life Rev. 9(1), 84-104 (2012b)

R.A. Sanchez, L.E. Orgel, Studies in prebiotic synthesis. V. Synthesis and photoanomerization of pyrimidine nucleosides. J. Mol. Biol. 47(3), 531-543 (1970)

R.A. Sanchez, J.P. Ferris, L.E. Orgel, Studies in prebiotic synthesis. II. Synthesis of purine precursors and amino acids from aqueous hydrogen cyanide. J. Mol. Biol. 30(2), 223-253 (1967)

R.A. Sanchez, J.P. Ferris, L.E. Orgel, Studies in prebiotic synthesis. IV. Conversion of 4-aminoimidazole-5carbonitrile derivatives to purines. J. Mol. Biol. 38(1), 121-128 (1968)

J. Sapp, G.E. Fox, The singular quest for a universal tree of life. Microbiol. Mol. Biol. Rev. 77(4), 541-550 (2013)

V. Sautter, M.J. Toplis, R.C. Wiens, A. Cousin, C. Fabre, O. Gasnault, S. Maurice, O. Forni, J. Lasue, A. Ollila, J.C. Bridges, N. Mangold, S. Le Mouélic, M. Fisk, P.-Y. Meslin, P. Beck, P. Pinet, L. Le Deit, W. Rapin, E.M. Stolper, H. Newsom, D. Dyar, N. Lanza, D. Vaniman, S. Clegg, J.J. Wray, In situ evidence for continental crust on early Mars. Nat. Geosci. 8, 605-609 (2015)

R.F. Say, G. Fuchs, Fructose 1, 6-bisphosphate aldolase/phosphatase may be an ancestral gluconeogenic enzyme. Nature 464, 1077-1081 (2010)

F. Schlunzen, R. Zarivach, J. Harms, A. Bashan, A. Tocilj, R. Albrecht, A. Yonath, F. Franceschi, Structural basis for the interaction of antibiotics with the peptidyl transferase centre in eubacteria. Nature 413(6858), 814-821 (2001)

E. Schrödinger, What Is Life? The Physical Aspect of the Living Cell (Cambridge University Press, Cambridge, 1944)

M.D. Schulte, E.L. Shock, Thermodynamics of Strecker synthesis in hydrothermal systems. Orig. Life Evol. Biosphere 25, 161-173 (1995)

B.S. Schuwirth, M.A. Borovinskaya, C.W. Hau, W. Zhang, A. Vila-Sanjurjo, J.M. Holton, J.H. Cate, Structures of the bacterial ribosome at 3.5 A resolution. Science 310(5749), 827-834 (2005)

D.W. Schwartzman, C.H. Lineweaver, The hyperthermophilic origin of life revisited. Thermophiles 32(2), 168-171 (2004)

P. Schwille, There and back again: from the origin of life to single molecules. Eur. Biophys. J. 47(4), 493-498 (2018)

M. Selmer, C.M. Dunham, F.V. Murphy IV, A. Weixlbaumer, S. Petry, A.C. Kelley, J.R. Weir, V. Ramakrishnan, Structure of the 70S ribosome complexed with mRNA and tRNA. Science 313(5795), 1935-1942 (2006)

M.A. Sephton, Organic compounds in carbonaceous meteorites. Natl. Prod. Rep. 19(3), 292-311 (2002)

J. Sgrignani, A. Magistrato, The structural role of $\mathrm{Mg}^{2+}$ ions in a class I RNA polymerase ribozyme: a molecular simulation study. J. Phys. Chem. B 116, 2259-68 (2012)

B. Sherwood Lollar, T.D. Westgate, J.A. Ward, G.F. Slater, G. Lacrampe-Couloume, Abiogenic formation of alkanes in the Earth's crust as a minor source for global hydrocarbon reservoirs. Nature 416, 522-524 (2002)

E.L. Shock, Geochemical constraints on the origin of organic compounds in hydrothermal systems. Orig. Life Evol. Biosph. 20(3-4), 331-367 (1990)

E.L. Shock, Chemical environments of submarine hydrothermal systems. Orig. Life Evol. Biosph. 22, 67-107 (1992)

E.L. Shock, T.M. McCollom, M.D. Schulte, The emergence of metabolism from within hydrothermal systems, in Thermophiles: The Keys to Molecular Evolution and the Origin of Life, ed. by J. Wiegel, M.W.W. Adams (Taylor \& Francis, London, 2002), pp. 59-76

A. Sievers, M. Beringer, M.V. Rodnina, R. Wolfenden, The ribosome as an entropy trap. Proc. Natl. Acad. Sci. USA 101(21), 7897-7901 (2004) 
N.H. Sleep, The hadean-archaean environment. Cold spring harbor perspectives in biology. Cold Spring Harb. Perspect. Biol. 2(6), A002527 (2010)

N.H. Sleep, Maintenance of permeable habitable subsurface environments by earthquakes and tidal stresses. Int. J. Astrobiol. 11(4), 257-268 (2012)

N.H. Sleep, Geological and geochemical constraints on the origin and evolution of life. Astrobiology 18(9), 1199-1219 (2018)

T.F. Smith, J.C. Lee, R.R. Gutell, H. Hartman, The origin and evolution of the ribosome. Biol. Direct 3, 16 (2008)

B. Snel, P. Bork, M.A. Huynen, Genome phylogeny based on gene content. Nat. Genet. 21(1), 108 (1999)

V. Sojo, A. Pomiankowski, N. Lane, A bioenergetic basis for membrane divergence in archaea and bacteria. PLoS Biol. 12, e1001926-e1001926 (2014)

F.L. Sousa, T. Thiergart, G. Landan, S. Nelson-Sathi, I.A. Pereira, J.F. Allen, N. Lane, W.F. Martin, Early bioenergetic evolution. Philos. Trans. R. Soc. Lond. B, Biol. Sci. 368, 20130088 (2013)

C.M. Spahn, R. Beckmann, N. Eswar, P.A. Penczek, A. Sali, G. Blobel, J. Frank, Structure of the 80 S ribosome from Saccharomyces cerevisiae-tRNA-ribosome and subunit-subunit interactions. Cell 107(3), 373-386 (2001)

A. Spang, J.H. Saw, S.L. Jørgensen, K. Zaremba-Niedzwiedzka, J. Martijn, A.E. Lind, R. van Eijk, C. Schleper, L. Guy, T.J.G. Ettema, Complex archaea that bridge the gap between prokaryotes and eukaryotes. Nature 521, 173-179 (2015)

A. Spang, E.F. Caceres, T.J.G. Ettema, Genomic exploration of the diversity, ecology, and evolution of the archaeal domain of life. Science 357, eaaf3883 (2017)

J. Stevenson, J. Lunine, P. Clancy, Membrane alternatives in worlds without oxygen: creation of an azotosome. Sci. Adv. 1, e1400067 (2015)

J. Strick, A modern spontaneous generation debate. Bull. Sci. Technol. Soc. 8, 302-305 (1988)

J.D. Sutherland, Studies on the origin of life - the end of the beginning. Nat. Rev. 1, 1-7 (2017)

A. Szent-Györgyi, Biosens. Bioelectron. 161, 988-990 (1968)

A. Szilagyi, I. Zachar, I. Scheuring, A. Kun, B. Konnyu, T. Czaran, Ecology and evolution in the RNA world dynamics and stability of prebiotic replicator systems. Life 7(4), 48 (2017)

J.W. Szostak, The eightfold path to non-enzymatic RNA replication. J. Syst. Chem. 3(1), 2 (2012)

O. Taran, C. Chen, T.O. Omosun, M.C. Hsieh, A. Rha, J.T. Goodwin, A.K. Mehta, M.A. Grover, D.G. Lynn, Expanding the informational chemistries of life: peptide/RNA networks. Phil. Trans. R. Soc. Lond. A, Math., Phy. Eng. Sci. 375, 2109 (2017)

R. Tartèse, M. Chaussidon, A. Gurenko, F. Delarue, F. Robert, Warm Archean oceans reconstructed from oxygen isotope composition of early-life remnants. Geochem. Perspect. Lett. 3, 55-65 (2017)

R.-S. Taubner, C. Schleper, M.G. Firneis, S.K.-M.R. Rittmann, Assessing the Ecophysiology of methanogens in the context of recent astrobiological and planetological studies. Life 5, 1652-1686 (2015)

R.-S. Taubner, P. Pappenreiter, J. Zwicker, D. Smrzka, C. Pruckner, P. Kolar, S. Bernacchi, A.H. Seifert, A. Karajete, W. Bach, J. Perkmann, C. Paulik, M.G. Firneis, C. Schleper, S.K.-M.R. Rittmann, Biological methane production under putative Enceladus-like conditions. Nat. Commun. 9, 748 (2018)

W.R. Taylor, Transcription and translation in an RNA world. Philos. Trans. R. Soc. Lond. B, Biol. Sci. 361(1474), 1751-1760 (2006)

S.G. Tessalina, B. Bourdon, M. Van Kranendonk, J-L. Birck, P. Philippot, Influence of Hadean crust evident in basalts and cherts from the Pilbara Craton. Nat. Geosci. 3, 214-217 (2010)

F. Tian, O.B. Toon, A.A. Pavlov, H. De Sterck, A hydrogen-rich early Earth atmosphere. Science 308(5724), 1014-1017 (2005)

F. Tian, J.F. Kasting, K. Zahnle, Revisiting HCN formation in Earth's early atmosphere. Earth Planet. Sci. Lett. 308(3-4), 417-423 (2011)

M.R. Tirumalai, V.G. Stepanov, A. Wunsche, S. Montazari, R.O. Gonzalez, K. Venkateswaran, G.E. Fox, Bacillus safensis FO-36b and Bacillus pumilus SAFR-032: a whole genome comparison of two spacecraft assembly facility isolates. BMC Microbiol. 18(1), 57 (2018b)

M.R. Tirumalai, Q. Tran, M. Paci, D. Chavan, A. Marathe, G.E. Fox, Exploration of RNA sequence space in the absence of a replicase. J. Mol. Evol. 86(5), 264-276 (2018a)

N.J. Tosca, S. Guggenheim, P.K. Pufahl, An authigenic origin for Precambrian greenalite: implications for iron formation and the chemistry of ancient seawater. Geol. Soc. Am. Bull. 128, 511-530 (2016)

D. Trail, E.B. Watson, N.D. Tailby, The oxidation state of Hadean magmas and implications for early Earth's atmosphere. Nature 480, 79 (2011)

D. Trail, P. Boehnke, P.S. Savage, M.-C. Liu, M.L. Miller, I. Binderman, Origin and significance of Si and $\mathrm{O}$ isotope heterogeneities in Phanerozoic, Archaean, and Hadean zircon. Proc. Natl. Acad. Sci. USA 115(41), 10287-10292 (2018)

S.K. Trumbo, M.E. Brown, K.P. Hand, Sodium chloride on the surface of Europa. Sci. Adv. 5(6), 7123 (2019) 
T.Y. Tsong, R.D. Astumian, Electroconformational coupling: how membrane-bound ATPase transduces energy from dynamic electric fields. Annu. Rev. Physiol. 50, 273-290 (1988)

A.M. Turner, A. Bergantini, M.J. Abplanalp, C. Zhu, S. Gobi, B.S. Sun, K. Chao, A.H.H. Chang, C. Meinert, R.I. Kaiser, An interstellar synthesis of phosphorous oxoacids. Nat. Commun. 9, 3851 (2018)

A. Udry, E. Gazel, H.Y. McSween Jr, Formation of evolved rocks at Gale crater by crystal fractionation and implications for Mars crustal composition. J. Geophys. Res., Planets 123, 1525-1540 (2018)

B.M. Uz, J.A. Yoder, V. Osychny, Pumping of nutrients to ocean surface waters by the action of propagating planetary waves. Nature 409(6820), 597 (2001)

J.W. Valley, J.S. Lackey, A.J. Cavosie, C.C. Clechenko, M.J. Spicuzza, M.A.S. Basei, I.N. Bindeman, V.P. Ferreira, A.N. Sial, E.M. King, W.H. Peck, 4.4 billion years of crustal maturation: oxygen isotope ratios of magmatic zircon. Contrib. Mineral. Petrol. 150, 561-580 (2005)

J.W. Valley, A.J. Cavosie, T. Ushikubo, D.A. Reinhard, D.F. Lawrence, D.J. Larson, P.H. Clifton, T.F. Kelly, S.A. Wilde, D.E. Moser, M.J. Spicuzza, Hadean age for a post-magma-ocean zircon confirmed by atomprobe tomography. Nat. Geosci. 7, 219 (2014)

S.H. van den Boorn, M.J. van Bergen, W. Nijman, P.Z. Vroon, Dual role of seawater and hydrothermal fluids in early Archean chert formation: evidence from silicon isotopes. Geology 35, 939-942 (2007)

P. van der Gulik, D. Speijer, How amino acids and peptides shaped the RNA world. Life 5(1), 230 (2015)

E.F. van Dishoeck, E.A. Bergin, D.C. Lis, J.I. Lunine, in Water: From Clouds to Planets in Protostars \& Planets VI (2014), pp. 835-858

A.K. Van Groos, P.J. Wyllie, Melting relationships in the system $\mathrm{NaAlSi}_{3} \mathrm{O}_{8}-\mathrm{NaCl}-\mathrm{H}_{2} \mathrm{O}$ at one kilobar pressure, with petrological applications. J. Geol. 77(5), 581-605 (1969)

M.J. Van Kranendonk, K.L. Kirkland, J. Cliff, Oxygen isotopes in Pilbara Craton zircons support a global increase in crustal recycling at 3.2 Ga. Lithos 228-229, 90-98 (2015)

S.J. Varma, K.B. Muchowska, P. Chatelain, J. Moran, Native iron reduces $\mathrm{CO}_{2}$ to intermediates and endproducts of the acetyl-CoA pathway. Nat. Ecol. Evol. 6, 1019-1024 (2018)

K. Vetsigian, C.R. Woese, N. Goldenfeld, Collective evolution and the genetic code. Proc. Natl. Acad. Sci. USA 103(28), 10696-10701 (2006)

G. Wächtershäuser, Pyrite formation, the first energy source for life: a hypothesis. Syst. Appl. Microbiol. 10, 207-210 (1988)

G. Wächtershäuser, Evolution of the first metabolic cycles. Proc. Natl. Acad. Sci. USA 87(1), 200-4 (1990)

G. Wächtershäuser, From volcanic origins of chemoautotrophic life to Bacteria, Archaea and Eukarya. Philos. Trans. R. Soc. Lond. B, Biol. Sci. 361, 1787-1806 (2006)

J. Wade, B. Wood, Core formation and the oxidation state of the Earth. Earth Planet. Sci. Lett. 236(1-2), 78-95 (2005)

E.G.H. Wagner, P. Romby, Small RNAs in bacteria and archaea: who they are, what they do, and how they do it. Adv. Genet. 90, 133-208 (2015)

J.H. Waite, W.S. Lewis, B.A. Magee, J.I. Lunine, W.B. McKinnon, C.R. Glein, O. Mousis, D.T. Young, T. Brockwell, J. Westlake, M.-J. Nguyen, B.D. Teolis, H.B. Hiemann, R.L. McNutt, W.-H. Perry Ip, Liquid water on Enceladus from observations of ammonia and 40Ar in the plume. Nature 460, 487-490 (2009)

J.H. Waite, C.R. Glein, R.S. Perryman, B.D. Teolis, B.A. Magee, G. Miller, J. Grimes, M.E. Perry, K.E. Miller, A. Bouquet, J.I. Lunine, T. Brockwell, S.J. Bolton, Cassini finds molecular hydrogen in the Enceladus plume: evidence for hydrothermal processes. Science 356(6334), 155-159 (2017)

S.I. Walker, M.A. Grover, N.V. Hud, Universal sequence replication, reversible polymerization and early functional biopolymers: a model for the initiation of prebiotic sequence evolution. PLoS ONE 7(4), e34166 (2012)

P.H. Warren, J.T. Wasson, The origin of KREEP. Rev. Geophys. Space Phys. 17, 73-88 (1979)

J.D. Watson, F.H. Crick, Genetical implications of the structure of deoxyribonucleic acid. Nature 171(4361), 964-967 (1953)

E.B. Watson, T.M. Harrison, Zircon thermometer reveals minimum melting conditions on earliest Earth. Science 308(5723), 841-844 (2005)

J.A.D. Wattis, P.V. Coveney, The origin of the RNA world: a kinetic model. J. Phys. Chem. B 103(21), $4231-4250$ (1999)

A.L. Weber, Prebiotic sugar synthesis: hexose and hydroxy acid synthesis from glyceraldehyde catalyzed by iron(III) hydroxide oxide. J. Mol. Evol. 35(1), 1-6 (1992)

M.C. Weiss, F.L. Sousa, N. Mrnjavac, S. Neukirchen, M. Roettger, S. Nelson-Sathi, W.F. Martin, The physiology and habitat of the last universal common ancestor. Nat. Microbiol. 25/1(9), 16116 (2016)

M.C. Weiss, M. Preiner, J.C. Xavier, V. Zimorski, W.F. Martin, The last universal common ancestor between ancient Earth chemistry and the onset of genetics. PLoS Genet. 14(8), e1007518 (2018)

F. Werner, D. Grohmann, Evolution of multisubunit RNA polymerases in the three domains of life. Nat. Rev. Microbiol. 9(2), 85 (2011) 
F. Westall, K.A. Campbell, J.G. Bréhéret, F. Foucher, P. Gautret, A. Hubert, S. Sorieul, N. Grassineau, D.M. Guido, Archean $(3.33 \mathrm{Ga})$ microbe-sediment systems were diverse and flourished in a hydrothermal context. Geology 43(7), 615-618 (2015)

F. Westall, K. Hickman-Lewis, N. Hinman, P. Gautret, K.A. Campbell, J.G. Bréhéret, F. Foucher, A. Hubert, S. Sorieul, A.V. Dass, T.P. Kee, T. Georgelin, A. Brack, A hydrothermal-sedimentary context for the origin of life. Astrobiology 18(3), 259-293 (2018)

F.H. Westheimer, Why nature chose phosphates. Science 235, 1173-1178 (1987)

A. Whicher, E. Camprubi, S. Pinna, B. Herschy, N. Lane, Acetyl phosphate as a primordial energy currency at the origin of life. Orig. Life Evol. Biosph. 48(2), 159-179 (2018)

D. Whitaker, M.W. Powner, Prebiotic nucleic acids need space to grow. Nat. Commun. 9(1), 5172 (2018)

R.H. Whittaker, New concepts of kingdoms or organisms. Evolutionary relations are better represented by new classifications than by the traditional two kingdoms. Science 163(3863), 150-160 (1969)

J.S. Wicken, Evolution, Thermodynamics, and Information: Extending the Darwinian Program (Oxford University Press, New York, 1987)

S.A. Wilde, J.W. Valley, W.H. Peck, C.M. Graham, Evidence from detrital zircons for the existence of continental crust and oceans on the Earth 4.4 gyr ago. Nature 409, 175-178 (2001)

T.A. Williams, P.G. Foster, C.J. Cox, T.M. Embley, An archaeal origin of eukaryotes supports only two primary domains of life. Nature 504, 231-236 (2013)

T.A. Williams, S.E. Heaps, S. Cherlin, T.M. Nye, R.J. Boys, T.M. Embley, New substitution models for rooting phylogenetic trees. Philos. Trans. R. Soc. Lond. B, Biol. Sci. 370, 20140336 (2015)

T.A. Williams, G.J. Szöllősi, A. Spang, P.G. Foster, S.E. Heaps, B. Boussau, T.J.G. Ettema, T.M. Embley, Integrative modeling of gene and genome evolution roots the archaeal tree of life. Proc. Natl. Acad. Sci. USA 114(23), E4602-E4611 (2017)

P.R. Wills, C.W. Carter Jr., Insuperable problems of the genetic code initially emerging in an RNA world. Biosystems 164, 155-166 (2018)

L. Wittgenstein, Philosophical Investigations (Macmillan Co., New York, 1953)

C.R. Woese, The Genetic Code: The Molecular Basis for Genetic Expression (Harper \& Row, New York, 1967)

C.R. Woese, The fundamental nature of the genetic code: prebiotic interactions between polynucleotides and polyamino acids and their derivatives. Proc. Natl. Acad. Sci. USA 59(1), 110-117 (1968)

C.R. Woese, The universal ancestor. Proc. Natl. Acad. Sci. USA 95(12), 6854-6859 (1998)

C.R. Woese, Interpreting the universal phylogenetic tree. Proc. Natl. Acad. Sci. USA 97(15), 8392-8396 (2000)

C.R. Woese, Translation: in retrospect and prospect. RNA 7(8), 1055-1067 (2001)

C.R. Woese, On the evolution of cells. Proc. Natl. Acad. Sci. USA 99(13), 8742-8747 (2002)

C.R. Woese, G.E. Fox, The concept of cellular evolution. J. Mol. Evol. 10(1), 1-6 (1977a)

C.R. Woese, G.E. Fox, Phylogenetic structure of the prokaryotic domain: the primary kingdoms. Proc. Natl. Acad. Sci. USA 74(11), 5088-5090 (1977b)

C.R. Woese, O. Kandler, M.L. Wheelis, Towards a natural system of organisms: proposal for the domains Archaea, Bacteria and Eucarya. Proc. Natl. Acad. Sci. USA 87(12), 4576-4579 (1990)

E.T. Wolf, Assessing the habitability of the TRAPPIST-1 system using a 3D climate modal. Astrophys. J. Lett. 839, L1 (2017)

Y.I. Wolf, E.V. Koonin, On the origin of the translation system and the genetic code in the RNA world by means of natural selection, exaptation, and subfunctionalization. Biol. Direct 2, 14 (2007)

J.M. Wolfe, G.P. Fournier, Horizontal gene transfer constrains the timing of methanogen evolution. Nat. Ecol. Evol. 2(5), 897 (2018)

M.L. Wong, B.D. Charnay, P. Gao, Y.L. Yung, M.J. Russell, Nitrogen oxides in early Earth's atmosphere as electron acceptors for life's emergence. Astrobiology 17, 975-983 (2017)

R. Woods, Electrochemistry of sulfide flotation, in Principles of Mineral Flotation, the Wark Symposium, Australian Institute of Mining and Metallurgy, ed. by M.H. Jones, J.T. Woodcock (1984), pp. 91-115

R. Wordsworth, R. Pierrehumbert, Hydrogen-nitrogen greenhouse warming in Earth's early atmosphere. Science 339(6115), 64-67 (2013)

L.-F. Wu, J.D. Sutherland, Provisioning the origin and early evolution of life. Emerg. Top. Life Sci. 3(5), 459-468 (2019)

M. Yarus, Amino acids as RNA ligands: a direct-RNA-template theory for the code's origin. J. Mol. Evol. 47(1), 109-117 (1998)

M. Yarus, Eighty routes to a ribonucleotide world; dispersion and stringency in the decisive selection. RNA 24(8), 1041-1055 (2018)

J.A. Yeates, C. Hilbe, M. Zwick, M.A. Nowak, N. Lehman, Dynamics of prebiotic RNA reproduction illuminated by chemical game theory. Proc. Natl. Acad. Sci. USA 113(18), 5030-5035 (2016) 
J.A. Yeates, P. Nghe, N. Lehman, Topological and thermodynamic factors that influence the evolution of small networks of catalytic RNA species. RNA 23(7), 1088-1096 (2017)

Y.L. Yung, M.B. McElroy, Fixation of nitrogen in the prebiotic atmosphere. Science 203(4384), 1002-1004 (1979)

M.M. Yusupov, G.Z. Yusupova, A. Baucom, K. Lieberman, T.N. Earnest, J.H. Cate, H.F. Noller, Crystal structure of the ribosome at 5.5 A resolution. Science 292(5518), 883-896 (2001)

K.J. Zahnle, Photochemistry of methane and the formation of hydrocyanic acid (HCN) in the Earth's early atmosphere. J. Geophys. Res., Atmos. 91(D2), 2819-2834 (1986)

K. Zahnle, N. Arndt, C. Cockell, A. Halliday, E. Nisbet, F. Selsis, N.H. Sleep, Emergence of a habitable planet. Space Sci. Rev. 129, 35-78 (2007)

K. Zahnle, L. Schaefer, B. Fegley, Earth's earliest atmospheres. Cold Spring Harb. Perspect. Biol. 2(10), A004895 (2010)

K. Zaremba-Niedzwiedzka, E.F. Caceres, J.H. Saw, D. Bäckström, L. Juzokaite, E. Vancaester, K.W. Seitz, K. Anantharaman, P. Starnawski, K.U. Kjeldsen, M.B. Stott, T. Nunoura, J.F. Banfield, A. Schramm, B.J. Baker, A. Spang, T.J.G. Ettema, Asgard archaea illuminate the origin of eukaryotic cellular complexity. Nature 541, 353-358 (2017)

N.E.B. Zellner, Cataclysm no more: new views on the timing and delivery of lunar impactors. Orig. Life Evol. Biosph. 47, 261-280 (2017)

G. Zhao, W. Kong, N. Weatherspoon-Griffin, J. Clark-Curtiss, Y. Shi, $\mathrm{Mg}^{2+}$ facilitates leader peptide translation to induce riboswitch-mediated transcription termination. EMBO J. 30(8), 1485-1496 (2011)

V.N. Zharkov, On the history of the lunar orbit. Astron. Vestn. 2000(34), 1-11 (2000)

E. Zuckerkandl, L. Pauling, Molecules as documents of evolutionary history. J. Theor. Biol. 8(2), 357-366 (1965) 